\title{
ANÁLISE ESPAÇO-TEMPORAL DE DADOS HIDROLÓGICOS DA BACIA DO RIO PIRACICABA
}

\author{
GIAMPAOLO QUEIROZ PELLEGRINO \\ Engenheiro Florestal
}

Orientador: Prof. Dr. Reynaldo Luiz Victória

Dissertação apresentada à Escola. Superior de Agricultura "Luiz de Queiroz", da Universidade de São Paulo, para obtenção do título de Mestre em Agronomia, Área de Concentração: Agrometeorologia.

Piracicaba Estado de São Paulo - Brasil

Novembro - 1995 


\section{Dados Internacionais de Catalogação na Publicação (CIP) \\ DIVISĀO DE BIBLIOTECA E DOCUMENTAÇĀO - Campus “Luiz de Queiroz"/USP}

Pellegrino, Giampaolo Queiroz

Análise espaço-temporal de dados hidrológicos da Bacia do Rio Piracicaba / Giampaolo

Queiroz Pellegrino. - Piracicaba, 1995.

$117 p$. : il.

Dissertação (mestrado) - - Escola Superior de Agricultura Luiz de Queiroz, 1996.

Bibliografia.

1. Bacia do Rio Piracicaba - Hidrologia - Análise de série temporal 2. Bacia do Rio Piracicaba - Mapeamento 3. Geoprocessamento I. Título 


\section{ANÁLISE ESPAÇO-TEMPORAL DE DADOS HIDROLÓGICOS DA BACIA DO RIO PIRACICABA}

\section{GIAMPAOLO QUEIROZ PELLEGRINO}

Aprovada em: 08.02 .1996

Comissão julgadora:

Prof. Dr. Reynaldo Luiz Victória

Prof. Dr. Jorge Marcos de Moraes

Prof. Dr. Eduardo Delgado Assad
ESALQ/USP CENA/USP

CPAC/EMBRAPA

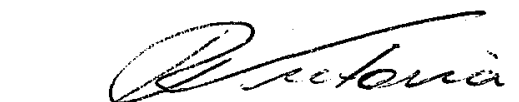

Prof. Dr. Reynaldo Luiz Victória

Orientador 
ENQUANTO ISSO

(Marisa Monte/Nando Reis, 1991)

Enquanto isso

anoitece em certas regiões

E se pudéssemos

ter a velocidade para ver tudo

assistiríamos tudo

Meanwhile night falls

A madrugada perto

into regions

da noite escurecendo

and if we could just see faster

ao lado do entardecer

we could watch everything

a tarde inteira

Dawn is next to night

logo após o almoço

and getting darker

O meio-dia acontecendo em pleno sol

seguido da manhã que correu

are falling, falling

desde muito cedo

and then just after lunch

e que só viram

Noon rose into full sunlight

os que levantaram para trabalhar

no alvorecer que foi surgindo

And then another morning

running early

seen only by those

who rose in time to work

In the dawn that was the rising

(versão Laurie Anderson) 
Dedico este trabalho

Aos grandes,

que me formaram e ensinaram,

Aos pequenos,

que me mostram que ainda há muito a aprender,

$\mathrm{E}$ aos iguais,

que me acompanham no aprendizado.

Em especial

Ao meu pai Mário, pelo exemplo de força e dedicação,

À minha mãe Glória, pelo abrigo seguro nas horas difíceis,

À minha esposa Carolina, pela beleza e carinho dos seus olhos,

Aos meus filhos Mateus e Pedro, por me concederem a pureza e alegria de ser criança,

E ao meu amigo Jorge, por tornar o trabalho prazeroso e possível. 


\section{AGRADECIMENTOS}

Agradeço ao Departamento de Física e Meteorologia da ESALQ a oportunidade concedida para a realização deste trabalho, em especial ao professor Dr. Luiz Roberto Angelocci, pela paciência e pelo incentivo para sua concretização, e ao professor Dr. Reynaldo Luiz Victória, pelo apoio, orientação e parceria nas canções.

Ao projeto PIRACENA, financiado pela ESSO do Brasil, CNPq e FAPESP, pelo apoio logístico. Ao CNPQ pela concessão de bolsa de estudo.

À Seção de Climatologia do IAC, ao Departamento de Física e Meteorologia da ESALQ e ao DAEE, pelo fornecimento dos dados, tornando possíveis as análises realizadas aqui.

Aos colegas da seção de Hidrologia e Isótopos Estáveis do CENA/USP (Aristides, Andrea, Alex e Victória, Chico, Fernando, Franklin, Hillândia, Sérgio), a todo seu corpo técnico (Geraldo, Isabel, Miguel, Nádia, Pingin e Toninha) e de pesquisadores (Drs. Epaminondas, Jeferson, José Albertino, Paulo e Plínio) por todos esses anos de convivência. Em especial, ao Dr. Luiz Antônio Martinelli, pelas valiosas sugestões, sempre muito bem humoradas, e à secretária Neuza Maria Augusti, por sua prontidão no auxílio.

Aos colegas do CEPAGRI/ UNICAMP (Carlos, Claudir, Edilene, Emília, Jurandir e Rosário, Wilson e Willian) pelo colaboração e convivência diária. Ao Dr. Hilton Silveira Pinto, pelo apoio irrestrito e pelas sugestões.

À minha família pelo interesse e acompanhamento do trabalho. Em especial, à minha irmã Silvana e suas amigas do curso especialização, pelo transporte de livros e material técnico entre Campinas e Piracicaba.

À Dra. Maria Helena de Almeida Mello e ao Dr. Hermano Vaz de Arruda (Climatologia do IAC), e ao Ms. Sérgio Zullo, pelo auxílio nas análises estatísticas. Ao Dr. Eduardo Delgado Assad (EMBRAPA/CPAC), pelo interesse no meu desenvolvimento científico e pelas sugestões. Um agradecimento muito especial ao Dr. Jorge Marcos de Moraes pelo acompanhamento passo a passo deste trabalho, realizado a quatro mãos.

A todos os que contribuíram, direta ou indiretamente, para que este trabalho se concretizasse, 


\section{SUMÁRIO}

Página

LISTA DE FIGURAS.......................................................................... vii

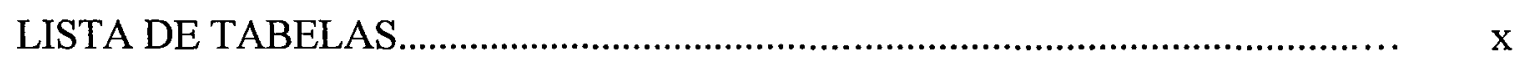

RESUMO .............................................................................................. xiii

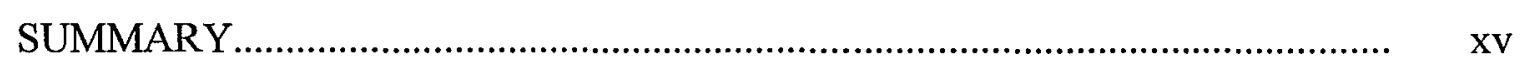

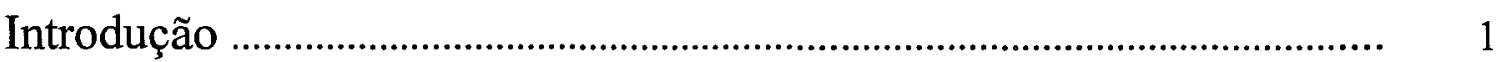

Capítulo 1: Área de Estudo: A Bacia do Rio Piracicaba .............................. 5

1.1. Localização e Caracterização Física da Bacia ............................................. 6

1.2. Aspectos Sócio-Econômicos e seu Impacto sobre os Recursos Hídricos ........ 15

Capítulo 2 : Espacialização dos Dados ....................................................... 18

2.1. Breve Revisão Bibliográfica .................................................................. 18

2.2. Métodos Utilizados na Análise e Geração dos Dados Espaciais...................... 22

2.2.1. A Base de Dados .................................................................... 22

a) Dados Pluviométricos ........................................................... 23

b) Dados Fluviométricos ............................................................. 27

2.2.2. Geração dos Mapas Anuais .......................................................... 29

a) Precipitação .......................................................................... 30

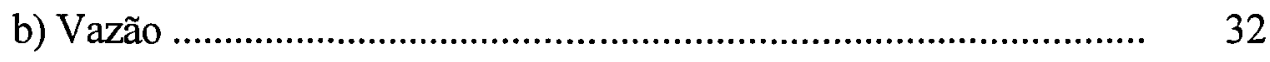

c) Evapotranspiração .............................................................. 33

2.3. Resultados e sua Discussão ................................................................ 34

2.3.1. Precipitação ............................................................................ 35

2.3.2. Vazão ..................................................................................... 43

2.3.3. Evapotranspiração ...................................................................... 45 
Capítulo 3 : Análise de Tendência Temporal ......................................... 52

3.1. Breve Revisão Bibliográfica ................................................................... 52

3.2. Métodos Utilizados na Análise Temporal ................................................. 55

3.2.1. Teste de Mann-Kendall ...................................................................... 56

3.2.2. Teste de Pettitt ................................................................................... 58

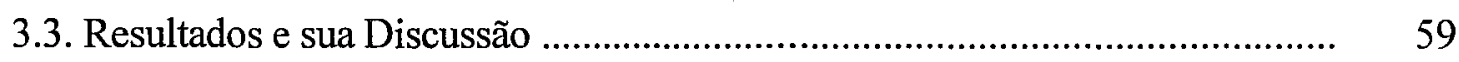

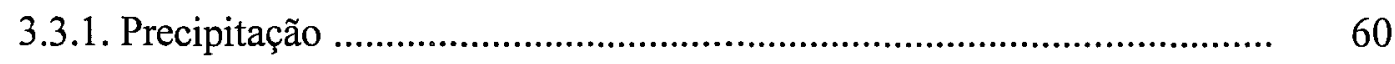

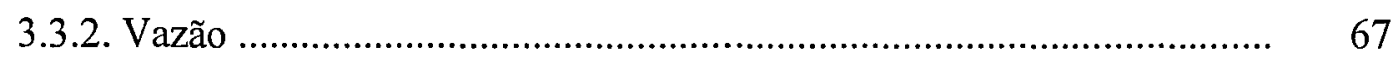

3.3.3. Evapotranspiração .......................................................................... $\quad 72$

Capítulo 4 : Análise Espaço-Temporal ................................................. 76

4.1. Breve Revisão Bibliográfica ........................................................................

4.2. Método Utilizado na Análise Espaço-Temporal .............................................. 79

4.2.1. A Análise de Componentes Principais Estandardizada (ACPE)............. $\quad 80$

4.3. Resultados e sua Discussão .................................................................. 84

4.3.1 Análise Espaço-Temporal .................................................................... 84

4.3.2 Análise de Agrupamentos ................................................................ 93

Capítulo 5 : Conclusões ................................................................... 96

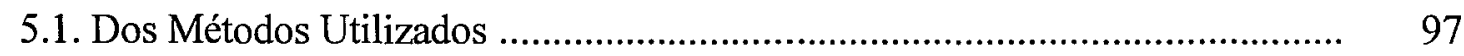

5.2. Dos Resultados Obtidos …………......................................................... 98

5.3. Considerações Finais .............................................................................. 100

Referências Bibliográficas ........................................................... 101

Apêndice: Comparação da Evapotranspiração Real ................................ 112

A.1. O Método de Turc ................................................................................ 112

A.2. O Método de Thornthwaite \& Mather (1955) ............................................... 113 


\section{LISTA DE FIGURAS}

\section{Capítulo 1}

Figura

Página

1.1. Localização espacial da bacia do rio Piracicaba com a rede de drenagem principal, os limites das sub-bacias e os postos pluviométricos e fluviométricos utilizados.

1.2. Características geológicas (a) e climáticas (b) da bacia do rio Piracicaba (extraída de São Paulo, 1990)

1.3. Crescimento populacional na bacia do rio Piracicaba (a) e a distribuição da população nos seus principais municípios (b) (adaptado de Prochnow, 1981).

\section{Capítulo 2}

Figura

Página

2.1. Distribuição espacial da precipitação normal anual (em $\mathrm{mm}$ ) na bacia do rio Piracicaba (a) e seu coeficiente de variação (em \%) (b). As isolinhas representam os pontos onde a variável assume os valores correspondentes aos centros de classe

2.2. Distribuição espacial da precipitação normal do trimestre úmido (em $\mathrm{mm}$ ) na bacia do rio Piracicaba (a) e seu coeficiente de variação (em \%) (b). As isolinhas representam os pontos onde a variável assume os valores correspondentes aos centros de classe.

2.3. Distribuição espacial da precipitação normal no trimestre seco (em $\mathrm{mm}$ ) na bacia do rio Piracicaba (a) e seu coeficiente de variação (\%) (b). As isolinhas representam os pontos onde a variável assume os valores correspondentes aos centros de classe. 
2.4. Comportamento espacial da precipitação média anual $(\mathrm{mm})$ dos anos secos extremos de 1963 (a) e 1968 (b).

2.5. Comportamento espacial da precipitação média anual $(\mathrm{mm})$ dos anos úmidos extremos de 1976 (a) e 1983 (b)

2.6. Distribuição espacial da evapotranspiração anual normal (em $\mathrm{mm}$ ) na bacia do rio Piracicaba.

2.7. Comparação entre os métodos de estimativa da Evapotranspiração Real (mm) para as cidades de Monte Alegre do Sul (a), Campinas (b), Limeira (c) e Piracicaba (d). (MBH= Método do Balanço Hídrico; Turc=Método de Turc; ThM= Método de Thornthwaite \& Mather)

\section{Capítulo 3}

Figura

3.1. Comportamento temporal das séries de precipitação na bacia toda (a) e nas sub-bacias (b-f). A linha tracejada mostra a regressão linear para a série, associada à equação apresentada.

3.2. Exemplo do resultado gráfico dos testes de Mann-Kendall (a) e de Pettitt (b) para a precipitação anual média na bacia toda. As retas tracejadas representam os limites de confiança para $10 \%$ (-------) e $5 \%($

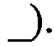

3.3. Média móvel (ordem 10) da chuva anual durante o período de 1890 a 1992, em Campinas, SP. (adaptado de SENTELHAS et al., 1994). 
3.4. Comportamento temporal das séries de vazão natural líquida na bacia toda (a) e nas sub-bacias (b-e; g). Também são apresentadas as vazões medidas para as bacias do Jaguari e do Atibaia ( $f$ e h). A linha tracejada mostra a regressão linear para a série, associada à equação apresentada...........

3.5. Comportamento temporal das séries de evapotranspiração real anual na bacia toda (a) e nas sub-bacias (b-f). A linha tracejada mostra a regressão linear para a série, associada à equação apresentada.

\section{Capítulo 4}

Figura

Página

4.1. Variação total explicada pelos 20 primeiros autovalores (\%)........................... $\quad 85$

4.2. Distribuição temporal dos três primeiros componentes principais gerados pela ACPE................................................................................... 86

4.3. Distribuição espacial do primeiro componente gerado pela ACPE.................... $\quad 88$

4.4. Comparação entre o segundo componente e a atividade solar (a). Abaixo (b), o segundo componente foi deslocado de -5 anos........................................ $\quad 89$

4.5. Distribuição espacial do segundo componente gerado pela ACPE..................... 91

4.6. Distribuição espacial do terceiro componente gerado pela ACPE..................... 92

4.7. Representação simultânea do primeiro e segundo componentes (a). As regiões delimitadas pelos polígonos representam os grupos obtidos. Abaixo (b), esses grupos estão representados sobre a bacia. 


\section{LISTA DE TABELAS}

\section{Capítulo 2}

Tabela

Página

2.1. Estações pluviométricas do DAEE pertencentes à bacia do Piracicaba........... 24

2.2. Estações pluviométricas do DAEE vizinhas à bacia do Piracicaba................... 25

2.3. Estações fluviométricas do DAEE pertencentes à bacia do Piracicaba............. 25

2.4. Vazões normais anuais, trimestrais úmidas (tru) e trimestrais secas (trs) nas sub-bacias da bacia do rio Piracicaba..................................................... 44

2.5. Séries de precipitação total anual média por sub-bacia (geradas pelo

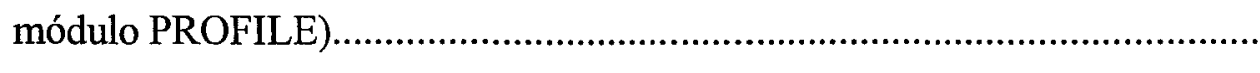

2.6. Séries de vazão total anual média por sub-bacia (dados obtidos diretamente do DAEE) .................................................................... 50

2.7. Séries de evapotranspiração total anual média por sub-bacia (geradas pelo módulo PROFILE)

\section{Capítulo 3}

Tabela

Página

3.1. Resultados obtidos pelo teste de análise de tendência de Mann-Kendall e pelo de mudança de médias de Pettitt para a precipitação. São assinaladas as tendências positivas significativas e pontos de ruptura para os níveis de $5 \%\left({ }^{* *}\right), 10 \%(*)$ e acima de $10 \%(\mathrm{~ns})$. Quando as tendências foram significativas, os anos de ruptura foram apresentados, mesmo que não significativos. 
3.2. Resultados obtidos pelo teste de análise de tendência de Mann-Kendall e pelo teste de mudança de médias de Pettitt para a vazão. São assinaladas as tendências negativas significativas e pontos de ruptura para os níveis de $5 \%(\sim \sim), 10 \%(\sim)$ e acima de $10 \%(\mathrm{~ns})$. Quando as tendências foram significativas, os anos de ruptura foram apresentados, mesmo que não significativos.

3.3. Resultados obtidos pelo teste de análise de tendência de Mann-Kendall e pelo teste de mudança de médias de Pettitt para a evapotranspiração. São assinaladas as tendências positivas significativas e pontos de ruptura para os níveis de $5 \%\left({ }^{* *}\right), 10 \%\left({ }^{*}\right)$ e acima de $10 \%$ (ns). Quando as tendências foram significativas, os anos de ruptura foram apresentados, mesmo que não significativos.

\section{Capítulo 4}

Tabela

Página

4.1. Autovalores e as porcentagens de variância explicada, simples e acumuladas

\section{Apêndice}

Tabela

Página

a.1. Comparação dos resultados obtidos pelos métodos de estimativa da evapotranspiração real anual $(\mathrm{mm})$ para a cidade de Monte Alegre do Sul. (MBH=Método do balanço hídrico; Turc=Método de Turc; $\mathrm{ThM}=$ Método de Thornthwaite \& Mather) 
a.2. Comparação dos resultados obtidos pelos métodos de estimativa da evapotranspiração real anual (mm) para a cidade de Campinas. (MBH=Método do balanço hídrico; Turc=Método de Turc; ThM=Método de Thornthwaite \& Mather)

a.3. Comparação dos resultados obtidos pelos métodos de estimativa da evapotranspiração real anual ( $\mathrm{mm})$ para a cidade de Limeira. (MBH=Método do balanço hídrico; Turc=Método de Turc; ThM=Método de Thornthwaite \& Mather)

a.4. Comparação dos resultados obtidos pelos métodos de estimativa da evapotranspiração real anual $(\mathrm{mm})$ para a cidade de Piracicaba. ( $\mathrm{MBH}=$ Método do balanço hídrico; Turc=Método de Turc; ThM=Método de Thornthwaite \& Mather) 


\title{
ANÁLISE ESPAÇO-TEMPORAL DE DADOS HIDROLÓGICOS DA BACIA DO RIO PIRACICABA
}

\author{
Autor: GIAMPAOLO QUEIROZ PELLEGRINO \\ Orientador: Prof. Dr. REYNALDO LUIZ VICTÓRIA
}

\section{RESUMO}

Diante da importância econômica da bacia do rio Piracicaba e da possibilidade de ocorrência de problemas no fornecimento de água para a região, tomou-se por objetivo conhecer o comportamento espacial e a evolução temporal dos dados hidrológicos de suas sub-bacias, através do mapeamento e da análise de tendências da precipitação, da vazão e da evapotranspiração. Utilizou-se para isso, 33 postos pluviométricos e 5 fluviométricos do Departamento de Águas e Energia Elétrica do Estado de São Paulo (DAEE-SP).

A espacialização dos dados de precipitação anual, trimestral seca e trimestral úmida, foi feita através da interpolação pelo método do inverso do quadrado da distância, com o auxílio do SGI-IDRISI. Pôde se detectar o padrão normal anual e a influência diferenciada das frentes polares sobre o padrão espacial dos períodos secos e úmidos. Para os anos extremamente úmidos, como os anos de 76 e 83, destacou-se a importância do período normalmente seco na precipitação anual total.

A presença de tendências nas séries de lâmina média anual de precipitação, vazão e evapotranspiração, por sub-bacia, foi analisada através dos testes não paramétricos de Mann-Kendall e de Pettitt. Observou-se tendência significativa de aumento da precipitação 
e da evapotranspiração anuais, em praticamente todas as sub-bacias. Apesar do aumento da precipitação, as séries de vazão reconstituída líquida anual não apresentaram nenhuma tendência. As séries de vazão medida apresentaram tendência significativa, mostrando a influência da operação das barragens.

A análise dos dados trimestrais mostra tendência positiva somente para a precipitação do período seco, sugerindo que os anos têm sido mais úmidos porque os meses normalmente secos têm sido menos secos. Isso está de acordo com o observado acima para os anos muito úmidos, ressaltando a importância dos meses secos no comportamento anual da precipitação.

Por fim, utilizou-se a análise de componentes principais para a determinação de padrões e de fatores influentes sobre o comportamento temporal e espacial dos postos pluviométricos da bacia. Essa análise permitiu apontar a atividade solar como o fator influente mais importante para o comportamento da precipitação. Permitiu ainda, um agrupamento adequado dos postos em regiões homogêneas dentro da bacia. 


\title{
SPATIAL AND TEMPORAL ANALYSIS OF HYDROLOGIC DATA OVER PIRACICABA RIVER BASIN
}

\author{
Author: GIAMPAOLO QUEIROZ PELLEGRINO \\ Adviser: Prof. Dr. REYNALDO LUIZ VICTÓRIA
}

\section{SUMMARY}

Face to the economic importance of the Piracicaba river basin and to the possibility of future water distribution problems, it is proposed to study how its watersheds hydrologic data behave spatially and temporally. It was achived by mapping and analyzing the precipitation, discharge and evapotranspiration temporal trends. Thirty three rainfall and five fluviometric stations of the São Paulo State Water and Electric Energy Department (DAEE-SP) were used.

The data spatialization was made for the annual, dry and wet periods by means of the reciprocal distance squared method, using the GIS IDRISI. It was possible to detect the annual normal spatial standard and the different influence of the polar air masses over the dry and wet ones. For the extremely wet years like 76 and 83 , the importance of the normally dry months for the annual precipitation could be noted.

The trend analyses were made by using the Mann-Kendall and Pettitt's nonparametric tests. It was analyzed, for each watershed, the mean annual precipitation, discharge and evapotranspiration. A significant positive trend could be observed for annual precipitation and evapotranspiration in almost all watersheds. Despite the precipitation 
increase, the net natural discharge did not show any significant trend. On the contrary, the measured discharge had a slightly decreasing trend, showing the dam operation influence.

Only precipitation dry period analysis showed a significant positive trend, suggesting that the years have been wetter because the normally dry months have been not so dry. This agrees with the above mentioned for the very wet years, emphasizing the importance of such months for the annual precipitation.

Yet, it was used the principal component analysis for studying the patterns and the influencing factors over the temporal and spatial behavior for the pluviometric basin stations. This kind of analysis allowed to point out that solar activity is the most important factor influencing the precipitation. It also allowed an appropriate station grouping into homogeneous basin regions. 


\section{Introdução}

A bacia do rio Piracicaba apresenta uma extensão de aproximadamente $12.400 \mathrm{~km}^{2}$, possuindo $90 \%$ da sua área total no Estado de São Paulo e o restante no Estado de Minas Gerais. Representa uma região de grande importância econômica para o Estado de São Paulo, tanto no ramo agrícola como no industrial, envolvendo cidades de grande expressão como Campinas, Piracicaba, Limeira, Americana e Rio Claro, dentre outras.

Segundo GANZELI (1991), com o desenvolvimento de alguns municípios da bacia, a região passou a ser um pólo de atração de diversas atividades altamente consumidoras e degradadoras dos recursos hídricos. Esse quadro é agravado pela limitada disponibilidade de água na bacia e pela reversão de aproximadamente $30 \mathrm{~m}^{3} / \mathrm{s}$ destinados ao abastecimento da região metropolitana de São Paulo, além do aumento da carga poluidora orgânica por esgotos domésticos e industriais. Portanto, mantendo-se a mesma tendência nas próximas décadas, os mananciais da bacia terão menos água e de pior qualidade.

Diante desse quadro, uma melhor compreensão do funcionamento da bacia em seu aspecto hidrológico e suas interações com as atividades antrópicas é de fundamental 
importância como subsídio para a tomada de decisões em relação à racionalização do uso da água e preservação desse recurso. Procurando trazer alguma contribuição nesse sentido, este trabalho tem o objetivo de estudar o comportamento espacial e a evolução temporal dos principais componentes do ciclo hidrológico da bacia do rio Piracicaba, através do mapeamento e da análise de tendência da precipitação, da vazão e da evapotranspiração, procurando indícios de quando e onde as interferências antrópicas começaram a influenciar esses componentes.

O estudo de séries temporais em bacias hidrográficas desse porte, de meso-escala, é mais complexo e demanda a manipulação de uma base de dados mais ampla que para áreas de cultivos agrícolas, para as quais geralmente pode se restringir à análise dos dados de apenas uma estação meteorológica. Dessa forma, dispôs-se de um Sistema Geográfico de Informações (SGI) para atender aos objetivos propostos, por ser uma ferramenta extremamente útil no mapeamento e na manipulação de variáveis georeferenciadas. Utilizou-se ainda, dois métodos não paramétricos robustos na análise das tendências temporais dessas variáveis. Complementariamente, procurou-se testar a utilização da Análise de Componentes Principais na análise simultânea do comportamento espacial e temporal das variáveis.

O SGI IDRISI foi utilizado inicialmente no estudo do comportamento espacial dos parâmetros meteorológicos na bacia, através do mapeamento e da geração de dados de lâmina total anual d'água precipitada por sub-bacia. Foram também geradas para a análise estatística, séries de lâminas totais para o trimestre seco (junho a agosto) e úmido (dezembro a fevereiro). Da mesma forma, os dados de vazão foram analisados usando os valores totais anuais e também os totais dos períodos secos e úmidos (julho a setembro e janeiro a março, respectivamente).

Posteriormente, realizou-se uma análise descritiva das séries anuais originais, e das 
geradas pelo SGI, no sentido de conhecer suas principais caracteristicas temporais. Os testes estatísticos de análise de tendência foram então aplicados, a fim de procurar algum padrão na evolução temporal dos elementos meteorológicos. Os dois testes adotados são não paramétricos e evitam a suposição de uma distribuição previamente conhecida. O primeiro deles é a versão seqüencial do teste de Mann-Kendall, que permite a detecção e também a localização aproximada do ponto inicial de uma certa tendência estatisticamente significativa. O segundo é o teste de Pettitt, que permite a detecção de uma mudança brusca na média de uma série histórica e o cálculo da sua significância.

Por fim, utilizou-se o módulo PCA, para análise de séries temporais, que é baseado na Análise de Componentes Principais. Essa técnica permite investigar a existência de padrões espaciais e temporais, através dos principais componentes da variação dos dados iniciais, que geralmente estão relacionados aos principais fatores influentes sobre estes.

Quanto à sua estrutura, este trabalho apresenta no capítulo 1, um apanhado sobre as principais características e os principais problemas da bacia do rio Piracicaba, relativos a seus recursos hídricos. Nos capítulos 2, 3 e 4, foram detalhados os métodos de análise utilizados, para cada qual foi incluída uma revisão bibliográfica específica. Embora individuais, os capítulos não são, de forma alguma, independentes entre si, mas sim complementares. Assim, o capítulo 2 apresenta o método empregado na espacialização dos dados; o capítulo 3, a análise de tendência temporal das séries geradas no capítulo 2; e o capítulo 4 , a análise espaço-temporal conjunta, também sobre os dados gerados no capítulo 2. No capítulo 5, faz-se a síntese e algumas considerações finais sobre as principais conclusões tiradas a partir das análises realizadas.

Mais que ilustrar a aplicabilidade e agilidade de uso de algumas ferramentas disponíveis ao mapeamento e à análise de séries temporais, principalmente no caso dos SGIs como manipulador de informações meteorológicas georeferenciadas, este trabalho 
pretende contribuir para o melhor conhecimento do comportamento dos componentes do ciclo hidrológico na bacia do rio Piracicaba, como forma de auxiliar na tomada de decisão quanto à utilização desse recurso. 


\section{Capítulo 1}

\section{Área de Estudo:}

A Bacia do Rio Piracicaba

Nesta análise da área de estudo, procurou se fazer uma descrição da bacia quanto a seus aspectos sócio-ecônomicos, geomorfológicos e hídricos, como base para o entendimento e discussão dos seus principais problemas. Pode ser considerada como uma sintese de informações referentes a essas características, encontradas em diversas referências sobre a bacia do rio Piracicaba.

A maioria dos trabalhos que enfocam a bacia do rio Piracicaba consiste em relatórios técnicos, planos diretores e projetos, publicados principalmente por órgãos ligados ao Governo do Estado de São Paulo. Dentre essas publicações, podemos destacar alguns relatórios do Departamento de Águas e Energia Elétrica (DAEE) (SÃO PAULO, 1984, 1985, 1986), que apresentaram uma boa descrição da bacia nos aspectos de caracterização física e sócio-econômica, balanço e disponibilidade hídrica, controle de poluição, demografia, uso e ocupação dos solos, e desenvolvimento industrial. Um apanhado sócioeconômico da bacia, assim como a proposição de alternativas de gestão do meio ambiente, 
pode ser encontrado no relatório da Fundação do Desenvolvimento Administrativo (FUNDAP) (SÃO PAULO, 1991). O detalhamento do Sistema Cantareira, incluindo sua concepção, operação e breve histórico, foi apresentado no relatório da Companhia de Saneamento Básico do Estado de São Paulo (SABESP) (SÃO PAULO, 1989).

Existem relativamente poucos trabalhos acadêmicos envolvendo estudos relativos à bacia do rio Piracicaba, em se considerando sua importância sócio-econômica no cenário nacional. Entre outros, pode-se citar algumas teses como: VIEIRA (1970), que abordou a questão do aproveitamento hidro-agrícola; PROCHNOW (1981), que enfatizou os problemas da qualidade de água; FELTRAN FILHO (1982), que fez uma análise fluviométrica; PROCHNOW (1990), que tratou da análise ambiental da sub-bacia do Piracicaba; e CHRISTOFOLETTI (1991), que apresentou um estudo da variabilidade espaço-temporal da precipitação na bacia.

Como um apanhado geral, baseado principalmente nos planos estaduais para a bacia (SÃO PAULO, 1990 e 1994), apresentam-se os itens a seguir, com o objetivo de descrever e caracterizar a bacia e seus principais problemas.

\subsection{Localização e Caracterização Física da Bacia.}

A bacia do rio Piracicaba, com uma superfície de aproximadamente $12.400 \mathrm{~km}^{2}$, situa-se entre os paralelos $22^{\circ} 00^{\prime}$ e $23^{\circ} 30^{\prime}$ de latitude sul e os meridianos $46^{\circ} 00^{\prime}$ e $48^{\circ} 00^{\prime}$ de longitude oeste. Aproximadamente $90 \%$ de sua área encontra-se no Estado de São Paulo e o restante no Estado de Minas Gerais, onde nasce o rio Jaguari, que, unindo-se ao Atibaia, forma o rio de Piracicaba. O rio Piracicaba por sua vez, atravessa a depressão periférica, desaguando no rio Tietê. A sua bacia percorre aproximadamente $250 \mathrm{~km}$ no sentido leste- 
oeste, com uma largura média de $50 \mathrm{~km}$. Além desses rios, o Camanducaia e o Corumbataí são também de importância, sendo, o primeiro, o principal afluente do Jaguari e, este último, afluente do Piracicaba que drena uma área relevante da bacia.

Esses foram os cinco rios escolhidos neste trabalho, sobre cujas bacias se desenvolveu o estudo das séries históricas de precipitação, de vazão e de evapotranspiração, como descrito no capítulo seguinte. A figura 1.1 mostra, além da rede de postos pluviométricos e fluviométricos utilizada, a posição da bacia no Estado de São Paulo, sua subdivisão, de acordo com as sub-bacias analisadas aqui, e sua rede de drenagem principal. De oeste para leste, estão a bacia do Corumbataí, com área de $1.621,25 \mathrm{~km}^{2}$, a do Piracicaba com $3.164,75 \mathrm{~km}^{2}$, a do Jaguari com $2.492,00 \mathrm{~km}^{2}$, a do Camanducaia com $910,00 \mathrm{~km}^{2}$ e a do Atibaia com $2.768,50 \mathrm{~km}^{2}$. O restante da área forma a sub-bacia do Piracicaba final, cujos parâmetros não foram estudados aqui, restringindo-se a área de estudo até o posto em Artemis (4d-007), que delimita a sub-bacia do Piracicaba.

Segundo SÃO PAULO (1990), a bacia pode ser dividida em duas, quanto a suas características geomorfológicas: à montante de Campinas predominam as rochas cristalinas e, na porção restante, as rochas sedimentares e intrusivas. "A primeira, estende-se desde as cabeceiras até a porção média da bacia, apresentando relevo montanhoso com declividade média a alta, acima de $15 \%$, drenagem de alta densidade e cotas variando desde 2.000 metros, nas cabeceiras, até 600 metros. A segunda zona corresponde aos terrenos sedimentares que formam a depressão periférica. $O$ relevo é do tipo colinoso, predominando as baixas declividades, cotas variando desde 700 metros até pouco abaixo de 500 metros, e drenagem de média a baixa densidade. O limite oeste da bacia é constituído por relevo característico de transição com as cuestas ou escarpas festonadas de alta declividade acima de $30 \%$, produto da erosão regressiva que atua sobre a seqüência de basaltos e sedimentos sotopostos, formando anfiteatros separados por espigões com vertentes de perfis retilíneos." (SÃO PAULO, 1990). A figura 1.2(a), adaptada desse trabalho, representa a geologia da 


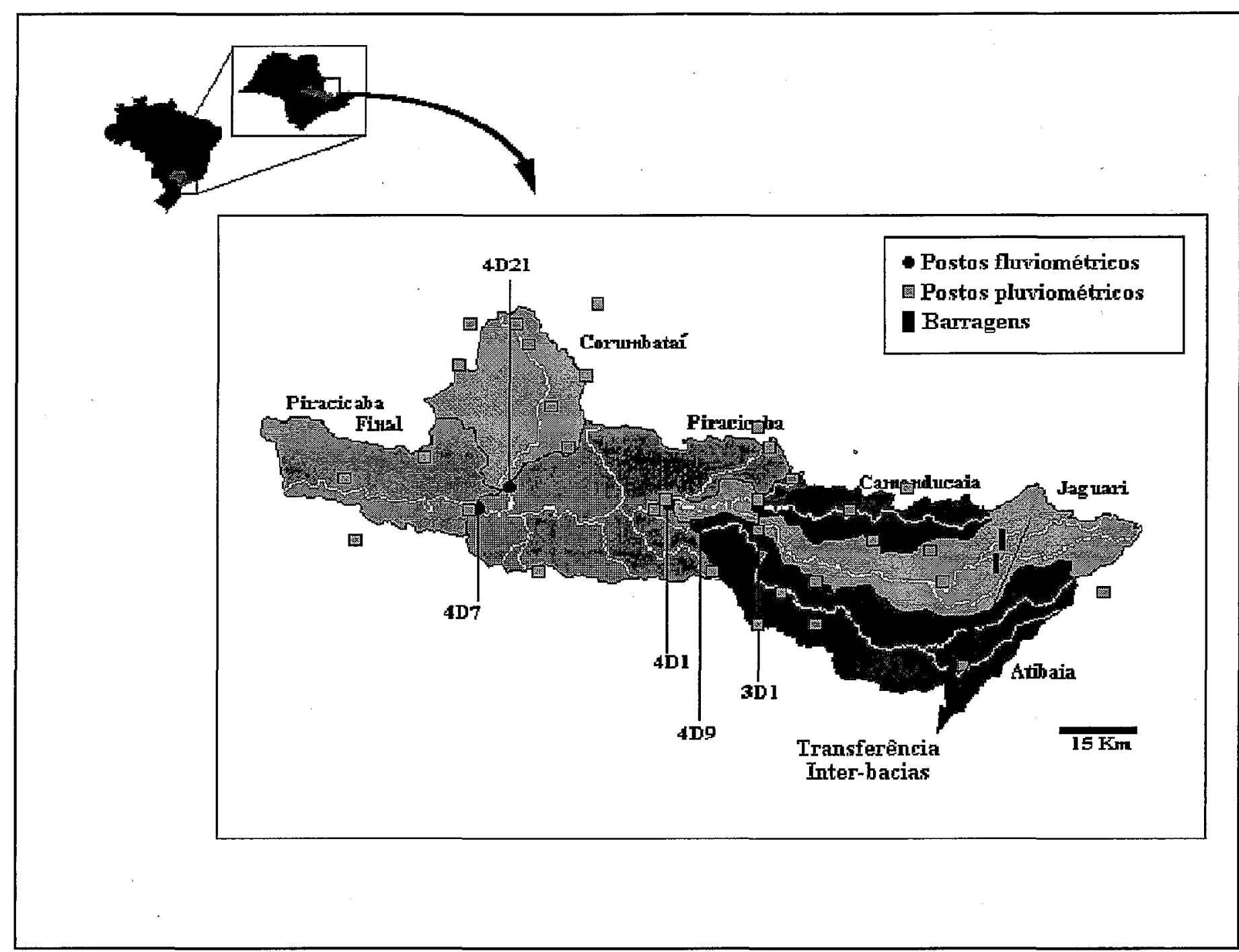

Figura 1.1 - Localização espacial da bacia do rio Piracicaba com a rede de drenagem principal, os limites das sub-bacias e os postos pluviométricos e fluviométricos utilizados. 


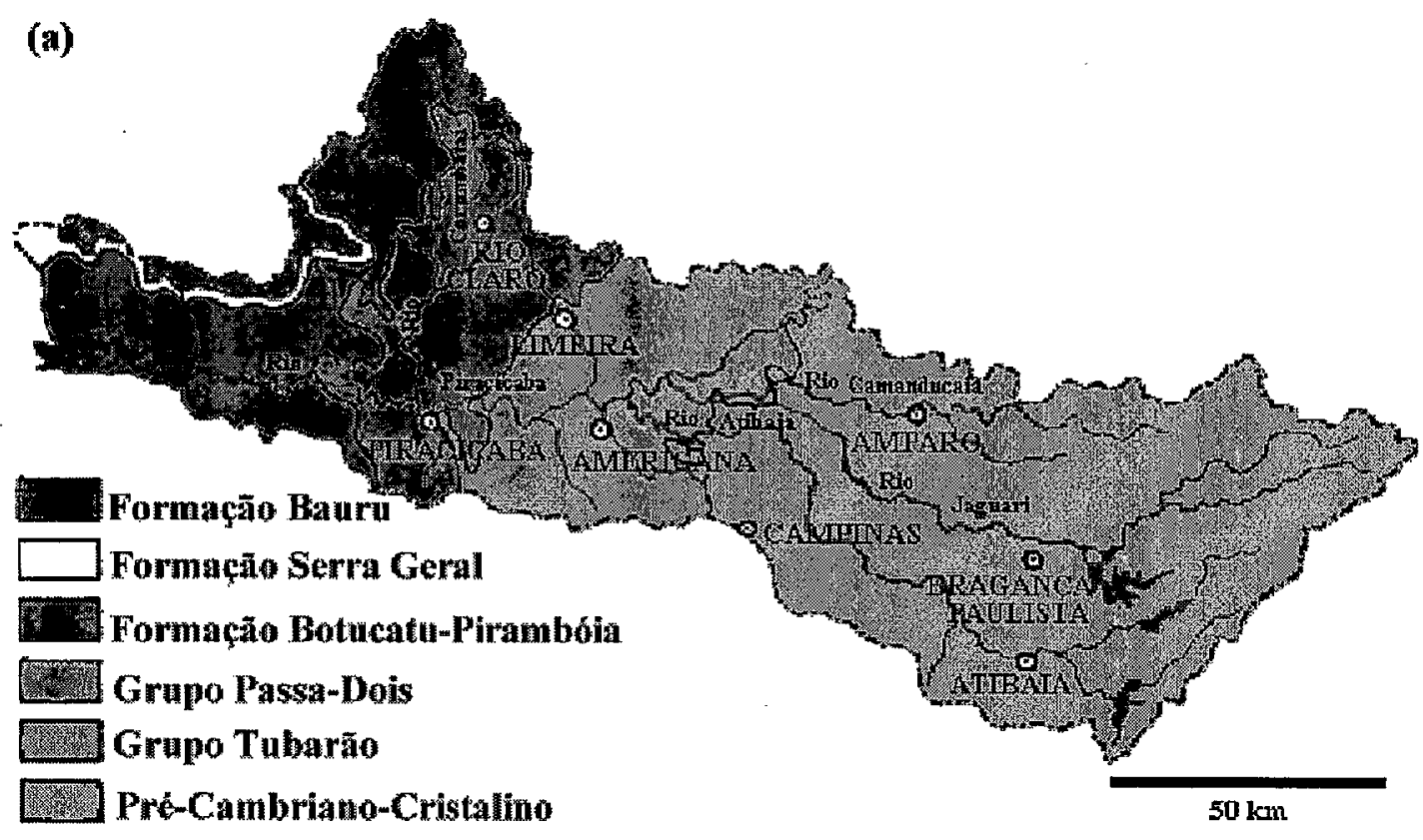

(b)

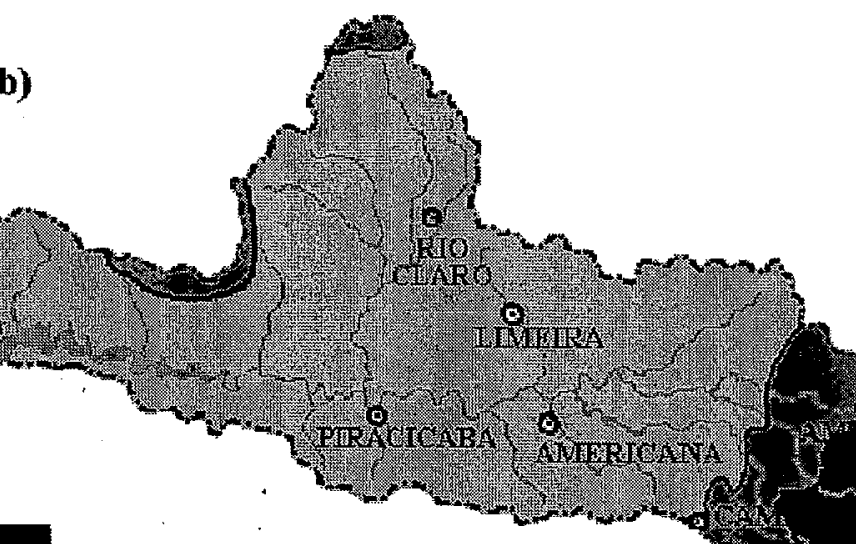

Muito úmido subtropical sem estlagem

Muito ámido subtropical iuvemo seco

Unmido subtropical sem estiagem

Uidido subtropical inverno seco

Super úmido temperado sem estiagem

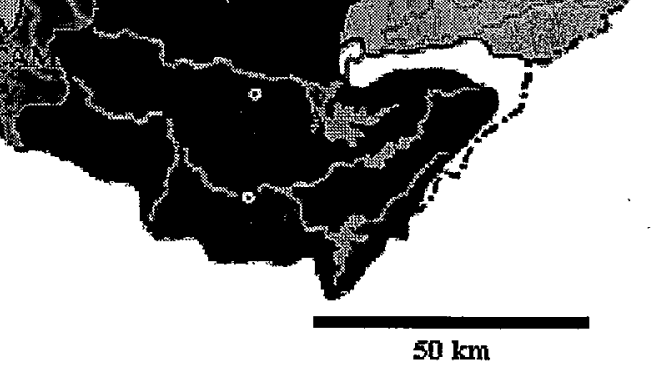

Figura 1.2 - Características geológicas (a) e climáticas (b) da bacia do rio Piracicaba (extraída de São Paulo, 1990). 
bacia.

Uma descrição mais detalhada da geomorfologia da região pode ser encontrada em FELTRAN FILHO (1982). O autor apresentou também, uma série de índices fluviomorfológicos, que permitem uma caracterização mais específica da bacia, dentre os quais podemos citar:

a) Índice de Sinuosidade: relaciona-se com a velocidade do fluxo e o tempo de concentração. É dado pela fórmula:

$$
\operatorname{Sin}=\frac{C v}{C t}
$$

onde : $\mathrm{Cv}$ é o comprimento real do rio principal, e

Ct é o comprimento vetorial do canal.

Para a bacia do rio Piracicaba, os índices calculados para o canal principal foram:

- à montante de Piracicaba: 1,46;

- entre Piracicaba e Artemis: 1,55; e

- à juzante de Artemis: 2,55.

Conclui-se daí, que a região a partir de Artemis apresenta trechos mais sinuosos, com maior tempo de concentração, menor velocidade de fluxo e, conseqüentemente, maior possibilidade de deposição de materiais sedimentares transportados.

b) Densidade de rios: é um índice que sugere a quantidade e freqüência de cursos d'água numa área padrão de $1 \mathrm{~km}^{2}$. Permite observar a capacidade da bacia de gerar novos cursos d'água. É dado pela fórmula: 


$$
\operatorname{Dr}=\frac{N}{A}
$$

onde $\quad \mathrm{N}$ é o número total de rios; $\mathrm{e}$

A é a área da bacia.

A bacia apresenta um índice de 1,74 canais de $1^{\mathrm{a}}$ ordem por $\mathrm{km}^{2}$, ou seja, 1,74 nascentes de rio por $\mathrm{km}^{2}$, o que significa uma baixa tendência para gerar novos cursos d'água.

c) Densidade de Drenagem: indica o grau de desenvolvimento de um sistema de drenagem. Por exemplo, quando uma bacia se encontra em locais rochosos, com menor infiltração, ela apresenta melhores condições para formação de canais de escoamento. Em bacias cuja drenagem é pobre, esse índice alcança 0,5 , e naquelas bem drenadas e de fluxo rápido, é da ordem de 3,5. É calculado através da seguinte fórmula:

$$
D d=\frac{L t}{A}
$$

onde Lt é o comprimento total dos canais; e

A é a área da bacia.

Para a bacia do rio Piracicaba, com $7.854 \mathrm{~km}$ de canais, esse índice alcançou 0,633 cursos d'água $/ \mathrm{km}^{2}$, o que significa ser uma bacia de infiltração, perfazendo uma densidade de drenagem baixa.

d) Extensão do Percurso Superficial: é a distância média que a água de precipitação tem que percorrer superficialmente em linha reta para atingir o leito do rio. Quanto maior for essa distância, maior será a atuação dos processos erosivos superficiais, maior será o 
atraso no escoamento das águas pluviais e maior será o favorecimento para os processos de evaporação e infiltração. No caso do rio Piracicaba, esse índice foi $3,48 \mathrm{~km}$. A fórmula é:

$$
E p s=\frac{1}{2 D d}
$$

onde Dd é a densidade de drenagem.

Os solos predominantes na região são os Podzólicos Vermelhos-Amarelos e os Latossolos Vermelhos-Amarelos, com deficiências químicas quanto à acidez e ao excesso de alumínio (SÃO PAULO, 1992), porém, com características físicas bastante favoráveis. De uma maneira geral, são propícios ao uso agrícola, à excessão daqueles situados em terrenos acidentados. De fato, segundo SÃO PAULO (1990), 68\% da área da bacia correspondem a terras potencialmente agricultáveis.

Quanto ao clima da região, FELTRAN FILHO (1982) fez uma explanação sobre as características das massas de ar atuantes, onde discutiu o favorecimento de sua entrada e passagem pela bacia, através da depressão periférica. Discutiu também, a barragem das correntes oceânicas pela serra da Mantiqueira, causando maiores índices de chuva nessa região. $\mathrm{O}$ autor concluiu que, do ponto de vista térmico, a bacia poderia ser classificada como subtropical, com temperatura média entre 20 e $21^{\circ} \mathrm{C}$ anuais e com acentuada amplitude térmica entre os meses quentes e os frios. Entretanto o regime de chuvas é tipicamente tropical, com máximos e mínimos coincidindo com os meses de verão e de inverno, respectivamente. Segundo SÃO PAULO (1990), quase a totalidade da bacia apresenta clima subtropical C segundo a classificação de Köeppen, com média de temperaturas anuais entre 18 e $22^{\circ} \mathrm{C}$. Uma pequena porção (2\%), apresenta clima temperado, com temperaturas médias anuais entre 12 e $18^{\circ} \mathrm{C}$. A figura $1.2(\mathrm{~b})$, adaptada desse trabalho, apresenta as características climáticas da bacia do rio Piracicaba. 
A precipitação anual média da bacia é de aproximadamente $1400 \mathrm{~mm}$, (variando de $1300 \mathrm{~mm}$ na sua parte oeste a $1800 \mathrm{~mm}$ na sua parte leste, nas proximidades da serra da Mantiqueira), as máximas ocorrendo nos meses de dezembro e janeiro e as mínimạs geralmente em agosto. CHRISTOFOLETTI (1991) definiu o período entre os meses de abril a setembro como sendo seco, e outubro a março, úmido. Segundo o autor, a precipitação média mensal do período seco é inferior a $20 \mathrm{~mm}$ e do período úmido por volta de $300 \mathrm{~mm}$. Dessa forma, observa-se que $70 \%$ do volume de precipitação ocorre no verão, situação característica de clima tropical.

A vazão natural média está em torno de $186 \mathrm{~m}^{3} / \mathrm{s}$ (aproximadamente $465 \mathrm{~mm}$ ), o que significa que por volta de $30 \%$ da água de precipitacão são convertidos em escoamento superficial, sendo o restante perdido basicamente pela evapotranspiração. Segundo MARTINELLI (1994), a sub-bacia do rio Jaguari (incluindo a do rio Camanducaia) é a que apresenta maior descarga média produzida na bacia, cerca de $63 \mathrm{~m}^{3} / \mathrm{s}$, seguindo-se as subbacias do Piracicaba com $45 \mathrm{~m}^{3} / \mathrm{s}$, do Atibaia com $35 \mathrm{~m} 3 / \mathrm{s}$ e do rio Corumbataí com $22 \mathrm{~m}$ 3s. A descarga específica é também maior na do Jaguari, $4,6 \mathrm{~m}^{3} / \mathrm{ha}$.ano. As demais praticamente não se diferenciam, apresentando valores de 4,0, 4,1 e' $3,9 \mathrm{~m}^{3} / \mathrm{ha}$.ano, respectivamente para as bacias do Corumbataí, Atibaia e Piracicaba.

Um ponto importante a ressaltar quanto à vazão do rio, é a reversão de água da bacia do rio Piracicaba para a bacia do Alto Tietê, o que constitui a principal fonte de abastecimento de água potável para a Região Metropolitana de São Paulo (RMSP). Esse sistema compreende quatro reservatórios localizados nas cabeceiras dos formadores do rio Piracicaba (Jaguari, Jacareí, Atibainha e Cachoeira) e um reservatório situado na cabeceira do rio Juqueri (fora da bacia do Piracicaba). Os reservatórios encontram-se interligados por túneis e canais, até a Estação de Tratamento de Água do Guarau, na cidade de São Paulo.

A construção do sistema teve início em 1965 (união dos rios) e foi implantada em 
duas etapas: a primeira compreendeu o aproveitamento dos rios Juqueri, Atibainha e Cachoeira, fornecendo a vazão nominal de 11 m³/s para São Paulo, com início em 1975. Em 1976, tiveram início as obras relativas à segunda etapa, compreendendo as barragens dos rios Jaguari e Jacareí, que propiciou a adução de $33 \mathrm{~m} / \mathrm{s}$ em 1982, dos quais $31 \mathrm{~m}^{3} / \mathrm{s}$ provêm da bacia do rio Piracicaba e 2 m³ da Bacia do Rio Juqueri (SÃO PAULO, 1986, 1989). A população atendida pelo sistema integrado saltou da cifra de $60 \%$ em 1975 , para 95\% em 1984 (SÃO PAULO,1989).

Segundo SÃO PAULO (1994), durante estiagens severas a disponibilidade hídrica média da bacia cai de 165 para $40 \mathrm{~m}^{3} / \mathrm{s}$. Com o Sistema Cantareira exportando $31 \mathrm{~m}^{3} / \mathrm{s}$ para a RMSP, nos meses mais secos a disponibilidade hídrica baixa para $128 \mathrm{~m}^{3} / \mathrm{s}$ e nas estiagens mais severas atinge $34 \mathrm{~m} / \mathrm{s}$. Entretanto, segundo esse trabalho, a vazão disponível é superior a $50 \mathrm{~m}^{3} / \mathrm{s}$ em cerca de $95 \%$ do tempo. Segundo dados da JAAKKO POYRY (1992), embora a SABESP tenha se comprometido a adotar regras operacionais para o Sistema Cantareira, que assegurassem descargas mínimas de $15 \mathrm{~m}^{3} / \mathrm{s}$ em Paulinia e $40 \mathrm{~m} / \mathrm{s}$ em Piracicaba, vazões mínimas inferiores têm ocorrido nesses dois pontos, como para o ano de 1990 , quando elas foram de $9 \mathrm{~m}^{3} / \mathrm{s}$ e $23 \mathrm{~m}^{3} / \mathrm{s}$, respectivamente.

Além desse sistema, outra reversão vai para a região de Jundiaí, cuja utilização dos recursos hídricos da bacia do rio Piracicaba ocorrem principalmente na época de estiagem, com uma vazão de reversão de $1,5 \mathrm{~m}^{3} / \mathrm{s}$ em 1990 . Existem também trocas de água entre as bacias do Piracicaba e Capivari na região de Campinas cuja quantificação é muito difícil, já que a captação de água e lançamento de esgotos sanitários ocorrem simultâneamente nas duas bacias (SÃO PAULO, 1986).

Diante de toda essa complexidade do uso da água na bacia, que dificulta a análise dos componentes do ciclo hidrológico em escala regional, torna-se importante um estudo dessa natureza, procurando avaliar simultaneamente seu comportamento espacial e 
temporal.

\subsection{Aspectos Sócio-Econômicos e seu Impacto sobre os Recursos Hídricos}

A bacia do rio Piracicaba é citada por AYABE et al. (1981) como "... excetuando a Região Metropolitana de São Paulo, é a mais importante do Estado, destacando seus 2.500.000 habitantes, as indústrias do setor sucro-alcooleiro, química, celulose e alimentícias.". Segundo SÃO PAULO (1994), ela está localizada numa das regiões de maior crescimento econômico do país, fruto da política de desenvolvimento da década de 70 . De acordo com SÃO PAULO (1990), esse crescimento econômico foi acompanhado de um alto crescimento populacional, numa taxa de $5 \%$ ao ano durante a década, superior à média do Estado, que na mesma época foi de 3,43\% ao ano, e ainda, superior à da Grande São Paulo que foi de 4,36\% ao ano. Na década de 80 , devido à tendência econômica recessiva, a taxa de crescimento demográfico da bacia baixou para 2,5\% ao ano (SÃO PAULO, 1994).

O crescimento populacional da região é desuniforme, ocorrendo com mais intensidade nos centros de maior importância como Campinas, Piracicaba, Limeira, Americana e Rio Claro, perfazendo quase $60 \%$ da população total da bacia. Sua evolução, baseada nos dados de PROCHNOW (1981), pode ser vista na figura 1.3(a) juntamente com a concentração populacional nos principais centros urbanos, na figura 1.3(b).

Os principais problemas, decorrentes desse alto crescimento, são o aumento na demanda d'água para uso doméstico, industrial e agrícola, e o aumento da carga orgânica dos esgotos domésticos e dos efluentes industriais. A análise conjunta dos setores urbano, industrial e agrícola, realizada por SÃO PAULO (1994), revelou que aproximadamente 27 $\mathrm{m}^{3} / \mathrm{s}$ são captados à juzante do Sistema Cantareira, sendo $49 \%$ para o setor industrial, $37 \%$ para o urbano e 14\% para a irrigação. Desse total, $15 \mathrm{~m}^{3} / \mathrm{s}$ (pouco mais de $50 \%$ ), não retorna aos corpos d'água, sendo desde já a quantidade de água um fator limitante. Quanto à 
(a)

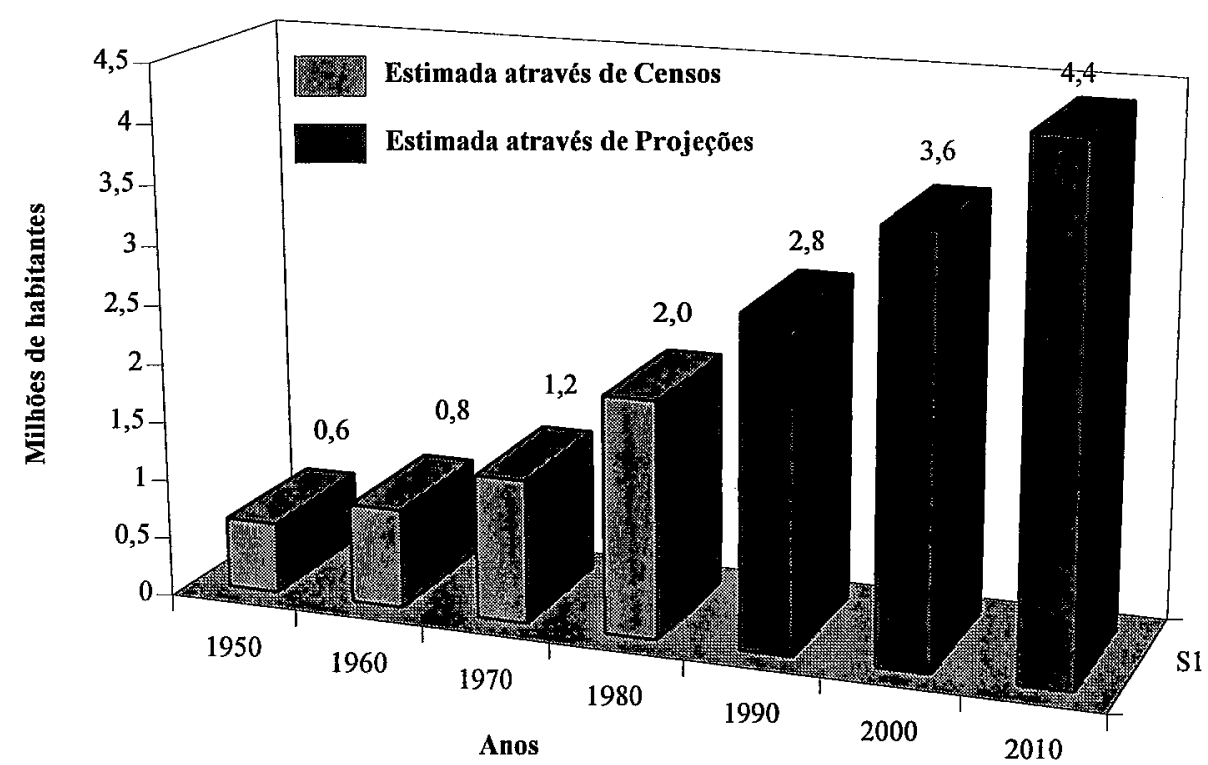

(b)

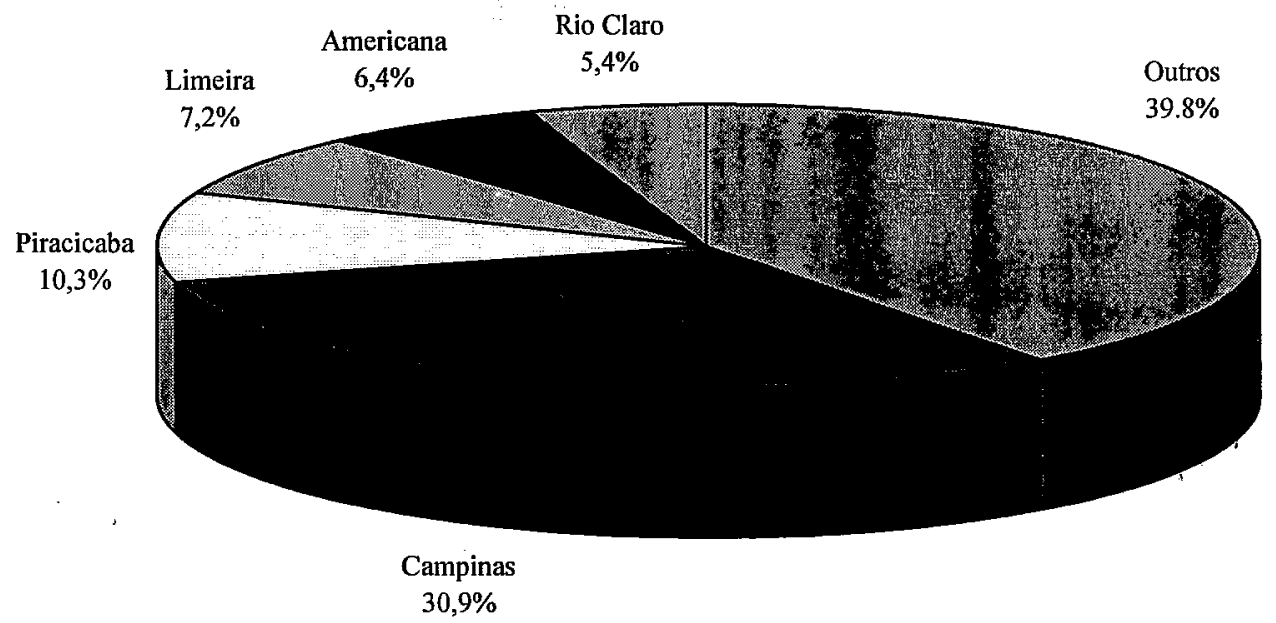

Figura 1.3 - Crescimento populacional na bacia do rio Piracicaba (a) e a distribuição da população nos seus principais munícipios (b) (adaptado de Prochnow, 1981). 
qualidade da água, a situação não é menos preocupante. SÃO PAULO (1990), estimou que, das cargas poluidoras remanescentes, 108 tDBO/dia (58\%) são de origem urbana, e 77 tDBO/dia (42\%) industrial. Segundo JAAKKO POYRY (1992), também os agroquímicos e as cargas inorgânicas são fontes potenciais significativas.

Ao que tudo indica, o quadro futuro parece agravante, pois haverá um aumento na demanda de água acompanhado de um aumento na carga poluidora orgânica (SÃO PAULO, 1990; ROSA, 1991), ou seja, haverá cada vez menos água e de pior qualidade. Como alternativa, aponta-se a construção de barragens à juzante do Sistema Cantareira, regularizando a distribuição da água. Quanto à carga poluidora, o tratamento da carga doméstica, que atualmente é de apenas $4 \%$, se faz urgente, principalmente para os grandes centros.

De maneira geral, as vazões mínimas do rio Piracicaba ocorrem no início da época chuvosa, no mês de setembro, devido à defasagem temporal entre a precipitação e a vazão (PROCHNOW, 1981; FELTRAN FILHO, 1982). Nessa época, os índices de DBO são superiores aos de qualquer outra, inclusive aos da estiagem que ocorre no mês de maio. Portanto, a qualidade da água dos rios está estritamente relacionada ao regime hídrico, uma vez que a diluição de seus resíduos depende da distribuição da chuva e da vazão na bacia. Embora uma análise mensal detalhada não seja realizada aqui, a análise de tendências nos trimestres secos e úmidos se justifica devido à sua relação com a qualidade da água, principalmente nos períodos secos. 


\section{Capítulo 2}

\section{Espacialização dos Dados}

Neste capitulo procura se descrever as técnicas adotadas na espacialização dos dados, desde o preenchimento de falhas e análise de sua consistência, até o método de interpolação e o de cálculo da evapotranspiração através do balanço hidrico superficial da bacia do rio Piracicaba. Mais do que para simples espacialização, esses métodos foram utilizados com o objetivo de obter novas séries temporais de dados da lâmina anual média d'água, precipitada e evapotranspirada, das suas principais sub-bacias.

\subsection{Breve Revisão Bibliográfica}

A espacialização dos dados climáticos sobre determinada região é uma etapa básica, porém essencial a qualquer estudo que pretende conhecer o comportamento do seu ciclo hidrológico. Ela tem sido realizada de diversas formas, mas quase sempre é representada através de mapas de isolinhas, principalmente para os dados de precipitação e evapotranspiração. Os primeiros trabalhos para o Estado de São Paulo foram os de SETZER (1946), SCHORODER (1956), SETZER (1966) e BLANCO \& GODOY (1967) que são verdadeiros atlas climatológicos. Com o advento da computação, a geração desses mapas 
se tornou mais fácil e rápida, especialmente através de pacotes gráficos ou dos Sistemas Geográficos de Informações (SGIs). Além da espacialização, ou seja, da conversão de um banco de dados qualquer a um plano georeferenciado, esse tipo de sistema permite a sua integração para utilização em diversos tipos de análises. Destacando a importância desse tipo de sistema, SERRA FILHO \& PINTO (1985) propuseram a criação de um SGI para o mapeamento agroclimático do Estado de São Paulo, como forma de integrar dados de diversas naturezas que se encontravam dispersos em companhias governamentais e privadas. Ele auxiliaria em projetos na área de uso da terra, monitoramento, previsão de safras, etc.

Particularmente para os dados hidrometeorológicos, vários são os autores que têm estudado sua distribuição espacial no território brasileiro. MOLINIER et al. (1991), HIEZ et al. (1991), MOLINIER et al. (1992) e GUYOT et al. (1993), por exemplo, realizaram estudos sobre balanço hídrico na Amazônia através da utilização de técnicas de regressão linear entre a descarga específica e a precipitação, com o objetivo de fazer a regionalização dos dados de vazão. SÁ et al. (1989), ZULLO et al. (1989) e ZULLO (1992) estudaram a espacialização de dados pluviométricos do Estado de São Paulo, separados em qüinqüídios, através de técnicas de análise multivariada, com fins de estabelecer cronograma agrícola e regionalização climática mais adequados. ZULLO (1992) incluiu ainda, esse mesmo tipo de análise para a região nordeste do Pará.

Dentre os trabalhos que fazem uso de SGI com o objetivo de espacialização e integração de dados meteorológicos no Brasil, destaca-se o livro de ASSAD \& SANO (1993) que apresentaram vários exemplos de aplicações de SGI na agricultura, dos quais dois são especificamente baseados no mapeamento de dados climáticos dos cerrados. ASSAD (1994) fez uma interpretação dos dados pluviométricos, também para a região de cerrado, e traz inúmeros mapas gerados através do pacote SGI do Instituto Nacional de Pesquisas Espaciais (INPE). 
Mais especificamente para a bacia do Piracicaba, CHRISTOFOLETTI (1991), objetivando uma regionalização da precipitação sobre a bacia, fez o traçado de isolinhas do seu desvio padrão e coeficiente de variação. Através dessas cartas o autor procurou fazer a separação em regiões homogêneas quanto a esses parâmetros, embora a amplitude de variação dos dados não fosse muito grande. PROCHNOW (1981) utilizou o método de Thiessen como forma de espacializar e estimar a lâmina média de água, porém não elaborou mapas de isoietas. PROCHNOW (1990), fazendo uso de SGI, apresentou um verdadeiro banco de dados ecológico sobre a sub-bacia do rio Piracicaba, através de imagens de satélite combinadas a uma extensa gama de mapas temáticos de diversos tipos, dentre os quais os polígonos de Thiessen para os dados de precipitação e a localização das estações.

O método de espacialização de dados e traçado de isolinhas mais freqüentemente usado, tanto nos trabalhos de SÁ et al. (1989), ZULLO et al. (1989) e ZULLO (1992), quanto nos de ASSAD \& SANO (1993) e ASSAD (1994), foi o Método do Inverso do Quadrado da Distância (MIQD). Testado por WEI \& MCGUINNESS (1973) quanto ao cálculo de dados perdidos e ao cálculo da lâmina d'água sobre uma superfície, apresentou melhores resultados quando comparado a outros métodos. Essa técnica também foi a adotada neste trabalho (ver item 2.2.2.).

Quanto à estimativa da evapotranspiração, DOORENBOS \& PRUITT (1977), PEREIRA (1992) e OLIVER (1983) descreveram os principais métodos, discutindo seus aspectos positivos e negativos. Este último autor fez uma separação dos métodos de acordo com sua escala temporal e espacial de aplicação, sugerindo o Método do Balanço Hídrico (MBH) para estudos em bacias de drenagem. Ele tem sido usado por diversos autores, principalmente para escalas temporais maiores. Dentre eles pode-se citar: SCHÄDLER (1987), que estudou sua tendência em quatro bacias na Suíça com longas séries mensais; LEOPOLDO et al. (1982), que estimaram evapotranspiração anual para uma pequena bacia de $1,3 \mathrm{~km}^{2}$ na reserva Ducke, a $26 \mathrm{~km}$ de Manaus; e também, a equipe formada pela 
Coordenadoria Técnica de Recursos Hídricos (CTRH) do DNAEE e pelo Instituto Francês de Pesquisa Científica para o Desenvolvimento em Cooperação (ORSTON), que vem fazendo levantamentos em escala anual em sub-bacias da Amazônia (MOLINIER et al., 1991; MOLINIER et al., 1992; e GUYOT et al. 1993). Ainda em escala anual, MATOS \& MATTOS (1981) estudaram a bacia do rio Jacaré Guaçu $\left(4.108 \mathrm{~km}^{2}\right)$ no centro-norte do Estado de São Paulo.

Normalmente se espera que os erros devidos às generalizações se anulem à medida que o período aumenta. ESSERY (1992) porém, discutindo sobre a influência do armazenamento profundo sobre o balanço hídrico, concluiu que é preciso cautela ao assumir essa hipótese, pois eles podem ser acumulativos e aumentarem com o tempo, caso haja erro sistemático na instrumentação utilizada na obtenção dos dados.

MOLINIER et al. (1991), seguindo as recomendações para longos períodos e grandes áreas do "Guía metodológica para la elaboratión del balance hídrico de América del Sur" (UNESCO, 1982), utilizaram o MBH, encontrando uma discrepância de aproximadamente $5 \%$ em comparação ao método de Turc, descrito nesse guia. MATOS \& MATTOS (1981) também utilizaram esse método comparado ao método de Turc e de Thornthwaite \& Mather, encontrando um termo de discrepância entre os métodos em torno de $10 \%$.

Neste trabalho também, a estimativa da evapotranspiração através do MBH foi comparada a estes dois últimos métodos, calculando-se a sua discrepância em relação a eles. 


\subsection{Métodos Utilizados na Análise e Geração dos Dados Espaciais.}

Todas as análises desenvolvidas contaram com o suporte institucional do Centro de Energia Nuclear na Agricultura, da Universidade de São Paulo (CENA/USP), e do Centro de Ensino e Pesquisa em Agricultura, da Universidade Estadual de Campinas (CEPAGRI/UNICAMP), tanto na utilização de equipamentos e softwares, como no apoio de seus corpos técnicos.

\subsubsection{A Base de Dados.}

Como base de dados para este trabalho foram utilizados os dados mensais de precipitação e vazão da rede hidrométrica do DAEE, cedidos diretamente pelo próprio órgão. O CEPAGRI/UNICAMP, que dispõe do mesmo banco de dados de precipitação, também serviu como fonte de dados suplementar. Por se tratar da mesma base, os dados serão tratados doravante como "dados do DAEE", indistintamente para as duas fontes. A partir deles foram calculadas as precipitações totais anuais dos postos e as vazões totais anuais médias para as sub-bacias.

Somente como fonte de dados para a checagem do cálculo de evapotranspiração real, calculada pelo Método do Balanço Hídrico (item 2.2.2.) e para a análise de consistência dos dados, utilizou-se os dados dos postos de Limeira, Monte Alegre do Sul e Campinas, pertencentes ao Instituto Agronômico de Campinas (IAC). O posto em Piracicaba, sob responsabilidade do Departamento de Física e Meteorologia da ESALQ/USP, também foi utilizado com esses fins.

Pelo fato de os dados serem fornecidos de forma bruta (isto é, sem correções) pelo 
DAEE, a seleção dos melhores postos e também algumas correções foram necessárias, e se fizeram da forma descrita nos itens que se seguem.

\section{a) Dados Pluviométricos.}

Contava-se com postos interiores e vizinhos à Bacia do Rio Piracicaba, dos quais 49 possuíam mais de 30 anos, como se aconselha para análises de séries. A mesma base de dados foi utilizada por PROCHNOW (1981), PROCHNOW (1990), COSTA (1989) e CHRISTOFOLETTI (1991), porém para períodos diferentes em cada um deles. Como havia o interesse aqui de tentar avaliar a influência da instalação de barragens na região, com alterações no regime fluvial iniciando por volta de 1968, um primeiro limite estabelecido para a escolha de determinado posto foi o de contar com registros desde pelo menos 20 anos antes dessa data até 1991, ano até o qual estava atualizado o banco. Dessa forma, foram selecionados postos com dados a partir de 1947 e anteriores. Dentro desse grupo foram escolhidos aqueles que não apresentassem interrupção de registros maior que 2 anos.

Quando um desses postos se localizava muito próximo a outro, de forma que pouco contribuiria para a melhoria do processo de interpolação dos dados, escolheu-se, dentre eles, o que apresentou menor número de falhas. Assim, foram selecionados 33 postos pluviométricos , cobrindo a área total da bacia de maneira uniforme e com boa densidade. Desses, 25 são internos à bacia e 8 são vizinhos a ela, sendo usados para melhorar a qualidade da interpolação nos seus limites (Tabelas 2.1 e 2.2 e figura 1.1) .

Devido à necessidade de se trabalhar com séries contínuas, as falhas nesses postos foram preenchidas segundo o método descrito em UNESCO (1982), FILL (1987) e DUNNE (1978). A precipitação em determinado posto é estimada tomando-se a média ponderada referente ao mesmo período, de pelo menos três postos vizinhos uniformemente espaçados. 
Tabela 2.1 - Estações pluviométricas do DAEE pertencentes à bacia do Piracicaba.

\begin{tabular}{|c|c|c|c|c|}
\hline Prefixo & Rio/Bacia & Nome do Posto & Município & Período \\
\hline D3-002 & Atibaia & Salto Grande & Campinas & $09 / 1931$ - 91 \\
\hline D3-009 & Jaguari & Martim Francisco & Mogi-Mirim & $01 / 1937-91$ \\
\hline D3-018 & Jaguari & Vargem & Bragança Paulista & 08/1937 - 91 \\
\hline D3-027 & Camanducaia & Mte. Alegre do Sul & Mte. Alegre do Sul & $10 / 1942-91$ \\
\hline D3-031 & Camanducaia & Faz. Chapadão & Amparo & $10 / 1940-91$ \\
\hline D3-035 & Jaguari & Pedra Bela & Pedra Bela & $11 / 1940-91$ \\
\hline D3-036 & Camanducaia & Pinhalzinho & Pinhalzinho & $12 / 1940-91$ \\
\hline D3-1042 & Camanducaia & Faz.Barra & Jaguariúna & $12 / 1942-91$ \\
\hline D3-046 & Jaguari & Morungaba & Morungaba & $07 / 1947-91$ \\
\hline D3-052 & Jaguari & Pedreira & Pedreira & $04 / 1946-91$ \\
\hline D4-004 & Piracicaba & Americana & Americana & $01 / 1937-91$ \\
\hline D4-012 & Corumbataí & Rio Claro & Rio Claro & $01 / 1936-91$ \\
\hline D4-014 & Jacaré-Guaçu & Itirapina & Itirapina & 01/1936 - 91 \\
\hline D4-035 & Corumbataí & Analândia & Analândia & $01 / 1937$ - 91 \\
\hline D4-036 & Corumbataí & Grauna & Itirapina & $02 / 1937-91$ \\
\hline D4-043 & Corumbataí & Corumbataí & Corumbatai & $05 / 1939-91$ \\
\hline D4-044 & Piracicaba & Campinas & Campinas & $01 / 1941-91$ \\
\hline D4-052 & Jaguari & Usina Ester & Cosmópolis & $05 / 1943-91$ \\
\hline D4-059 & Corumbataí & Sta. Gertrudes & Sta. Gertrudes & $11 / 1941-91$ \\
\hline D4-060 & Piracicaba & São Pedro & São Pedro & $01 / 1943-91$ \\
\hline D4-061 & Piracicaba & Artemis & Piracicaba & $06 / 1943-.91$ \\
\hline D5-062 & Piracicaba & Sta. Maria da Serra & Sta. Maria da Serra & 03/1945- 91 \\
\hline E3-015 & Jacarezinho & Itatiba & Itatiba & $10 / 1939-91$ \\
\hline E3-017 & Atibaia & Vinhedo & Vinhedo & $09 / 1936-91$ \\
\hline E3-099 & Atibainha & Nazaré Paulista & Nazaré Paulista & 07/1946-91 \\
\hline
\end{tabular}


Tabela 2.2 - Estações pluviométricas do DAEE vizinhas à bacia do Piracicaba.

\begin{tabular}{|lllll|}
\hline Prefixo & Rio/Bacia & Nome do Posto & Município & Período \\
\hline D2-021 & Jaguari & S.Francisco Xavier & São José dos Campos & 05/1939 - 91 \\
D3-008 & Moji-Mirim & Moji-Mirim & Moji-Mirim & $01 / 1941$ - 91 \\
D3-030 & Peixe & Socorro & Socorro & $11 / 1942-91$ \\
D4-027 & Araras & Faz. Belmonte & Araras & $10 / 1936-91$ \\
D4-032 & Mogi-Guaçu & Sítio S. Geraldo & S. Cruz Conceição & $10 / 1936-91$ \\
D4-037 & Feijão & Visc. de Rio Claro & Itirapina & $02 / 1937-91$ \\
D4-068 & Capivari & Rio das Pedras & Rio das Pedras & $10 / 1946-91$ \\
D5-044 & Tietê sup. & Faz. Barreiro Rico & Anhembi & $10 / 1939-91$ \\
\hline
\end{tabular}

Tabela 2.3 - Estações fluviométricas do DAEE pertencentes à bacia do Piracicaba.

\begin{tabular}{|lllll|}
\hline Prefixo & Rio/Bacia & Nome do Posto & Município & Período \\
\hline 3D-001 & Camanducaia & Faz. Barra & Jaguariúna & $01 / 1943-91$ \\
4D-001 & Jaguari & Usina Ester & Cosmópolis & $05 / 1943-91$ \\
4D-007 & Piracicaba & Artemis & Piracicaba & $06 / 1943-91$ \\
4D-009 & Atibaia & Paulínia & Paulínia & $11 / 1947-91$ \\
4D-021 & Corumbataí & Recreio & Piracicaba & $10 / 1972-91$ \\
\hline
\end{tabular}


O peso de cada posto vizinho é dado pela relação entre a sua precipitação normal anual e a do posto a ser estimado. Assim, a precipitação estimada no posto $\mathrm{X}$ é dada pela equação (2.1):

$$
P_{X}=\frac{1}{3}\left(\frac{N_{x}}{N_{A}} P_{A}+\frac{N_{x}}{N_{B}} P_{B}+\frac{N_{x}}{N_{C}} P_{C}\right)
$$

onde $\mathrm{P}$ é a precipitação estimada ou medida;

$\mathrm{N}$ é a precipitação normal anual; e os índices

A, B e C representam os postos vizinhos ao posto $\mathrm{X}$.

Esse método permite uma simplificação quando a precipitação normal anual em cada um dos postos vizinhos apresenta uma diferença de no máximo $10 \%$ da precipitação normal do posto com falha. Quando isto ocorre, a falha é estimada pela média aritmética da precipitação das três estações.

Após o preenchimento das falhas foi realizada a análise da consistência dos dados de cada estação em relação aos dados observados em estações vizinhas. Essa análise foi realizada a nível mensal, de acordo com o método clássico das Duplas Massas descritos em TUCCI \& BELTRAME (1993), UNESCO (1982), FILL (1987) e DUNNE (1978), no qual se constrói uma curva duplo-acumulativa, onde são comparados os valores acumulados da precipitação total mensal ou vazões médias mensais da estação em estudo com os valores acumulados de um grupo de estações que estejam sob condições meteorológicas similares. Aqui, adotou-se os mesmos postos utilizados para o preenchimento de falhas, isto é, os três postos vizinhos mais próximos e que não apresentassem diferenças de mais de $10 \%$ entre seus valores normais e os do posto a ser estimado.

A correção dos valores, quando necessária, ou seja, quando se detectou mudança de 
declividade na curva duplo-acumulativa, o que representa anomalia nas medidas realizadas, foi feita utilizando-se como fator de correção a inclinação da reta do período com melhor ajuste, o que corresponde ao método da razão sugerido por THOM (s/d). Esse método pode ser expresso pela equação (2.2):

$$
\Sigma y=b * \Sigma x
$$

que é a própria regressão linear da curva duplo-acumulativa, passando pela origem dos eixos, onde:

$\Sigma$ y é a soma acumulada do período com bom ajuste do posto a ser estimado; b é justamente o coeficiente angular da reta e que funciona como fator multiplicativo de correção;e

$\Sigma x$ é a soma acumulada da média dos postos vizinhos do mesmo período.

\section{b) Dados Fluviométricos.}

FELTRAN FILHO \& CHRISTOFOLETTI (1981) apresentaram sua análise de freqüência na escala diária e anual, através do cálculo do período de retorno para oito postos dentro da bacia do rio Piracicaba. AYABE et al. (1981) fizeram um relato dos produtos disponíveis no DAEE, como resultado do acompanhamento diário dos postos fluviométricos disponíveis. Aqui, a escolha dentre eles foi baseada principalmente na seleção dos rios mais importantes e que dividissem a bacia em regiões submetidas a diferentes influências antrópicas. Por exemplo, sub-bacias com reservatórios (Jaguari, Atibaia e Piracicaba) e subbacias que não os possuíssem (Camanducaia e Corumbataí). Esses postos são todos com registros anteriores a 1947, com exceção do Corumbataí (4D-021), que teve sua série reconstruída no período de 1947 a 1973 através de regressão linear múltipla entre ele e os 
postos de Piracicaba e de Artemis (4D-007), localizados imediatamente antes e depois de sua desembocadura no rio Piracicaba. Considerou-se essa aproximação razoável, uma vez que esse rio é o principal tributário do rio Piracicaba entre estes dois postos.

O preenchimento das falhas, bem menos numerosas que as dos postos pluviométricos, foi realizado segundo as recomendações de FILL (1987), através de regressões lineares simples ou múltiplas entre as vazões medidas em diferentes postos de coleta de um mesmo rio. A série histórica do rio Piracicaba, na cidade de Piracicaba, foi gerada pela complementação dos dados dos postos do DNAEE-62707000 (até 1964) com os da Companhia Energética de São Paulo (CESP) (após 1964). As eventuais discrepâncias dessas reconstituições foram minimizadas pela análise de consistência.

A análise de consistência e a correção dos dados, quando esta foi necessária, foram feitas da mesma forma que para a precipitação, ou seja, pelo método de Duplas Massas e pelo cálculo do coeficiente angular da reta do período com bom ajuste.

Neste estudo, encontrou-se uma dificuldade adicional nos cálculos da evapotranspiração e na análise do comportamento das vazões dos principais rios da bacia, que é a retirada de água para a Região Metropolitana de São Paulo (RMSP) através do Sistema Cantareira. Esse problema pôde ser contornado utilizando-se vazões reconstituídas ou naturais, que foram elaboradas através dos dados de operação do sistema fornecido pela Sabesp a partir do início do seu funcionamento.

Na realidade, essa vazão foi reconstituída só parcialmente, já que não leva em conta o consumo de água para fins urbanos, industriais e agrícolas, nem as trocas de água entre bacias que ocorrem na região de Jundiaí e Campinas. A inclusão desses dados apresentaria alguns inconvenientes, tais como, inexistência de registros históricos confiáveis e valores incoerentes nas diversas fontes consultadas. 
Como citado no capítulo anterior, segundo SÃO PAULO (1994), do total de água retirada para esses fins, $15 \mathrm{~m}^{3} / \mathrm{s}$ não retornam diretamente à calha do rio (uso consuntivo), o que corresponde a pouco mais de $8 \%$ da vazão natural média. Porém, a maior parte dessa água se mantém no sistema hídrico da bacia de outras formas, como evapotranspiração ou escoamento superficial, subsuperficial ou subterrâneo, podendo ser considerada de menor importância para o balanço hídrico, embora ainda seja importante como diminuição instantânea da vazão. Quanto às trocas de água entre bacias, em Jundiaí, a retirada é esporádica e ocorre principalmente nos períodos mais secos, podendo ser considerada desprezível no balanço anual. Em Campinas, a quantificação exata é muito difícil devido às interações entre captação e lançamento de esgoto, que ocorrem simultaneamente nas bacias dos rios Atibaia e Capivari.

Além de reconstituída ou natural, a vazão utilizada neste trabalho é líquida, ou seja, diz respeito apenas à área de determinada sub-bacia, de forma que se pudesse gerar dados de evapotranspiração para essa sub-bacia. Assim, a vazão natural líquida foi calculada através da subtração das vazões naturais entrando e saindo de determinada sub-bacia. Essa consideração evita o efeito das barragens e das transferências de água entre bacias e permite uma observação mais adequada da região em foco. Quando de interesse, dispôs-se da vazão medida, isto é, sem reconstituições, para fins de comparação.

Os postos fluviométricos selecionados para este trabalho estão representados na figura 1.1 e listados na tabela 2.3.

\subsubsection{Geração dos Mapas Anuais}

Optou-se por empregar um Sistema Geográfico de Informações (SGI) na análise dos dados, porque esse tipo de sistema se enquadra perfeitamente à função de análise e 
visualização espacial regional, com rotinas já estabelecidas para a interpolação, a delimitação de polígonos de Thiessen e métodos estatísticos avançados. Alguns também possuem módulo de análise temporal e agilizam sobremaneira a manipulação e interpretação dos dados. O software escolhido foi o IDRISI (Eastman, 1992a) por não necessitar de uma configuração de hardware muito avançada, e por apresentar recursos suficientes para auxiliar nas análises, comparativamente a outros SGIs mais exigentes.

Para que mapas anuais de precipitação, vazão e evapotranspiração pudessem ser elaborados, foi necessária a digitalização de mapas da bacia e de suas sub-bacias, bem como da localização espacial dos postos, para os quais foram atribuídos códigos. Dessa forma, pôde-se associar seus dados à sua posição no espaço. Para tanto, usaram-se as cartas elaboradas por SÃO PAULO (1986) e PROCHNOW (1981).

A seguir são descritos os procedimentos empregados na geração dos mapas, ou imagens, que serviram também de fonte de dados nas análises estatísticas realizadas.

\section{a) Precipitação.}

Os mapas anuais de precipitação foram obtidos da maneira seguinte:

- os dados do DAEE para os postos interiores e vizinhos à bacia foram combinados de forma a gerarem arquivos anuais, ou seja, uma lista para cada ano composta dos totais anuais de precipitação de cada um dos postos em seqüência;

- esses dados foram referenciados geograficamente, associando-se a seu valor uma posição no espaço através do código de cada posto nos mapas digitalizados; e, por fim,

- realizou-se a interpolação desses dados, utilizando-se do módulo INTERPOL do IDRISI, com a escolha da opção de interpolação pelo MIQD, tomando-se apenas os seis postos mais próximos do ponto a ser calculado como base para a estimativa do seu valor 
(EASTMAN, 1992; WEI \& MCGUINNESS, 1973).

Através da interpolação dos dados iniciais pôde se estimar a altura de chuva para cada ponto da bacia onde ela era desconhecida. O MIQD, tomando os seis pontos de controle (postos do DAEE com valores conhecidos) mais próximos, foi escolhido porque, depois de testar as formas linear, quadrática e cúbica, foi o que apresentou melhores resultados em comparação com os mapas de isoietas normais para a bacia já existentes, como também foi constatado por WEI \& MCGUINNESS (1973) para uma bacia experimental nos Estados Unidos. Segundo esses autores, esse método foi o que apresentou melhores resultados, quando comparado ao método de Thiessen e ao da média aritimética, tomando-se como padrão o método das isoietas.

Esse método assume que a precipitação a ser estimada para determinado ponto é proporcional à precipitação medida em $\mathrm{n}$ postos vizinhos e é inversamente proporcional à distância entre o ponto e cada um desses postos. O valor estimado pelo MIQD pode ser expresso pela equação (2.3):

$$
P=\frac{\left(\sum_{i=1}^{n} \frac{P_{i}}{D_{i}^{2}}\right)}{\left(\sum_{i=1}^{n} \frac{1}{D_{i}^{2}}\right)}
$$

onde $\mathrm{P}$ é a precipitação estimada para determinado ponto;

$\mathrm{P}_{\mathrm{i}}$ é a precipitação medida no posto $\mathrm{i}$;

$D_{i}$ é a distância entre o ponto e o posto i;

$\mathrm{n}$ é o número de postos usados para a estimativa de $\mathrm{P}$ ( $\mathrm{n}=6$ neste caso); $\mathrm{e}$ i é o número do posto. 
$\mathrm{Na}$ geração de imagens georeferenciadas usou-se uma malha de 82 linhas por 141 colunas. Cada cruzamento linha/coluna é chamado de pixel (elemento de imagem). Para cada pixel, representando uma área de $4 \mathrm{~km}^{2}(2 \times 2 \mathrm{~km})$, foi estimada uma altura de chuva através da interpolação. Essa malha foi escolhida por representar visualmente a bacia de forma bastante satisfatória e por não exigir um custo computacional muito alto, visto que o número de imagens a serem geradas seria grande. Essas imagens se tornam então, em seqüências de pixels com valores de alturas, ou lâminas, totais anuais de água precipitada, alterando-se gradativamente no espaço bidimensional, podendo serem visualizadas também em três dimensões.

O valore de altura de chuva total anual utilizado na interpolação foi expresso $\mathrm{em} \mathrm{mm}$ e representa a altura total de chuva na área representada pelo pixel naquele ano. A média dos valores de um conjunto de pixels representa a altura de chuva total anual média para a região delimitada por eles. Ou seja, ela representa a lâmina d'água que se acumularia sobre aquela área num determinado ano, caso esta fosse plana e não houvesse nenhum tipo de retirada. Assim, a altura de chuva total anual de uma sub-bacia pode facilmente ser calculada através da média dos valores dos pixels que a compreendem, sem que haja a necessidade de pesos como no Método de Thiessen, pois todos os pixels possuem a mesma área.

Isso é importante de ser frisado, visto que esse foi o método empregado para a obtenção das séries de valores médios para cada sub-bacia, que serviu nas análises de tendências (item 3.2.).

\section{b) Vazão}

A confecção dos mapas de vazão foi feita de maneira mais simples, sem a necessidade de interpolação, e serviu apenas para a geração dos dados de evapotranspiração real (item c). O procedimento aqui foi simplesmente gerar os arquivos da sequiência das 
descargas totais anuais de cada sub-bacia, já convertidas $\mathrm{de}^{3} / \mathrm{s}$ para mm/ano. A partir desses arquivos, foram geradas as imagens anuais de vazão pela simples substituição do código de cada sub-bacia pelo valor neles apresentados. Dessa forma, todas as imagens de vazões possuem cinco regiões distintas e homogêneas, que são as sub-bacias, nas quais todos os pixels possuem a mesma altura de descarga anual.

\section{c) Evapotranspiração}

Como o objetivo primordial na estimativa da evapotranspiração é gerar uma série de lâmina d'água média para cada sub-bacia, para a análise de tendência, e na indisponibilidade de dados que permitissem a utilização de métodos mais precisos para toda a área da bacia do rio Piracicaba, optou-se pela estimativa da evapotranspiração através do Método do Balanço Hídrico, por só depender da precipitação e da vazão, para o caso de grandes áreas e para períodos longos, quando a influência da variação de armazenamento do solo $(\Delta \mathrm{S})$ pode ser desprezada em relação à escala das demais grandezas (UNESCO, 1982).

Considerou-se essa solução viável, devido à sua simplicidade e à existência de uma rede suficientemente densa de postos fluviométricos e pluviométricos. Estimou-se assim a evapotranspiração real anual (ETR) através da equação do balanço hídrico, obtida pela aplicação do princípio de conservação de massa a um corpo de água em um determinado período de tempo (TUCCI \& BELTRAME, 1993; VILA NOVA \& REICHARDT, 1989; UNESCO, 1982). Em sua forma simplificada tem-se:

$$
E T R=P-\left(Q_{e}-Q_{a}\right) \pm \Delta S
$$

onde ETR é a evapotranspiração média do período e área;

$\mathrm{P}$ é a precipitação média do período e área; 
Qe é a vazão média efluente do período e área;

Qa é a vazão média afluente do período e área; e

$\Delta \mathrm{S}$ é a variação do armazenamento de água no período e área (desprezada aqui).

Portanto, a criação dos mapas de evapotranspiração pôde ser feita pela simples sobreposição por diferença dos mapas de precipitação e vazão de cada ano, usando o módulo OVERLAY no IDRISI com a opção de subtração. Essa operação num SGI é extremamente simples pois, possuindo ambas as imagens a mesma configuração geográfica e a mesma malha de pontos, basta subtrair o pixel de determinada posição na imagem de precipitação pelo seu correspondente na imagem de vazão.

Os resultados obtidos por esse método foram comparados aos estimados pelos métodos de Thornthwaite \& Mather e de Turc, recomendados por UNESCO (1982), para todo o período de estudo. Foram utilizados nessa comparação, os dados dos postos de Campinas, Limeira e Monte Alegre do Sul do Instituto Agronômico de Campinas (IAC) e o posto de Piracicaba da Escola Superior de Agricultura "Luiz de Queiroz" (ESALQ), que possuem boa infra-estrutura e cujos parâmetros medidos permitem tal estimativa.

Da mesma forma que para a $\mathrm{P}$, a estimativa da ETR média por bacia foi obtida pela média dos pixels de uma determinada sub-bacia e representa a lâmina média d'água, agora evapotranspirada em determinado ano. Como já citado, esses valores foram usados nas análises de tendência para a ETR (item 3.2.).

\subsection{Resultados e sua Discussão}

Um primeiro resultado desse trabalho é a própria geração de um banco de mapas anuais de precipitação, vazão e evapotranspiração. A sua atualização para os dados de 
precipitação e de vazão pode ser feita em qualquer escala temporal com grande facilidade. Para a evapotranspiração, essa atualização só pode ser realizada na escala anual. Devido ao grande volume deles ( 45 anos), optou-se por apresentar aqui somente os mapas de valores normais para os três tipos de dados.

\subsubsection{Precipitação}

$\mathrm{Na}$ figura 2.1.a, as isolinhas representam os pontos onde os dados normais assumem exatamente o valor dos centros de classes, representadas por cores homogêneas, onde os dados assumem valores de $\pm 25 \mathrm{~mm}$ em relação ao valor da isolinha. Pode se observar claramente a tendência crescente da chuva à medida que se avança para o leste da bacia, apresentando seu ponto mais alto no extremo leste, próximo ao início da serra da Mantiqueira, no Estado de Minas Gerais, com valor normal anual máximo em torno de 1850 $\mathrm{mm}$. Essa é também a região com maior taxa de variação, passando rapidamente de 1850 $\mathrm{mm}$ para $1600 \mathrm{~mm}$, próximo à divisa de Estado. Outro sentido com tendência espacial de ligeiro aumento é a região noroeste da sub-bacia do Corumbataí, também próximo ao início da serra, com valores máximos em torno de $1500 \mathrm{~mm}$. A região central e a oeste da bacia são as que apresentam menores valores, atingindo aproximadamente os $1300 \mathrm{~mm}$, sendo baixos também os valores em todo seu eixo sul. A grande região central da bacia é a mais homogênea e apresenta valores em torno de 1350 a $1400 \mathrm{~mm}$. Esses dados apresentam grande semelhança com os apresentados por SETZER (1966).

Para o trimestre úmido (figura 2.2.a), que vai de dezembro a fevereiro, o comportamento espacial é parecido, sendo o valor máximo em torno de $830 \mathrm{~mm}$ e o mínimo de $580 \mathrm{~mm}$. Já para o trimestre seco (figura 2.3.a), entre junho e agosto, a tendência lesteoeste permanece, porém, há alterações no padrão da região ao norte da bacia do Corumbataí e no eixo sul da bacia. 

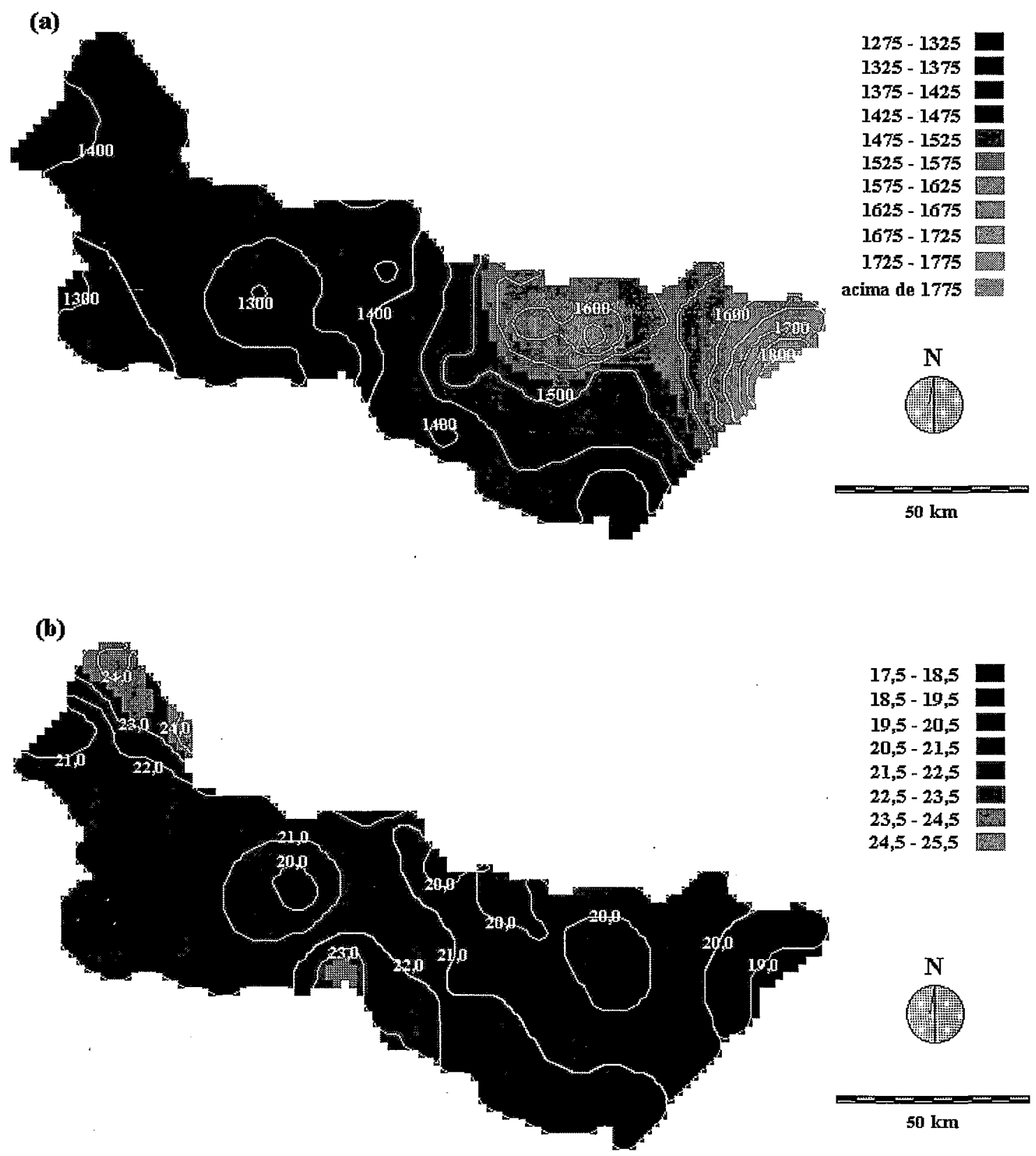

Figura 2.1 - Distribuição espacial da precipitação normal anual (em mm) na bacia do rio Piracicaba (a) e seu coeficiente de variação (em \%) (b). As isolinhas representam os pontos onde a variável assume os valores correspondentes aos centros de classe. 


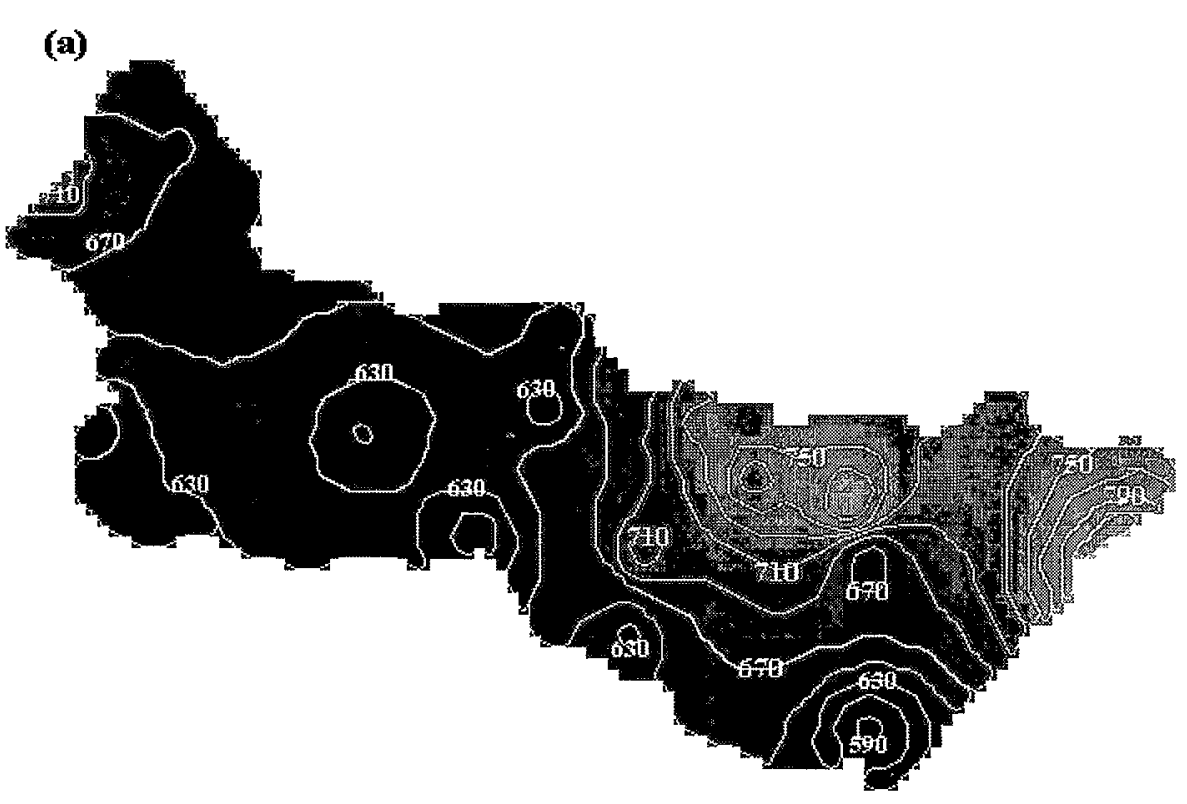

$580-600$

$600-620$

$620-640$

$640-660$

660 - 680

$680-700$

$700-720$ 잘

$720-740$ 极

740 - 760

$760-780$

780 - 800

800 - 820

acima de 820

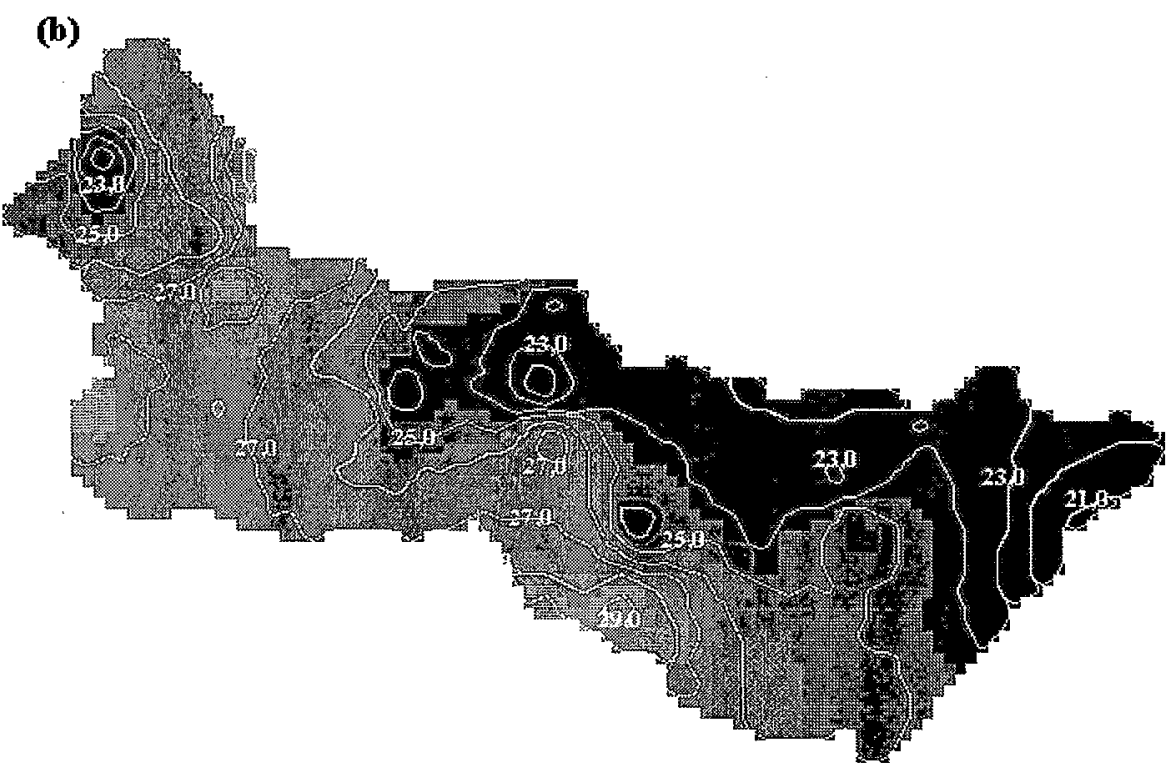

$20,5-21,5$

$21,5-22,5$

$22,5-23,5$

$23,5-24,5$

$24,5-25,5$

25,5-26,5 㱐稫

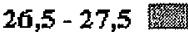

$27,5-28,5$ 格被

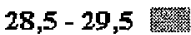

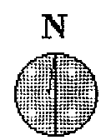

$50 \mathrm{~km}$

Figura 2.2 - Distribuição espacial da precipitação normal do trimestre úmido (em mm) na bacia do rio Piracicaba (a) e seu coeficiente de variação (em \%) (b). As isolinhas representam os pontos onde a variável assume os valores correspondentes aos centros de classe. 

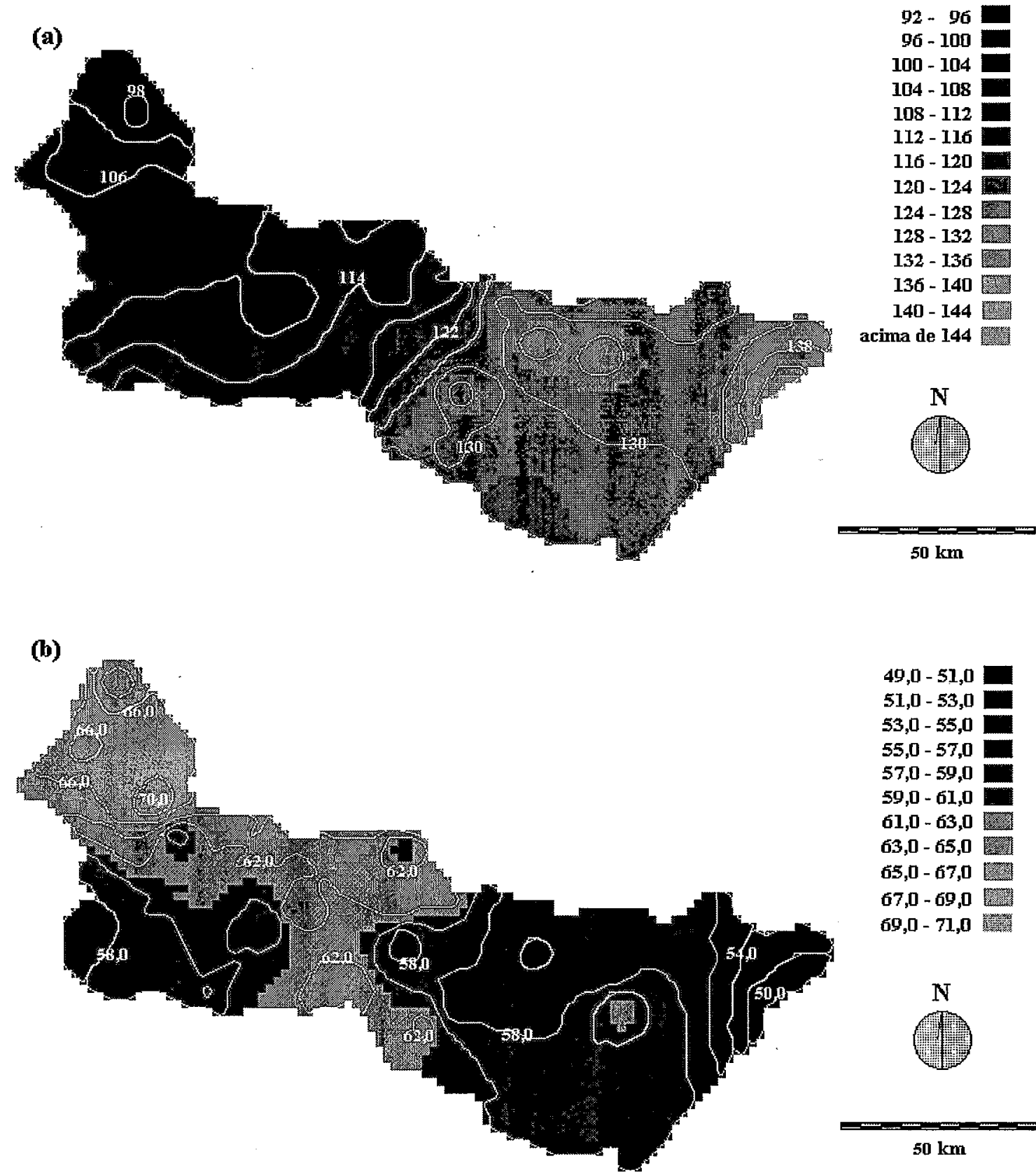

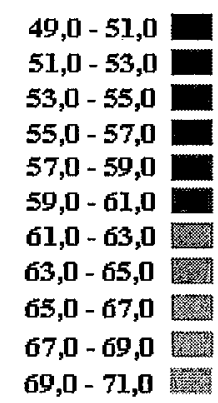

$69,0-71,0$ 叙整

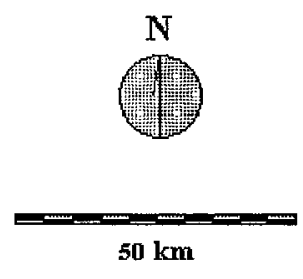

Figura 2.3 - Distribuição espacial da precipitação normal no trimestre seco (em mm) na bacia do rio Piracicaba (a) e seu coeficiente de variação (\%) (b). As isolinhas representam os pontos onde a variável assume os valores correspondentes aos centros de classe. 
Os maiores valores de desvio padrão, gerados a partir da interpolação dos valores de desvio padrão de cada posto, se encontram também no extremo leste e no norte da subbacia do Corumbataí, por volta de $330 \mathrm{~mm}$, e os menores na região central da bacia, por volta de $250 \mathrm{~mm}$. Esse também é o padrão para o trimestre úmido, variando entre 130 e 180 mm. Os desvios no trimestre seco seguem novamente um padrão próprio, diferente dos demais, e vai de aproximadamente 60 a $80 \mathrm{~mm}$.

Uma imagem mais clara da variabilidade dos dados é dada pelas figuras 2.1.b, 2.2.b e 2.3.b, que representam o coeficiente de variação da precipitação na bacia para o período anual, trimestre úmido e trimestre seco, respectivamente. Embora a informação da quantidade de variação dada pelo desvio padrão seja importante quando encarada como alteração média da disponibilidade hídrica de determinada região, esse índice é mais adequado à comparação entre pontos distintos e entre os períodos. De fato, pode se observar uma distribuição muito homogênea dos valores de coeficiente de variação, com valores mais baixos na região central e também extremo leste e pouco mais altos na região norte da subbacia do Corumbataí e no centro-sul da bacia, sendo da ordem de 20 a $30 \%$ tanto para o ano todo como para o trimestre úmido. O coeficiente de variação para o trimestre seco, entretanto, é bem maior, variando entre 50 e 70\%, sendo sua distribuição espacial praticamente a mesma. Destaca-se então, o maior coeficiente de variação dos dados do trimestre seco que, embora apresente escala de valores médios seis vezes menores que o úmido, apresenta valores de desvio apenas duas vezes menores. A espacialização desse coeficiente na bacia apresentada por CHRISTOFOLETTI (1991), apresenta grande similaridade com as figuras apresentadas aqui.

Comparando-se as figuras 2.2.a e 2.3.a, pode se observar que, no período úmido, as faixas homogêneas de precipitação (ou as isoietas) têm disposição sudeste-noroeste, o que parece estar relacionado à influência das frentes-frias, que nessa época penetram na bacia, principalmente por via continental, passando pelo Norte da Argentina, região Sul e Sudeste 
do Brasil, provocando maior intensidade das chuvas em direção às serras, como já destacado. No período seco porém, as frentes-frias têm uma ascensão principalmente pelo oceano Atlântico e, embora haja pouca chuva em toda a bacia, a sua influência é maior na região leste, decrescendo para oeste, inclusive no início da serra na sub-bacia do Corumbataí, que possui os valores mais baixos do período. Portanto, as faixas homogêneas se invertem, passando a ter disposição sudoeste-nordeste. Então, uma conclusão importante a respeito da distribuição espacial da precipitação é a influência diferenciada das frentesfrias sobre o padrão dos períodos secos e úmidos, além da clara influência do relevo.

Seria possível supor que a distribuição espacial dos anos secos fosse semelhante à do trimestre seco e a dos anos úmidos, à do trimestre úmido. Entretanto, analisando o comportamento espacial dos anos extremos, como os de 1963 e 1968 (figura 2.4), que foram os mais secos da série, ou os de 1976 e 1983 (figura 2.5), os mais úmidos, observa-se o contrário.

Os anos secos extremos possuem comportamento espacial semelhante ao normal, com faixas de isovalores no sentido noroeste-sudeste, apresentando apenas valores numa escala menor. Quando analisada a variação dos dados mensais médios ao longo do ano, notou-se que ela é a mesma que a normal.

Nos anos úmidos extremos, o sentido dessas faixas é sudoeste-nordeste, comportamento espacial parecido ao do trimestre seco. Analisada mais uma vez a variação dos dados mensais médios ao longo do ano, notou-se que os meses normalmente secos também são bastante úmidos, sendo diferente da variação normal, tanto na escala quanto na seqüência dos valores mensais. Isso leva a crer que nesses anos úmidos, as frentes frias de inverno têm umidade suficiente para provocar precipitações na região, ou que seu deslocamento, embora mudando para o oceano, ainda seja parcialmente por via contimental. 

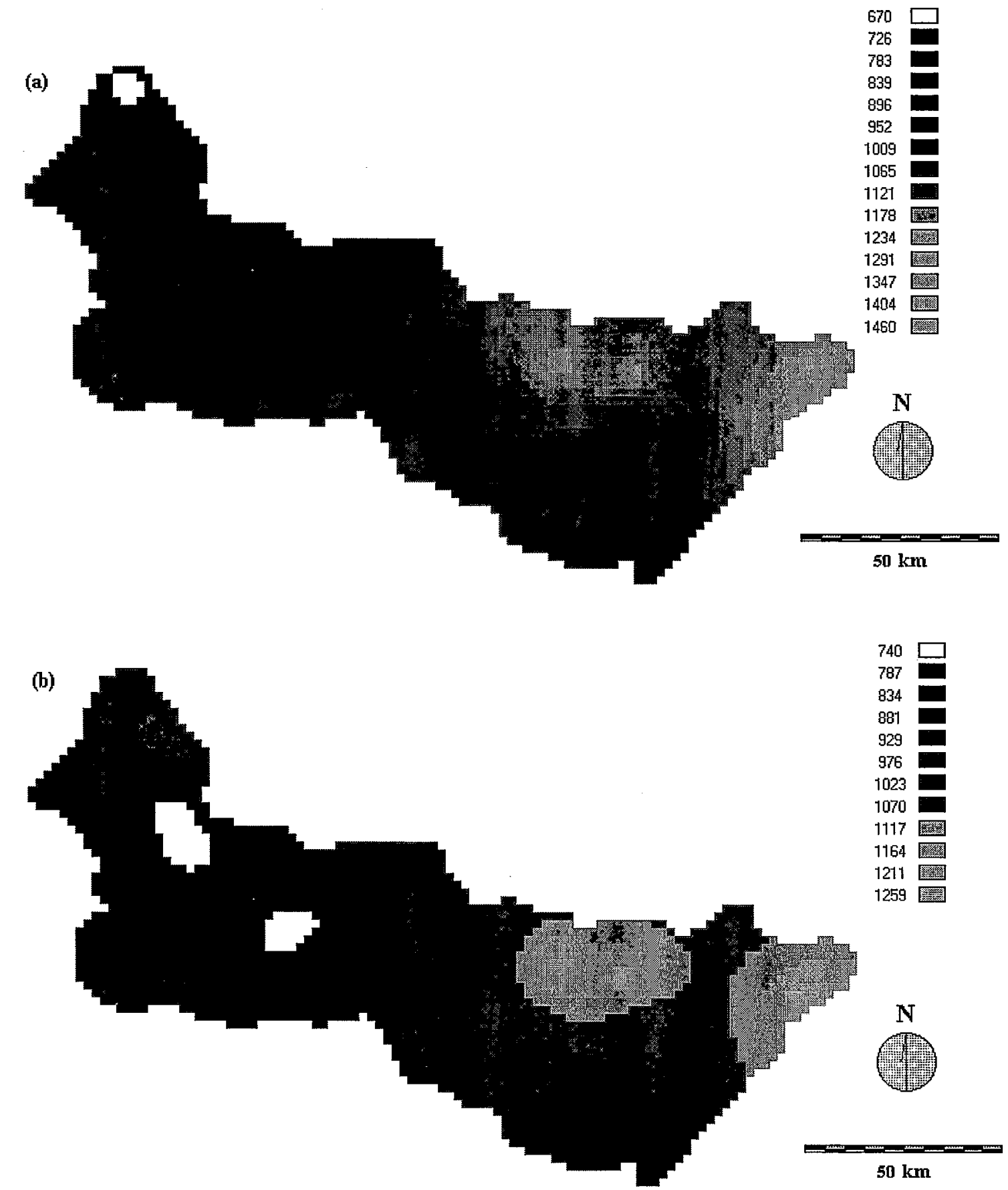

Figura 2.4 - Comportamento espacial da precipitação média anual (mm) dos anos secos extremos de 1963 (a) e 1968 (b). 

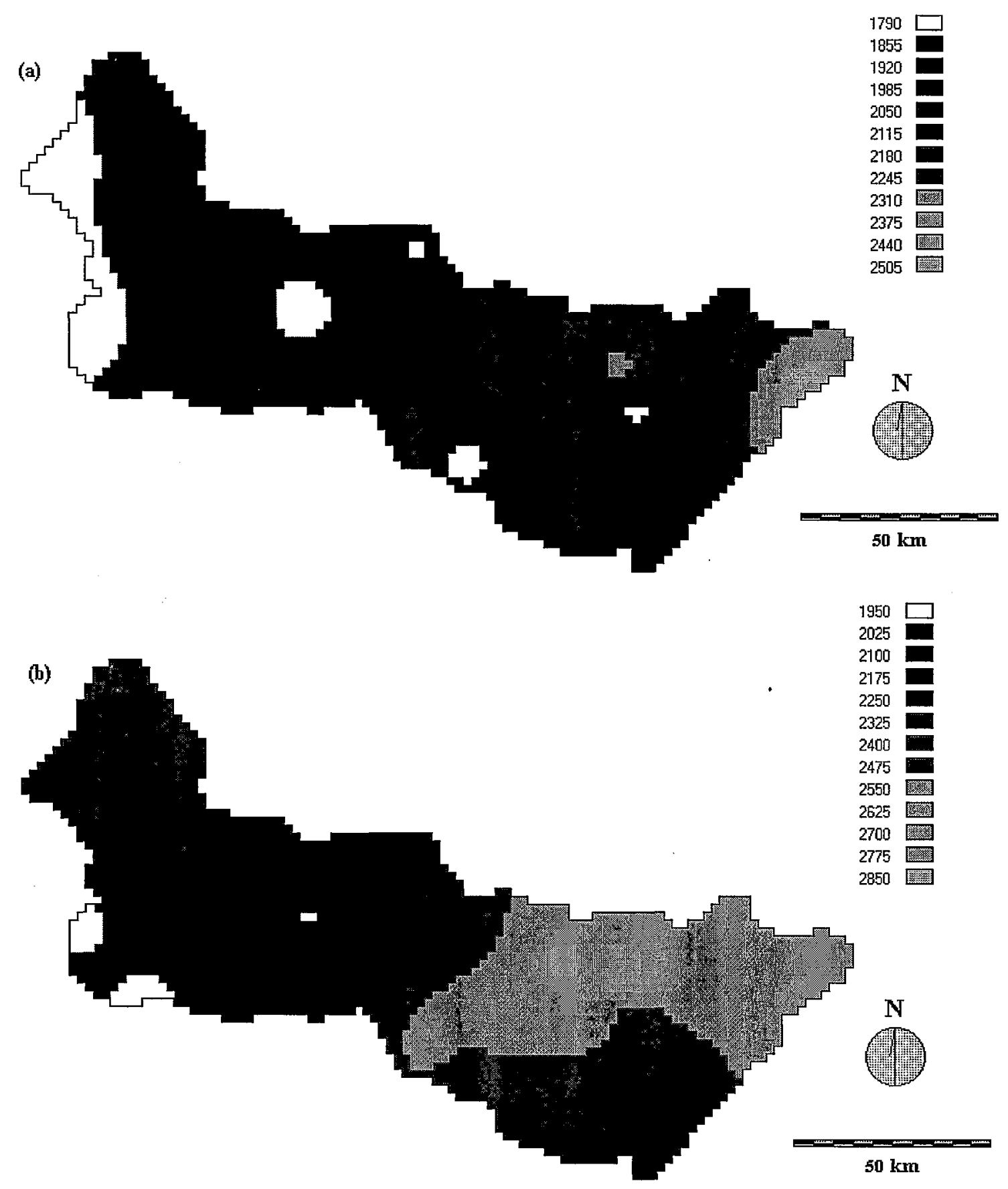

Figura 2.5 - Comportamento espacial da precipitação média anual (mm) dos anos úmidos extremos de 1976 (a) e 1983 (b). 


\subsubsection{Vazão}

Para os dados de vazão por sub-bacia, retirou-se o efeito de operação de barragens (dados reconstituídos ou naturais) e as entradas de vazões das sub-bacias à montante (dados líquidos). Portanto, não há mapas com a variação espacial contínua como para a precipitação, sendo seus resultados dados pela tabela 2.4 , que apresenta os valores normais $(\mathrm{mm})$, de desvio padrão $(\mathrm{mm})$ e do coeficiente de variação (\%) para dados anuais, trimestrais úmidos (Tru) e trimestrais secos (Trs) de cada sub-bacia. As sub-bacias com maiores vazões anuais normais são a do Jaguari, com $561 \mathrm{~mm}\left(44,3 \mathrm{~m}^{3} / \mathrm{s}\right)$, e a do Camanducaia, com $491 \mathrm{~mm}\left(25,2 \mathrm{~m}^{3} / \mathrm{s}\right)$. Isso pode ser facilmente explicado pela maior contribuição da zona serrana que apresenta os maiores índices pluviométricos e também as maiores declividades, fazendo, provavelmente, com que uma maior porcentagem da chuva daquela região seja destinada ao escoamento superficial.

A que apresenta menor vazão é a do Piracicaba, com $391 \mathrm{~mm}\left(39,2 \mathrm{~m}^{3} / \mathrm{s}\right)$, que é também, a com maior coeficiente de variação (48 \%). Essa observação de menor precipitação na sub-bacia do Piracicaba pode ser explicada com base na figura 2.1.a, pois a sua área de drenagem é justamente a região com menores índices pluviométricos. Todas as outras possuem cabeceiras em regiões mais chuvosas e, conseqüentemente, vazões mais elevadas.

A posição das sub-bacias em relação às zonas mais ou menos chuvosas determina seu lugar na classificação das vazões. Assim, Jaguari e Camanducaia são as vazões mais elevadas e Piracicaba a mais baixa. A alternância entre Corumbataí e Atibaia é interessante de ser notada como o reflexo das precipitações totais trimestrais. No trimestre úmido, quando a influência da serra faz com que a sub-bacia do Corumbataí tenha índices pluviométricos elevados, a sua vazão é maior que a do Atibaia. No trimestre seco, quando ela é a região mais seca da bacia, sua vazão fica mais baixa que a do Atibaia. No total anual 
Tabela 2.4 - Vazões normais anuais, trimestrais úmidas (tru) e trimestrais secas (trs) nas sub-bacias da bacia do rio Piracicaba.

\begin{tabular}{|c|c|c|c|c|}
\hline Bacia & Período & Média (mm) & Desvio (mm) & C.V(\%) \\
\hline \multirow{3}{*}{ Corumbataí } & anual & 463 & 168 & 36 \\
\hline & tru & 191 & 81 & 43 \\
\hline & trs & 65 & 33 & 50 \\
\hline \multirow{3}{*}{ Piracicaba } & anual & 391 & 188 & 48 \\
\hline & tru & 172 & 84 & 49 \\
\hline & $\operatorname{trs}$ & 49 & 36 & 73 \\
\hline \multirow{3}{*}{ Jaguari } & anual & 561 & 174 & 31 \\
\hline & tru & 233 & 85 & 36 \\
\hline & trs & 80 & 33 & 42 \\
\hline \multirow{3}{*}{ Camanducaia } & anual & 491 & 183 & 37 \\
\hline & tru & 202 & 78 & 39 \\
\hline & $\operatorname{trs}$ & 70 & 37 & 53 \\
\hline \multirow{3}{*}{ Atibaia } & anual & 459 & 144 & 31 \\
\hline & tru & 177 & 59 & 33 \\
\hline & trs & 72 & 34 & 47 \\
\hline \multirow{3}{*}{ Bacia Toda } & anual & 466 & 163 & 35 \\
\hline & tru & 192 & 70 & 36 \\
\hline & $\operatorname{trs}$ & 66 & 33 & 49 \\
\hline
\end{tabular}


porém, suas vazões são praticamente iguais. Portanto, espacialmente fica clara a influência da precipitação sobre os índices fluviométricos.

\subsubsection{Evapotranspiração}

O MBH não permite estimar a evapotranspiração real para escala menores que um ano apenas com os dados disponíveis, por isso não são apresentados dados trimestrais para esse parâmetro. A evapotranspiração anual normal é representada na figura 2.6. Percebe-se uma mescla dos padrões de distribuição espacial da precipitação e da vazão, ou do desenho das sub-bacias, não apresentando propriamente um contínuo, como seria de se esperar. Isso não permitiu o traçado adequado de isolinhas, que não foram apresentadas, então, para esse
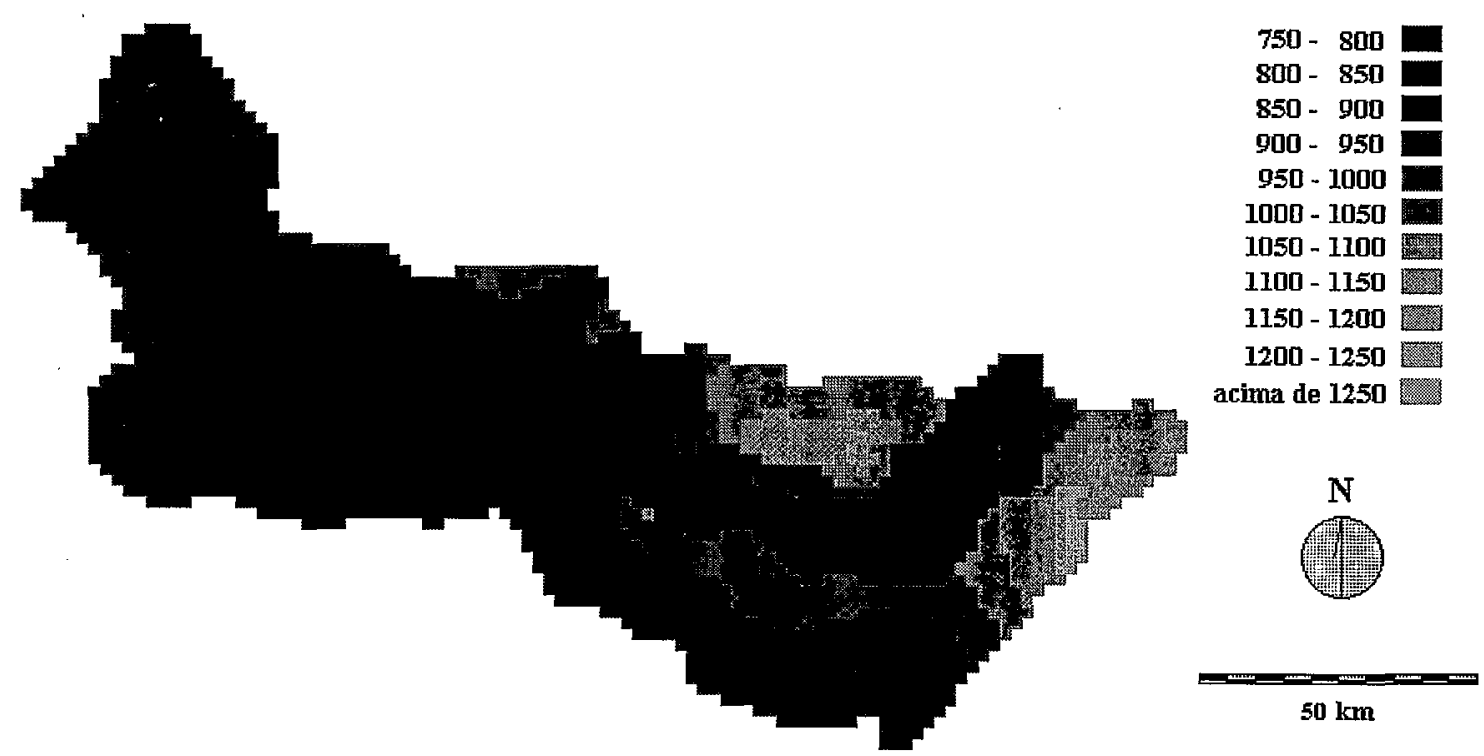

Figura 2.6 - Distribuição espacial da evapotranspiração anual normal (em mm) na bacia do rio Piracicaba. 
parâmetro. Essa característica ocorreu principalmente pelo fato de a vazão ter sido representada por sub-bacias, ressaltando a importância dos seus limites.

Quando se compara essa imagem à carta de evapotranspiração potencial de SETZER (1966), detectam-se diferenças fundamentais na distribuição dos valores, principalmente no início da região serrana no extremo leste da bacia. Como o método Thornthwaite \& Mather empregado por ele baseia-se fundamentalmente na temperatura para a estimativa, o autor obteve valores mais baixos nessa região. Já o $\mathrm{MBH}$, da maneira usada aqui, fornece valores mais elevados, pois baseia-se no balanço da entrada de água pela precipitação, que como já visto é bem maior ali, e da saída através da vazão, que não é tão maior que nas demais sub-bacias.

Esse pode ser outro problema decorrente da utilização de mapas de vazão natural líquida por sub-bacias maiores, pois provavelmente se fosse possivel dividir a sub-bacia do Jaguari em duas, uma mais para o início da bacia na região serrana e outra já mais central e próxima à bacia do Camanducaia, provavelmente a vazão da região serrana seria acentuada e a da região mais central estaria mais próxima dos valores das suas vizinhas Camanducaia e Atibaia. Um aprimoramento nesse ponto seria a elaboração de mapas de valores interpolados contínuos também para a vazão, baseados numa rede fluviométrica mais numerosa e melhor distribuída que a empregada aqui, como tem sido realizado para a região amazônica por LONGSDON ${ }^{1}$ e DUNNE 2 .

Comparando valores do $\mathrm{MBH}$, em pontos isolados do mapa, com os obtidos pelos métodos de Turc e de Thornthwaite $\&$ Mather (apêndice), encontram-se discrepâncias individuais altas, com valores máximos em torno de $45 \%$. Porém estas ocorrem com

\footnotetext{
${ }^{1}$ LONGSDON, M. (School of Oceanography) $\mathrm{e}^{2}$ DUNNE, T. (Departament of Geology) da University of Washington, Seattle, USA., Comunicações pessoais, 1994.
} 
freqüência muito baixa. A média das discrepâncias, em torno de $15 \%$ para o método de Turc, e de $20 \%$ para o de Thornthwaite \& Mather, é aceitável mas acima dos valores de 5 e $10 \%$ exibidos por MOLINIER et al. (1991) e MATOS \& MATTOS (1981), respectivamente. Comparando entre si, Turc e Thornthwaite \& Mather apresentram discrepâncias médias abaixo de 10\% e máximas em torno de $30 \%$. Na figura 2.7 observa-se que, embora haja discrepâncias individuais altas e o MBH apresente uma maior amplitude de variação, ele manteve-se em sincronia com os demais.

Porém, integrado por sub-bacia, o $\mathrm{MBH}$ representa bem a lâmina média d'água evapotranspirada. Como o objetivo maior aqui foi o de gerar séries médias anuais por subbacias para análise de tendência, ele pode ser considerado satisfatório diante das limitações dos dados disponíveis. Essas séries, geradas pelo módulo PROFILE do IDRISI, estão apresentadas nas tabelas 2.5 , para precipitação, e 2.6, para evapotranspiração, juntamente com a de vazão, gerada diretamente a partir dos dados do DAEE (tabela 2.7) e serão analisadas no capítulo seguinte. 

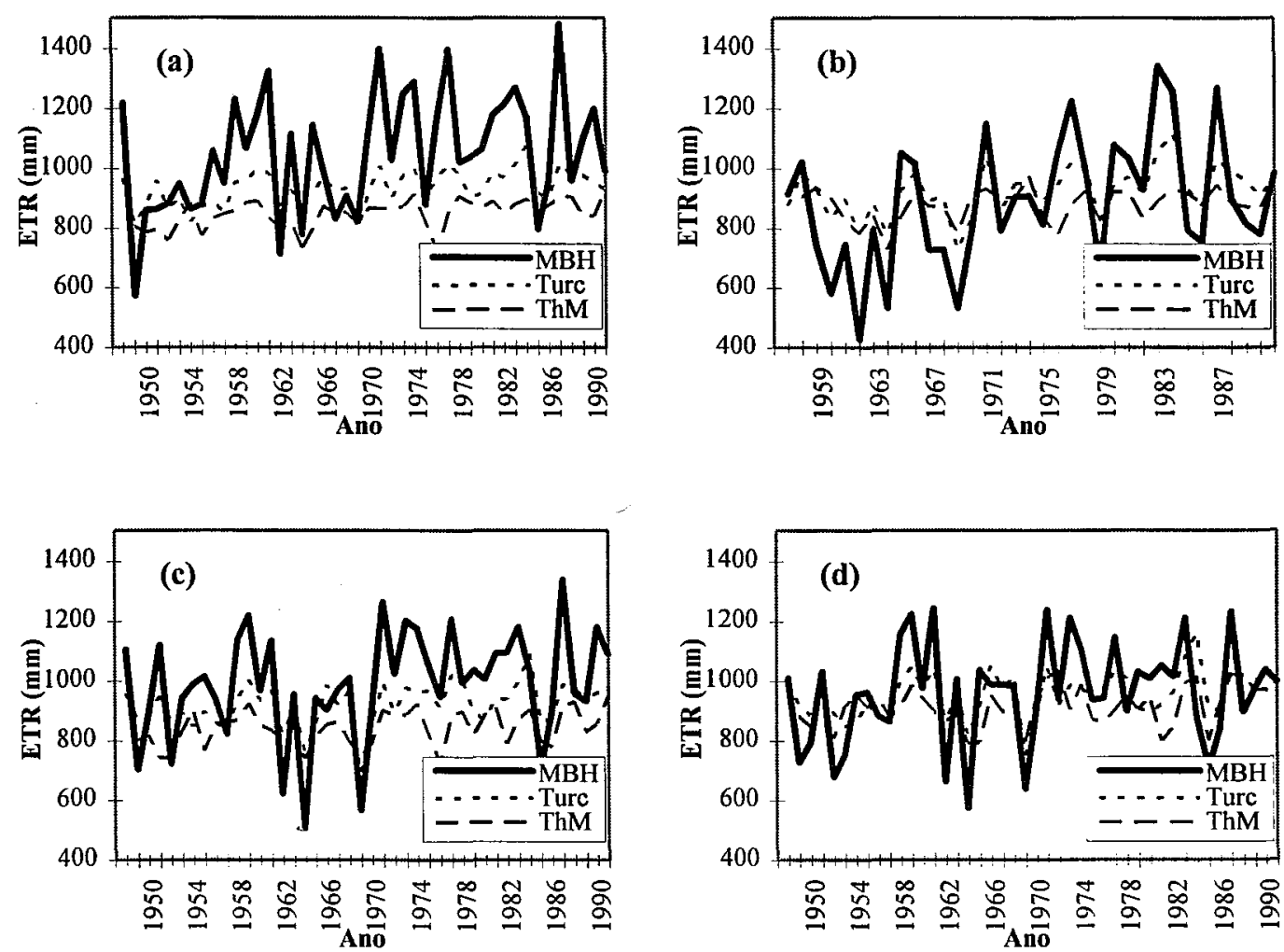

Figura 2.7 - Comparação entre os métodos de estimativa da Evapotranspiraçã Real(mm) para as cidades de Monte Alegre do Sul(a), Campinas(b Limeira (c) e Piracicaba (d). (MBH=Método do Balanço Hídrico; Turc=Método de Turc; ThM=Método de Thornthwaite $\&$ Mather 
Tabela 2.5 - Séries de precipitação total anual média $(\mathrm{mm})$ por sub-bacia (geradas pelo módulo PROFILE).

\begin{tabular}{|c|c|c|c|c|c|c|}
\hline Ano & Bacia & Corumb. & Piracic. & Jaguari & Camand. & Atibaia \\
\hline 1947 & 1658,13 & 1663,65 & 1580,14 & 1672,04 & 1665,20 & 1728,04 \\
\hline 1948 & 1132,04 & 1090,82 & 1122,89 & 1105,46 & 1084,61 & 1204,52 \\
\hline 1949 & 1181,88 & 1204,99 & 1158,98 & 1189,30 & 1220,69 & 1175,56 \\
\hline 1950 & 1361,59 & 1392,90 & 1328,59 & 1345,33 & 1407,22 & 1380,86 \\
\hline 1951 & 1264,80 & 1225,23 & 1192,27 & 1350,91 & 1306,67 & 1279,11 \\
\hline 1952 & 1178,78 & 1169,51 & 1068,24 & 1263,18 & 1250,19 & 1210,69 \\
\hline 1953 & 1098,58 & 1050,50 & 1061,31 & 1155,64 & 1129,94 & 1107,29 \\
\hline 1954 & 1228,51 & 1159,88 & 1168,84 & 1303,99 & 1305,09 & 1243,47 \\
\hline 1955 & 1235,78 & 1101,87 & 1161,42 & 1359,48 & 1373,03 & 1242,48 \\
\hline 1956 & 1234,77 & 1104,55 & 1152,56 & 1323,40 & 1362,46 & 1282,44 \\
\hline 1957 & 1620,17 & 1501,56 & 1545,29 & 1714,53 & 1691,92 & 1665,50 \\
\hline 1958 & 1611,90 & 1659,45 & 1573,76 & 1668,51 & 1672,76 & 1558,03 \\
\hline 1959 & 1408,41 & 1332,59 & 1299,87 & 1566,25 & 1646,97 & 1357,97 \\
\hline 1960 & 1675,35 & 1700,28 & 1586,66 & 1763,94 & 1795,49 & 1644,04 \\
\hline 1961 & 1200,56 & 1094,49 & 1098,41 & 1395,33 & 1291,84 & 1173,85 \\
\hline 1962 & 1481,70 & 1421,72 & 1406,82 & 1593,77 & 1642,56 & 1449,64 \\
\hline 1963 & 1018,03 & 886,81 & 950,89 & 1110,38 & 1174,36 & 1036,94 \\
\hline 1964 & 1415,93 & 1129,90 & 1248,85 & 1610,21 & 1545,67 & 1553,37 \\
\hline 1965 & 1663,88 & 1565,53 & 1615,65 & 1757,03 & 1827,33 & 1639,81 \\
\hline 1966 & 1384,28 & $.1385,23$ & 1299,45 & 1492,41 & 1493,72 & 1348,33 \\
\hline 1967 & 1461,03 & 1548,75 & 1430,38 & 1494,79 & 1529,20 & 1393,79 \\
\hline 1968 & 966,58 & 887,42 & 870,81 & 1068,74 & 1094,64 & 988,15 \\
\hline 1969 & 1194,99 & 1180,85 & 1080,66 & 1310,66 & 1367,61 & 1174,16 \\
\hline 1970 & 1729,48 & 1670,81 & 1647,90 & 1795,01 & 1862,68 & 1754,34 \\
\hline 1971 & 1289,91 & 1280,20 & 1140,97 & 1409,25 & 1411,82 & 1318,21 \\
\hline 1972 & 1556,21 & 1647,20 & 1518,24 & 1592,08 & 1635,55 & 1489,91 \\
\hline 1973 & 1513,51 & 1502,92 & 1382,14 & 1619,48 & 1638,07 & 1533,61 \\
\hline 1974 & 1395,74 & 1489,71 & 1347,63 & 1441,83 & 1425,83 & 1345,62 \\
\hline 1975 & 1361,31 & 1295,39 & 1268,15 & 1483,66 & 1508,20 & 1348,44 \\
\hline 1976 & 2001,65 & 1887,34 & 1897,87 & 2102,10 & 2134,49 & 2052,31 \\
\hline 1977 & 1487,74 & 1522,82 & 1414,34 & 1547,08 & 1543,71 & 1479,74 \\
\hline 1978 & 1284,53 & 1325,91 & 1199,62 & 1359,26 & 1321,06 & 1278,31 \\
\hline 1979 & 1340,55 & 1222,57 & 1251,05 & 1465,45 & 1438,04 & 1366,64 \\
\hline 1980 & 1502,61 & 1487,34 & 1363,79 & 1632,80 & 1640,03 & 1508,14 \\
\hline 1981 & 1453,92 & 1383,49 & 1318,54 & 1619,52 & 1616,94 & 1452,00 \\
\hline 1982 & 1834,14 & 1706,39 & 1742,39 & 1937,98 & 1968,42 & 1875,49 \\
\hline 1983 & 2371,30 & 2285,53 & 2173,83 & 2531,46 & 2585,74 & 2432,09 \\
\hline 1984 & 1221,03 & 1080,52 & 1140,48 & 1327,65 & 1312,17 & 1268,20 \\
\hline 1985 & 1274,42 & 1241,60 & 1166,90 & 1393,25 & 1334,10 & 1289,47 \\
\hline 1986 & 1620,53 & 1535,06 & 1494,14 & 1733,51 & 1806,86 & 1652,11 \\
\hline 1987 & 1577,05 & 1476,00 & 1479,39 & 1652,01 & 1648,68 & 1655,25 \\
\hline 1988 & 1592,45 & 1464,26 & 1461,82 & 1712,94 & 1653,00 & 1686,22 \\
\hline 1989 & 1541,47 & 1460,10 & 1424,24 & 1684,97 & 1646,02 & 1559,05 \\
\hline 1990 & 1375,24 & 1427,35 & 1343,64 & 1391,15 & 1349,62 & 1374,92 \\
\hline 1991 & 1769,85 & 1709,16 & 1722,80 & 1849,96 & 1810,98 & 1773,14 \\
\hline Média & 1439,38 & 1390,23 & 1353,39 & 1531,06 & 1537,14 & 1451,81 \\
\hline Desvio & 262,78 & 270,13 & 252,78 & 273,71 & 284,79 & 271,54 \\
\hline C.V. & 18,26 & 19,43 & 18,68 & 17,88 & 18,53 & 18,70 \\
\hline Máximo & 2371,30 & 2285,53 & 2173,83 & 2531,46 & 2585,74 & 2432,09 \\
\hline Mínimo & 966,58 & 886,81 & 870,81 & 1068,74 & 1084,61 & 988,15 \\
\hline
\end{tabular}


Espacialização dos dados

50

Tabela 2.6 - Séries de vazão total anual média (mm) por sub-bacia (dados obtidos diretamente do DAEE)

\begin{tabular}{|c|c|c|c|c|c|c|c|c|}
\hline Ano & Bacia & Corumb. & Piracic. & Jaguari & Jag. Med. & Camand. & Atibaia & Atib. Med. \\
\hline 1947 & 612,05 & 468,70 & 548,92 & 748,44 & 748,44 & 682,66 & 622,19 & 622,19 \\
\hline 1948 & 531,70 & 495,30 & 497,70 & 569,39 & 569,39 & 508,47 & 565,61 & 565,61 \\
\hline 1949 & 401,10 & 435,90 & 366,95 & 403,09 & 403,09 & 444,73 & 403,63 & 403,63 \\
\hline 1950 & 566,31 & 570,02 & 330,06 & 795,40 & 795,40 & 738,36 & 571,45 & 571,45 \\
\hline 1951 & 514,20 & 442,54 & 521,37 & 613,42 & 613,42 & 456,69 & 477,55 & 477,55 \\
\hline 1952 & 443,25 & 388,96 & 315,12 & 597,39 & 597,39 & 443,48 & 482,69 & 482,69 \\
\hline 1953 & 220,60 & 193,82 & 126,41 & 288,91 & 288,91 & 241,82 & 275,49 & 274,26 \\
\hline 1954 & 303,02 & 284,21 & 217,09 & 390,24 & 390,24 & 344,84 & 319,99 & $3,19,99$ \\
\hline 1955 & 288,37 & 305,92 & 240,22 & 366,34 & 366,34 & 284,37 & 264,26 & 264,26 \\
\hline 1956 & 341,98 & 351,76 & 296,20 & 443,24 & 443,24 & 322,75 & 303,74 & 303,74 \\
\hline 1957 & 513,35 & 517,37 & 383,23 & 652,21 & 652,21 & 449,37 & 555,78 & 555,78 \\
\hline 1958 & 564,68 & 592,74 & 411,72 & 725,88 & 725,88 & 569,24 & 576,51 & 576,51 \\
\hline 1959 & 410,41 & 385,32 & 327,70 & 505,73 & 505,73 & 380,16 & 443,81 & 443,81 \\
\hline 1960 & 514,96 & 564,06 & 396,72 & 648,75 & 648,75 & 438,86 & 525,95 & 525,95 \\
\hline 1961 & 462,66 & 359,66 & 382,92 & 585,05 & 585,05 & 455,82 & 506,23 & 506,23 \\
\hline 1962 & 455,27 & 355,53 & 386,74 & 583,77 & 583,77 & 479,18 & 468,51 & 468,51 \\
\hline 1963 & 404,37 & 369,06 & 372,47 & 480,18 & 480,18 & 449,73 & 378,36 & 378,36 \\
\hline 1964 & 287,12 & 268,61 & 203,27 & 382,70 & 382,70 & 330,26 & 293,61 & 293,61 \\
\hline 1965 & 630,66 & 682,04 & 669,34 & 687,69 & 687,69 & 680,16 & 488,77 & 488,77 \\
\hline 1966 & 471,71 & 549,34 & 336,33 & 584,56 & 584,56 & 562,63 & 449,52 & 449,52 \\
\hline 1967 & 561,37 & 670,97 & 475,12 & 665,61 & 665,61 & 539,10 & 509,28 & 509,28 \\
\hline 1968 & 312,51 & 373,63 & 239,58 & 358,80 & 358,80 & 259,23 & 335,94 & 332,47 \\
\hline 1969 & 243,86 & 202,25 & 205,45 & 315,08 & 315,08 & 253,40 & 244,87 & 244,87 \\
\hline 1970 & 571,62 & 579,18 & 377,94 & 790,71 & 790,71 & 516,38 & 609,54 & 589,55 \\
\hline 1971 & 314,84 & 318,83 & 240,51 & 367,96 & 367,96 & 358,76 & 335,24 & 335,24 \\
\hline 1972 & 462,49 & 606,38 & 340,68 & 501,83 & 501,83 & 471,66 & 479,04 & 479,04 \\
\hline 1973 & 386,74 & 404,30 & 252,17 & 480,28 & 480,28 & 443,54 & 427,42 & 427,42 \\
\hline 1974 & 471,82 & 544,11 & 451,54 & 511,01 & 511,01 & 509,28 & 405,10 & 405,10 \\
\hline 1975 & 390,44 & 482,50 & 328,29 & 478,26 & 478,26 & 448,14 & 309,55 & 260,53 \\
\hline 1976 & 758,32 & 818,91 & 727,30 & 809,75 & 809,75 & 803,59 & 697,11 & 619,09 \\
\hline 1977 & 508,68 & 484,49 & 515,19 & 536,55 & 536,55 & 519,52 & 486,76 & 391,86 \\
\hline 1978 & 306,16 & 337,91 & 202,93 & 358,28 & 358,28 & 307,24 & 358,30 & 251,18 \\
\hline 1979 & 314,63 & 345,62 & 188,64 & 420,93 & 420,93 & 379,94 & 323,34 & 214,89 \\
\hline 1980 & 407,83 & 467,36 & 292,35 & 526,62 & 526,62 & 469,38 & 377,81 & 227,90 \\
\hline 1981 & 411,66 & 462,60 & 320,86 & 550,64 & 387,61 & 463,36 & 343,55 & 232,69 \\
\hline 1982 & 628,00 & 621,81 & 523,28 & 846,19 & 576,86 & 662,86 & 543,46 & 422,34 \\
\hline 1983 & 1203,38 & 1142,21 & 1279,77 & 1240,76 & 1243,89 & 1349,18 & 1070,31 & 998,53 \\
\hline 1984 & 440,32 & 325,36 & 384,92 & 541,91 & 388,31 & 518,44 & 453,83 & 396,11 \\
\hline 1985 & 381,75 & 392,78 & 299,32 & 482,31 & 410,39 & 371,99 & 382,23 & 376,83 \\
\hline 1986 & 353,76 & 348,24 & 249,14 & 460,16 & 258,02 & 432,82 & 354,83 & 276,95 \\
\hline 1987 & 582,75 & 427,10 & 540,44 & 683,93 & 426,18 & 668,18 & 603,10 & 508,20 \\
\hline 1988 & 547,71 & 556,94 & 455,32 & 619,31 & 449,19 & 577,96 & 573,53 & 464,54 \\
\hline 1989 & 467,01 & 386,25 & 405,23 & 558,20 & 388,51 & 485,64 & 496,72 & 413,18 \\
\hline 1990 & 393,69 & 337,58 & 356,67 & 441,93 & 243,53 & 440,08 & 410,18 & 326,17 \\
\hline 1991 & 607,97 & 615,46 & 603,60 & 656,81 & 438,16 & 588,41 & 571,03 & 469,05 \\
\hline Média & 465,94 & 462,97 & 390,82 & 561,25 & 519,66 & 491,15 & 459,46 & 425,45 \\
\hline Desvio & 162,59 & 167,91 & 188,36 & 173,51 & 182,34 & 182,63 & 144,33 & 144,68 \\
\hline C.V. & 34,90 & 36,27 & 48,20 & 30,91 & 35,09 & 37,18 & 31,41 & 34,01 \\
\hline Máximo & 1203,38 & 1142,21 & 1279,77 & 1240,76 & 1243,89 & 1349,18 & 1070,31 & 998,53 \\
\hline Mínimo & 220,60 & 193,82 & 126,41 & 288,91 & 243,53 & 241,82 & 244,87 & 214,89 \\
\hline
\end{tabular}


Tabela 2.7 - Séries de evapotranspiração total anual média $(\mathrm{mm})$ por sub-bacia (geradas pelo módulo PROFILE).

\begin{tabular}{|c|c|c|c|c|c|c|}
\hline Ano & Bacia & Corumbat. & Piracicab. & Jaguari & Camand. & Atibaia \\
\hline 1947 & 1045,89 & 1194,65 & 1031,14 & 924,04 & 982,20 & 1106,04 \\
\hline 1948 & 623,57 & 622,02 & 689,01 & 538,62 & 577,98 & 640,88 \\
\hline 1949 & 780,76 & 768,99 & 791,98 & 786,30 & 775,69 & 771,56 \\
\hline 1950 & 795,57 & 822,90 & 998,59 & 550,33 & 669,22 & 809,86 \\
\hline 1951 & 750,44 & 782,23 & 671,27 & 737,91 & 849,67 & 801,11 \\
\hline 1952 & 735,19 & 780,51 & 753,24 & 666,18 & 807,19 & 727,69 \\
\hline 1953 & 877,86 & 856,50 & 935,31 & 866,64 & 887,94 & 832,29 \\
\hline 1954 & 925,47 & 875,88 & 951,84 & 913,99 & 960,09 & 923,47 \\
\hline 1955 & 947,66 & 795,87 & 921,42 & 993,48 & 1089,03 & 978,48 \\
\hline 1956 & 892,80 & 752,54 & 856,56 & 880,39 & 1039,46 & 978,44 \\
\hline 1957 & 1106,50 & 984,55 & 1162,29 & 1062,53 & 1242,92 & 1109,50 \\
\hline 1958 & 1046,77 & 1066,45 & 1161,76 & 942,51 & 1103,76 & 981,03 \\
\hline 1959 & 997,52 & 947,59 & 971,87 & 1060,25 & 1266,97 & 913,97 \\
\hline 1960 & 1159,94 & 1136,28 & 1189,66 & 1114,94 & 1356,49 & 1118,04 \\
\hline 1961 & 749,34 & 734,79 & 716,47 & 838,98 & 867,40 & 677,56 \\
\hline 1962 & 1025,84 & 1065,72 & 1019,82 & 1009,77 & 1163,56 & 980,64 \\
\hline 1963 & 613,98 & 517,81 & 578,89 & 630,38 & 724,36 & 658,94 \\
\hline 1964 & 1128,60 & 860,90 & 1045,85 & 1227,21 & 1215,67 & 1259,37 \\
\hline 1965 & 1033,89 & 883,53 & 946,65 & 1069,03 & 1147,33 & 1150,81 \\
\hline 1966 & 912,69 & 836,23 & 963,45 & 907,41 & 930,72 & 898,33 \\
\hline 1967 & 899,86 & 877,75 & 955,38 & 828,79 & 990,20 & 884,79 \\
\hline 1968 & 653,67 & 513,42 & 630,81 & 709,74 & 835,64 & 652,15 \\
\hline 1969 & 951,20 & 978,85 & 875,66 & 995,66 & 1114,61 & 929,16 \\
\hline 1970 & 1157,19 & 1091,81 & 1269,90 & 1004,00 & 1346,68 & 1144,34 \\
\hline 1971 & 974,87 & 961,20 & 899,97 & 1041,25 & 1052,82 & 983,21 \\
\hline 1972 & 1093,69 & 1041,20 & 1177,24 & 1090,08 & 1163,55 & 1010,91 \\
\hline 1973 & 1126,84 & 1098,92 & 1130,14 & 1139,48 & 1194,07 & 1106,61 \\
\hline 1974 & 924,24 & 945,71 & 895,63 & 930,83 & 916,83 & 940,62 \\
\hline 1975 & 971,44 & 813,39 & 940,15 & 1005,65 & 1060,20 & 1038,44 \\
\hline 1976 & 1243,70 & 1068,34 & 1170,87 & 1292,10 & 1330,49 & 1355,31 \\
\hline 1977 & 979,04 & 1038,82 & 899,34 & 1010,08 & 1023,71 & 992,74 \\
\hline 1978 & 978,25 & 987,91 & 996,62 & 1001,26 & 1014,06 & 920,31 \\
\hline 1979 & 1025,82 & 876,57 & 1062,05 & 1044,45 & 1058,04 & 1043,64 \\
\hline 1980 & 1095,00 & 1020,34 & 1071,79 & 1105,80 & 1171,03 & 1130,14 \\
\hline 1981 & 1042,27 & 920,49 & 997,54 & 1068,52 & 1153,94 & 1103,53 \\
\hline 1982 & 1206,50 & 1084,39 & 1219,39 & 1091,98 & 1305,42 & 1332,49 \\
\hline 1983 & 1168,65 & 1143,54 & 893,83 & 1290,46 & 1236,74 & 1362,09 \\
\hline 1984 & 780,55 & 755,52 & 755,48 & 785,65 & 794,17 & 814,20 \\
\hline 1985 & 892,73 & 848,60 & 867,90 & 911,25 & 962,10 & 907,47 \\
\hline 1986 & 1266,84 & 1187,06 & 1245,14 & 1273,51 & 1373,86 & 1297,11 \\
\hline 1987 & 994,24 & 1049,00 & 939,39 & 968,01 & 980,68 & 1052,25 \\
\hline 1988 & 1044,65 & 907,26 & 1006,82 & 1093,94 & 1075,00 & 1112,22 \\
\hline 1989 & 1074,21 & 1074,10 & 1019,24 & 1126,97 & 1160,02 & 1062,05 \\
\hline 1990 & 981,33 & 1089,35 & 986,64 & 949,15 & 909,62 & 964,92 \\
\hline 1991 & 1161,90 & 1094,16 & 1118,80 & 1192,96 & 1222,98 & 1202,14 \\
\hline Média & 974,20 & 927,86 & 964,06 & 970,50 & 1046,76 & 992,46 \\
\hline Desvio & 161,29 & 163,56 & 165,26 & 180,71 & 191,38 & 184,80 \\
\hline C.V. & 16,56 & 17,63 & 17,14 & 18,62 & 18,28 & 18,62 \\
\hline Máximo & 1266,84 & 1194,65 & 1269,90 & 1292,10 & 1373,86 & 1362,09 \\
\hline Mínimo & 613,98 & 513,42 & 578,89 & 538,62 & 577,98 & 640,88 \\
\hline
\end{tabular}




\section{Capítulo 3}

\section{Análise de Tendência Temporal}

Neste capitulo procurou se detalhar a análise de tendência temporal realizada através dos métodos de Mann-Kendall e Pettitt, aplicados para cada sub-bacia, sobre as séries de lâminas médias totais anuais e trimestrais de precipitação e anuais de evapotranspiração, geradas como descrito no capítulo anterior, $e$ sobre as séries dos totais anuais e trimestrais de vazão.

\subsection{Breve Revisão Bibliográfica}

A análise de tendência de uma série de dados qualquer pode ser realizada por diversos métodos. Provavelmente o método mais simples é o da própria observação direta da plotagem dos dados da série, como utilizado por SCHÄDLER (1987) que plotou a média de cada dez anos dos dados de precipitação, evapotranspiração e vazão de quatro bacias da Suíça. SENTELHAS et al. (1994) também fazem análise gráfica de médias móveis de dez anos dos dados seculares de precipitação, temperatura média do ar e excedentes e deficiências hídricas do posto meteorológico da cidade de Campinas, mantido pelo IAC, procurando fazer correlações desses elementos com a tendência decrescente da cobertura 
florestal na cidade.

Outro método simples e rápido é o da regressão linear dos dados observados ao longo do tempo, onde se busca a reta que apresente a menor soma de quadrados dos erros. A tendência é considerada positiva, caso o coeficiente angular da reta seja positivo, e negativa, caso contrário. ROCHA et al. (1989) utilizaram esse tipo de análise para dados de precipitação e vazão de algumas estações meteorológicas na bacia Amazônica. CHRISTOFOLETTI (1991) utilizou esse método e também o das semi-médias para analisar a tendência dos dados de precipitação do Departamento de Águas e Energia Elétrica (DAEE) do Estado de São Paulo. No método das semi-médias divide-se os dados em duas partes, para as quais se calculam as médias separadamente e se traça uma reta entre os dois pontos, abrangendo toda a extensão da série. Encontrou tendência positiva de 8 a 27\% para os dados de 18 estações dentro da bacia. Outro método apresentado pelo autor é o das somas acumuladas CUSUM.

GENOVEZ (1982) apresenta um estudo de séries de vazões mensais do rio Tietê no qual utiliza a técnica CUSUM, que é a representação seqüencial e acumulada dos desvios dos valores da série em relação à média do período anterior a uma intervenção, que se deseja analisar. Uma desvantagem desse método é a necessidade de conhecer o ponto a partir do qual a série sofre a influência da mudança. A análise gráfica permite avaliar o comportamento da série de dados.

Embora essas análises permitam detectar a tendência de maneira relativamente simples, elas não são métodos robustos, tendo seus resultados facilmente distorcidos caso ocorram valores extremos ou anômalos. PETTITT (1979), ao apresentar seu método para teste de mudança da média ocorrida em um ponto no tempo desconhecido, descrito no item 3.2.2. , faz uma comparação com a técnica de CUSUM através da introdução forçada de valores anômalos em séries observadas e através da geração de séries teóricas conhecidas. 
Ele observou que essa técnica sofreu a influência dos valores introduzidos, o que não aconteceu com seu método, que se apresentou simples e robusto em relação aos distúrbios introduzidos. Outra vantagem destacada pelo autor é a de seu método não supor ou necessitar do conhecimento prévio do tipo de distribuição de probabilidades que melhor se enquadre aos dados e nem do ponto de início da mudança, o qual ele próprio detecta.

SNEYERS (1975) apresentou um item sobre métodos de análise de tendência, no qual se encontram descritos dois testes estatísticos. O primeiro deles é o cálculo do coeficiente $r_{s}$ de Spearman, onde as observações originais $x_{i}, i=1,2, \ldots, N$, são substituídas pela sua posição na hierarquia dos valores crescentes, $y_{i}$. $O$ valor de $_{s} r$ é dado pelo coeficiente de correlação da regressão linear entre os valores de i e $y_{\mathrm{i}}$. Aceita-se a existência de tendência para grandes valores de $\left|r_{s}\right|$ e ela é crescente ou decrescente caso $r_{s}>0$ ou $r_{s}<0$, respectivamente. Calcula-se, então, a significância da tendência. $O$ segundo teste apresentado pelo autor é a versão seqüencial do teste de Mann-Kendall que detecta a existência de uma tendência, quando esta se torna significativa e, aproximadamente, o seu ponto de início.

GOOSSENS \& BERGER (1986) empregaram esse método com o propósito de detectar mudanças climáticas e calcular sua significância estatística, comparando-o a vários outros. Segundo eles, o teste de Spearman tem a mesma eficiência que o de Mann-Kendall na detecção de uma tendência, porém não permite definir o início da mudança climática nem o momento em que esta se torna significativa. Analisando outros métodos, os autores concluem que a filtragem de séries através de médias móveis de trinta anos, ou do filtro Gaussiano passa-baixa, apresenta problemas quanto à redução do número de registros disponíveis e quanto ao fato de as curvas suavizadas não permitirem a detecção de mudanças climáticas bruscas. $\mathrm{O}$ teste de Cramer, que mede a diferença entre médias de períodos sucessivos de dez anos e a do período total, exige especial cuidado na avaliação de sua significância estatística, devido à sobreposição de períodos. O teste de Mann- 
Kendall, julgado por eles como o mais adequado, foi então aplicado para quase uma dezena de séries seculares apresentadas por diversos autores, além da sua própria base de dados, sobre temperatura e precipitação do hemisfério norte.

SNEYERS et al. (1990) destacaram a importância da utilização de métodos nãoparamétricos na análise de tendência ou mudança na média de séries temporais para evitar a limitação de assumir previamente determinada distribuição para os dados. Esses autores também sugeriram a utilização do método de Mann-Kendall, por ser eficaz e de fácil aplicação, progressiva e regressivamente. Porém, para o caso de mudanças climáticas abruptas, ou quando se deseja detectar o ponto de mudança e calcular seu nível de significância, o teste de Pettitt mostra-se mais adequado. Os autores aplicaram a combinação desses dois testes para séries de temperatura, chuva, pressão atmosférica, horas de brilho solar, umidade do ar e velocidade do vento de Bruxelas, encontrando tendência significativa apenas para os dados de temperatura e precipitação.

DEMARÉE (1990) utilizou a análise de tendência de Mann-Kendall e a de mudança de média de Pettitt para os registros de precipitação da estação meteorológica de Kaédi (Mauritânia). DEMARÉE \& NICOLIS (1990) dispuseram dessa mesma base de dados da região oeste do Sahel, utilizando também esses dois testes como forma de analisar a estacionalidade dos dados, auxiliando na elaboração de um modelo matemático que explicasse os períodos de forte seca ocorridos na região.

Pelas vantagens descritas, optou-se então neste trabalho pela combinação do método de Mann-Kendall e o de Pettitt para a análise de tendência temporal das séries de precipitação, de evapotranspiração e de vazão, geradas no capítulo anterior. Esses dois métodos são descritos a seguir. 


\subsection{Métodos Utilizados na Análise Temporal.}

\subsubsection{Teste de Mann-Kendall.}

A versão seqüencial do teste de Mann-Kendall foi proposta inicialmente por SNEYERS (1975). Esse teste não-paramétrico é baseado no fato de que, na hipótese de estabilidade de uma série, a sucessão de valores deve ser independente e a distribuição de probabilidade deve permanecer sempre a mesma (séries randômicas simples) (GOOSSENS \& BERGER, 1986).

Supondo uma série qualquer de $\mathrm{N}$ termos $\mathrm{x}_{\mathrm{i}}$, onde $1 \leq \mathrm{i} \leq \mathrm{N}$, pode-se calcular o valor $n_{i}$ para cada elemento $x_{i}$, sendo $n_{i}$ o número de elementos $x_{j}$ que o precedem $(i>j)$ tal que $x_{i}>x_{j}$. A estatística té dada então pela relação:

$$
t=\Sigma_{i}^{N} n_{i}
$$

Considerando a hipótese nula, ou seja, que não haja tendência, a distribuição de $t$ para $\mathrm{N}$ grande é normal com média e variância:

$$
E(t)=\frac{N(N-1)}{4} \quad e \quad \operatorname{var}(t)=\frac{N(N-1)(2 N+5)}{72}
$$

A hipótese nula é descartada para valores altos de $|\mathrm{U}(\mathrm{t})|$, que é equivalente à variável reduzida $\mathrm{z}$ da curva normal $(\mathrm{z}=(\mathrm{x}-\mu) / \sigma)$ na sua forma bilateral: 


$$
U(t)=\frac{[t-E(t)]}{\sqrt{\operatorname{var}(t)}}
$$

A probabilidade $\alpha_{1}$ é determinada com o auxílio de uma tabela normal reduzida, de forma que:

$$
\alpha_{1}=P(|U|>|U(t)|)
$$

sendo $\alpha_{0}$ o nível de significância do teste, a hipótese nula é aceita ou rejeitada se $\alpha_{1}>\alpha_{0}$ ou se $\alpha_{1}<\alpha_{0}$, respectivamente. Se a hipótese nula for rejeitada, existe uma tendência significativa, sendo ela crescente se $U(t)>0$ ou decrescente se $U(t)<0$.

A versão seqüencial desse teste permite identificar aproximadamente o ponto de início da tendência, através de análise gráfica de duas curvas. A primeira representa a série de valores de $\mathrm{U}(\mathrm{t})$ para os $\mathrm{N}$ anos, série progressiva, onde o valor de $\mathrm{t}$ é dado pela soma dos i primeiros termos:

$$
t_{i}=n_{1}+n_{2}+\ldots+n_{i} \quad \text { para } 1 \leq i \leq N
$$

Nessa curva, quando o valor de U(t) excede o limite crítico determinado pelo nível de significância escolhido, 1,96 para $\alpha_{0}=0,05$ e 1,65 para $\alpha_{0}=0,10$, aceita-se a existência de tendência significativa.

A segunda é a sẹ́rie regressiva. Nesse caso calcula-se o valor $\mathrm{n}^{*}{ }_{\mathrm{i}}$ para cada elemento $x_{i}$, sendo $n^{*}{ }_{i}$ o número de elementos $x_{j}$ que o sucedem $(i<j)$ tal que $x_{i}>x_{j}$. Considerando $\mathrm{y}_{\mathrm{i}}$ como a posição que $\mathrm{x}_{\mathrm{i}}$ ocupa noclassificação crescente de valores da série, temos: 


$$
n_{i}+n *_{i}=y_{i}-1, \quad i *=(N+1)-i \quad \text { e } \quad n *_{i}=n_{i *}
$$

os valores de $U^{*}(t)$ para essa série são dados pela relação:

$$
U^{*}(t)=-U\left(t_{i *}\right)
$$

$\mathrm{Na}$ ausência total de tendência, a representação gráfica de $U(t)$ e de $U^{*}(t)$ em função de i geralmente mostra essas duas curvas se entrelaçando dentro do intervalo delimitado pelas duas linhas de intervalo de confiança. No caso de uma tendência significativa, o valor das curvas de $\mathrm{U}(\mathrm{t})$ e de $\mathrm{U}^{*}(\mathrm{t})$ ultrapassam esses limites. $\mathrm{O}$ cruzamento dessas estatísticas deve se encontrar dentro desse intervalo, e permite situar aproximadamente o início do fenômeno (SNEYERS, 1975; GOOSSENS \& BERGER,1986; DEMARÉE \& NICOLIS, 1990).

\subsubsection{Teste de Pettitt.}

Quando as curvas no teste de Mann-Kendall se entrelaçam várias vezes ao mostrar uma tendência significativa, torna-se difícil detectar o seu ponto de início. Para evitar esse problema e encontrar com maior proximidade o ponto de transição, utiliza-se o teste de Pettitt (PETTITT, 1979), que permite detectar uma mudança na média e calcular seu nível de significância estatística, sem se conhecer previamente o ponto no tempo onde ela ocorre. Assim, tem-se:

$$
D_{i j}=\operatorname{Sin}\left(x_{i}-x_{j}\right)
$$

onde $j=t+1$ e $\operatorname{Sin}(x)$ expressa o sinal da operação, $\operatorname{sendo} \operatorname{Sin}(x)=1$ se $x>0,0$ se $x=0$ e -1 se $\mathrm{x}<0$. Então, considera-se 


$$
u_{t, N}=\Sigma_{i}^{t} \Sigma^{N} D_{i j}
$$

Segundo PETTITT (1979), a estatística $\mathrm{u}_{\mathrm{t}, \mathrm{N}}$ é equivalente à de Mann-Whitney para teste de duas amostras $\mathrm{x}_{1}, \ldots, \mathrm{x}_{\mathrm{t}}$ e $\mathrm{x}_{\mathrm{t}+1}, \ldots, \mathrm{x}_{\mathrm{N}}$ que vêm da mesma população. Ela é considerada para os valores de $\mathrm{t}$ com $1 \leq \mathrm{t}<\mathrm{N}$ e expressa o número de vezes que um membro da primeira amostra supera um membro da segunda (DEMARÉE \& NICOLIS, 1990). O teste da hipótese nula (não ocorrência de mudança), é feito pelo uso da estatística

$$
K_{N}={ }_{1 \leq t<N} m a ́ x\left|u_{t, N}\right| \text {. }
$$

Deve ser notado que, na hipótese nula, a esperança matemática para $\mathrm{D}_{\mathrm{ij}}$ é igual a zero $\left(E\left(D_{i j}\right)=0\right)$ e a distribuição de $u_{t, N}$ para cada $t$ é simétrica em torno desse valor. $O$ método para o cálculo do nível de significância da mudança encontra-se detalhado em PETTITT (1979), e foi estimado aqui para os níveis de 10 e 5\%, através da equação:

$$
p \cong 2 \exp \left[\frac{-6 K_{N}^{2}}{t^{3}+t^{2}}\right]
$$

\subsection{Resultados e sua Discussão}

Embora as retas de regressão, apresentadas nas figuras 3.1, 3.4 e 3.5, representem a tendência das séries, uma análise mais detalhada pode ser realizada mais adequadamente pelos métodos apresentados acima, principalmente quanto à sua significância estatística. Os resultados discutidos abaixo estão expressos pelas diversas tabelas, para a lâmina d'água de 
precipitação anual e trimestral média, para a lâmina d'água de vazão anual e trimestral natural líquida média, para a lâmina d'água de vazão anual e trimestral medida líquida média e para a lâmina d'água de evapotranspiração anual média.

À excessão da vazão medida líquida, que representa dados apenas das sub-bacias do Jaguari e do Atibaia, as tabelas dos ítens a seguir representam os dados de todas as subbacias e da bacia do rio Piracicaba como um todo. Essas tabelas sumarizam aqui os valores obtidos através da análise gráfica dos resultados gerados pelos teste de Mann-Kendall e de Pettitt. Assim, elas apresentam os níveis de significância das tendências e, caso eles estejam além dos limites de $10 \%$, o seu ano de início.

\subsubsection{Precipitação}

A figura 3.1 representa as séries anuais de precipitação média na bacia toda, cujos valores foram apresentados na tabela 2.5. Comparando os valores para as sub-bacias, a do Jaguari e do Camaducaia apresentam sempre valores mais altos que a média da bacia, ou seja, elas estão situadas nas regiões com maiores índices pluviométricos. Comportamento contrário é apresentado pelas sub-bacias do Corumbataí e do Piracicaba. A sub-bacia do Atibaia apresenta valores mais próximos à média da bacia toda. Essas observações se confirmam ao se comparar os valores médios normais das sub-bacias (tabela 2.5). $\mathrm{O}$ ano de 1968 foi o extremo inferior, seguido pelo ano de 1963 . O ano de 1953 também foi seco, caracterizando o período ocorrido entre 1951 e 1955 . O extremo superior se deu no ano de 1983, seguido do ano de 1976.

Uma tendência positiva pode ser notada através da simples plotagem dos valores e através da reta de regressão linear para a série de precipitação sobre toda a bacia do rio Piracicaba, que possui coeficiente angular aproximadamente igual a 8 (reta tracejada com 

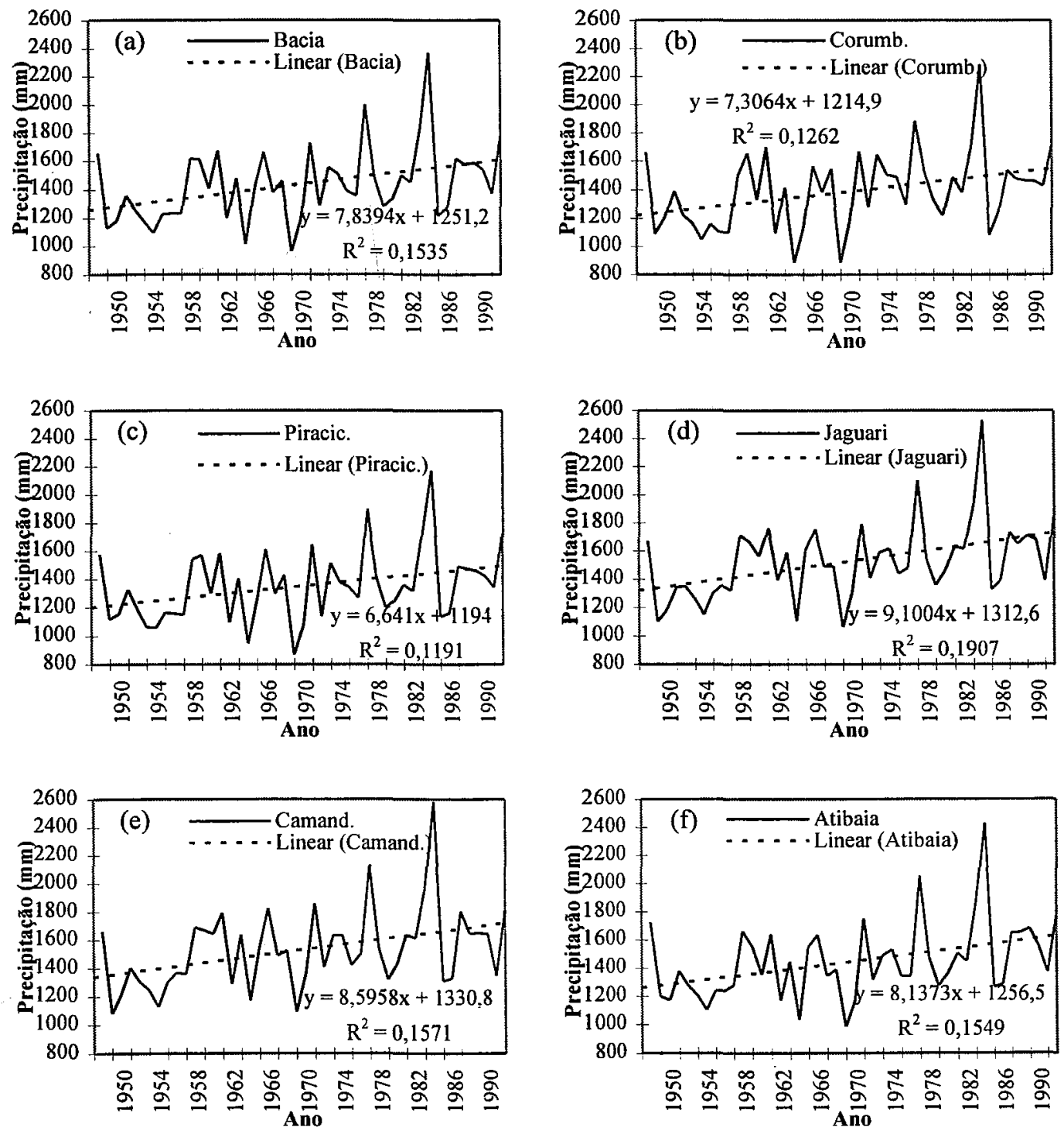

Figura 3.1 - Comportamento temporal das séries de precipitação na bacia toda (a) e nas sub-bacias (b-f). A linha tracejada mostra a regressão linear para a série, associada à equação apresentada. 
sua respectiva equação de regressão e coeficiente de correlação no canto inferior direito da figura 3.1). As retas de regressão para as sub-bacias possuem praticamente a mesma inclinação, ou seja, a mesma tendência.

Os resultados mais importantes do teste de Mann-Kendall e de Pettitt estão sumarizados na tabela 3.1. A figura 3.2, que exemplifica a análise gráfica, apresenta 0 resultado desses testes para a bacia toda. Os seus niveis de significância são apresentados através de retas com tracejados curtos para o nível de $10 \%$ ( - - - ) , e com tracejados longos para o nível de 5\% (----). Para que a tendência possa ser detectada, o cruzamento entre as curvas das estatísticas $\mathrm{U}(\mathrm{t})$ e $\mathrm{U}^{*}(\mathrm{t})$ (ponto aproximado de início) deve aparecer dentro dos limites de significância e, depois, a curva U(t) (linha em negrito na figura) deve cruzá-lo (ponto em que passa a ser significativa) e manter-se além deles. Tanto as sub-bacias, como a bacia como um todo, apresentam tendência positiva para a precipitação anual.

Para as sub-bacias do Corumbatai, do Piracicaba e do Atibaia, a significância da tendência aparece a partir de 1982 e pelo método de Pettitt, o ano de 1969 foi apontado como o ponto de início da tedência, ou então, o ponto onde a série pode ser dividida em duas amostras estatisticamente diferentes (ponto de quebra da série). Note-se que o ano de 1968 foi o ano mais seco de toda a série, estando o ponto de quebra encontrado em 1969 provavelmente relacionado a ele. Para as sub-bacias do Jaguari e do Camanducaia, a tendência torna-se significativa em 1959 e novamente em 1972/1973. O teste de Pettitt indica como ruptura mais expressiva o ano de 1956, ou seja, logo após a queda causada pela seca de 1951-1955. A bacia como um todo, que engloba o comportamento de todas as subbacias, apresenta o início da significância da tendência num ponto intermediário entre os dois anteriores, em 1976. Porém, o ponto de início da tendência se mantém em 1969.

Um ponto interessante de se observar é a diferença entre as sub-bacias do Jaguari e do Camanducaia e as demais. Isto é, a seca de 1951-1955 influenciou mais fortemente as 
Tabela 3.1 - Resultados obtidos pelo teste de análise de tendência de Mann-Kendall e pelo de mudança de médias de Pettitt para a precipitação.São assinaladas as tendências positivas significativas e pontos de ruptura para os níveis de $5 \%\left({ }^{* *}\right), 10 \%\left({ }^{*}\right)$ e acima de $10 \%(n s)$. Quando as tendências foram significativas, os anos de ruptura foram apresentados, mesmo que não significativos.

\begin{tabular}{|c|c|c|c|c|}
\hline \multicolumn{2}{|c|}{ Bacia } & anual & tru & trs \\
\hline Corumb. & $\begin{array}{c}\text { Tend. } \\
\text { Ruptura } \\
\text { Nível Sig. }\end{array}$ & $\begin{array}{l}1982^{* *} \\
1969^{*} \\
0,0553\end{array}$ & $\begin{array}{l}\text { ns } \\
\text { ns } \\
\text { ns }\end{array}$ & $\begin{array}{l}1977^{* *} \\
1969^{*} \\
0,0588\end{array}$ \\
\hline Piracic. & $\begin{array}{c}\text { Tend. } \\
\text { Ruptura } \\
\text { Nível Sig. }\end{array}$ & $\begin{array}{l}1982^{* *} \\
1969 \mathrm{~ns} \\
0,1106\end{array}$ & $\begin{array}{l}\text { ns } \\
\text { ns } \\
\text { ns }\end{array}$ & $\begin{array}{l}1980^{* *} \\
1969^{*} \\
0,0663\end{array}$ \\
\hline Jaguari & $\begin{array}{c}\text { Tend. } \\
\text { Ruptura } \\
\text { Nível Sig. }\end{array}$ & $\begin{array}{l}1973 * * \\
1956^{* *} \\
0,0335\end{array}$ & $\begin{array}{l}\mathrm{ns} \\
\mathrm{ns} \\
\mathrm{ns}\end{array}$ & $\begin{array}{l}1980^{* *} \\
1969^{*} \\
0,0663\end{array}$ \\
\hline Camand. & $\begin{array}{c}\text { Tend. } \\
\text { Ruptura } \\
\text { Nível Sig. }\end{array}$ & $\begin{array}{l}1972 * * \\
1956^{*} \\
0,0553\end{array}$ & $\begin{array}{l}\text { ns } \\
\text { ns } \\
\text { ns }\end{array}$ & $\begin{array}{l}1979 * * \\
1969 \\
0,1106\end{array}$ \\
\hline Atibaia & $\begin{array}{c}\text { Tend. } \\
\text { Ruptura } \\
\text { Nível Sig. }\end{array}$ & $\begin{array}{l}1982 * * \\
1969 * * \\
0,0335\end{array}$ & $\begin{array}{l}\text { ns } \\
\text { ns } \\
\text { ns }\end{array}$ & $\begin{array}{l}1981^{* *} \\
1969^{*} \\
0,0588\end{array}$ \\
\hline Bacia toda & $\begin{array}{c}\text { Tend. } \\
\text { Ruptura } \\
\text { Nível Sig. }\end{array}$ & $\begin{array}{l}1976^{* *} \\
1969^{*} \\
0,0521\end{array}$ & $\begin{array}{l}\text { ns } \\
\text { ns } \\
\text { ns }\end{array}$ & $\begin{array}{l}1979 * * \\
1969 * \\
0,0663\end{array}$ \\
\hline
\end{tabular}


(a)

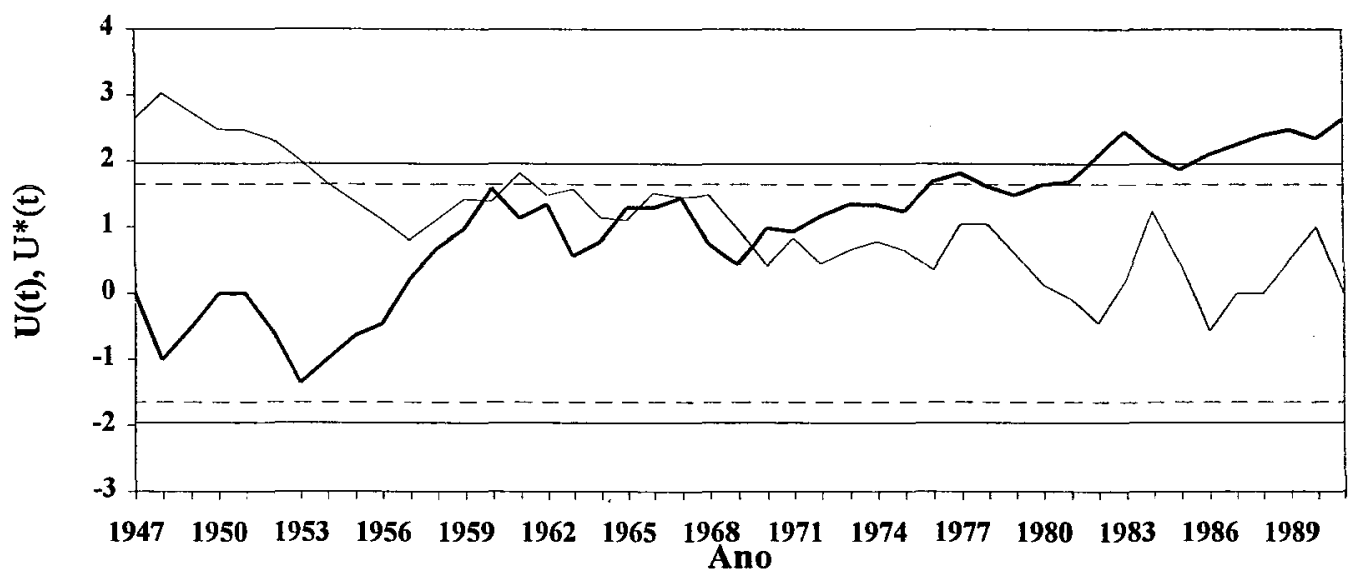

(b)

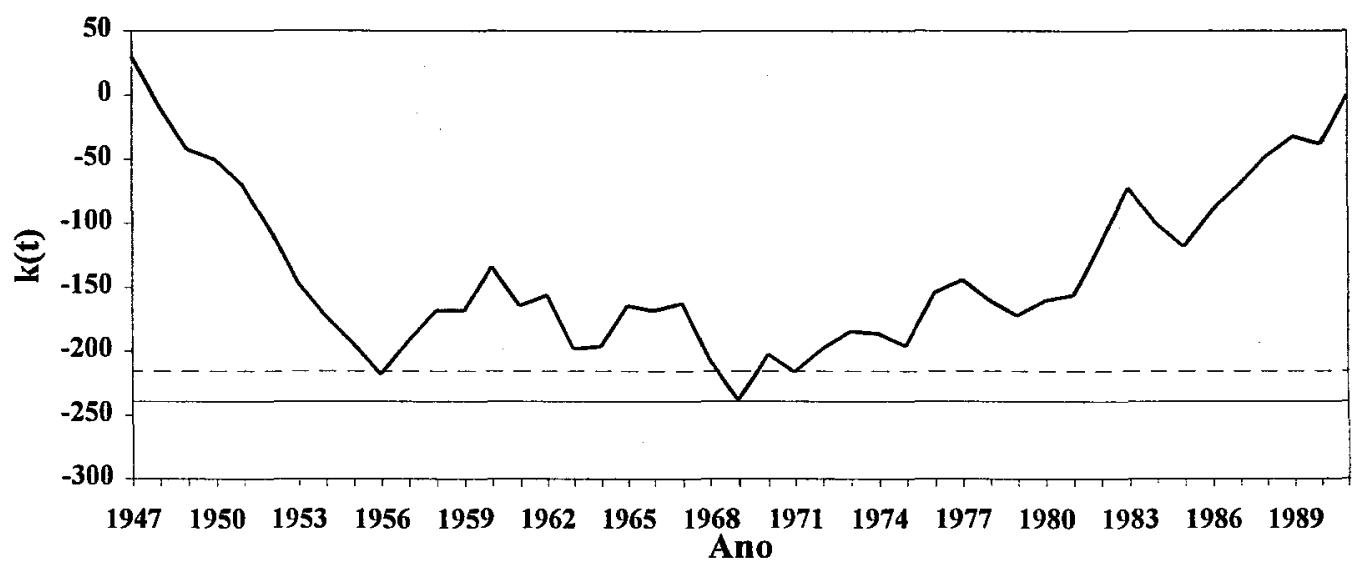

Figura 3.2 - Exemplo do resultado gráfico dos testes de Mann-Kendall (a) e de Pettitt (b) para a precipitação anual média na bacia toda. As retas tracejadas representam os limites de confiança para $10 \%$ (------) e $5 \%\left(\ldots-\_\right)$. 
duas primeiras, embora a variação climática ocorrida em 1969 também tenha sido detectada. Essa diferença parece sugerir que naquela seca a região baixa da bacia foi privilegiada no recebimento da pouca água disponível, provavelmente porque o deslocamento das massas de ar se deu no sentido continente-oceano, sendo o fator continentalidade importante. Infelizmente, essa hipótese não pôde ser comprovada, pois não se estudou aqui o aspecto da circulação atmosférica geral. Uma discussão mais profunda quanto a essas datas também não pôde ser realizada aqui pelo mesmo motivo. Pôde-se, portanto, apenas detectar a existência ou não de tendência significativa e apontar seu ponto de início.

Embora CHRISTOFOLETTI (1991) não apresente a significância, nem os pontos de início, ele também detectou tendência positiva na maior parte das estações na bacia. Os coeficientes angulares de suas retas de regressão variam entre -8 a 14 , sendo que apenas três de 21 estações apresentam valores levemente negativos. A sua média é 7 , concordando com a reta média estimada para a bacia toda (figura 3.1). SENTELHAS et al. (1994) também encontraram a mesma tendência para o posto do IAC em Campinas, no período.

Deve-se salientar que embora a tendência positiva seja clara e ocorra no período analisado em toda a bacia, não se pode afirmar que ela continue indefinidamente, devendo se ter cuidado com extrapolações muito além do periodo analisado. Infelizmente não dispomos ainda de séries seculares suficientes, que nos permitam analisar ciclos com períodos mais longos. O gráfico de SENTELHAS et al. (1994) para a estação do IAC em Campinas, reproduzido aqui na figura 3.3, ilustra bem essa observação apesar de expressar apenas o comportamento desse posto isolado. Pode-se notar que, coincidentemente, ocorreu uma tendência negativa até o extremo de baixa por volta de 1950, a partir de quando os valores voltaram a subir, mantendo essa tendência positiva até hoje. Não se pode, portanto, afirmar que essa tendência se manterá indefinidamente, nem tampouco que ela foi provocada por fatores antrópicos. Parece mais adequado supor, baseando-se na figura, que se esteja num período de ascensão de um ciclo, com período mais longo que o analisado 


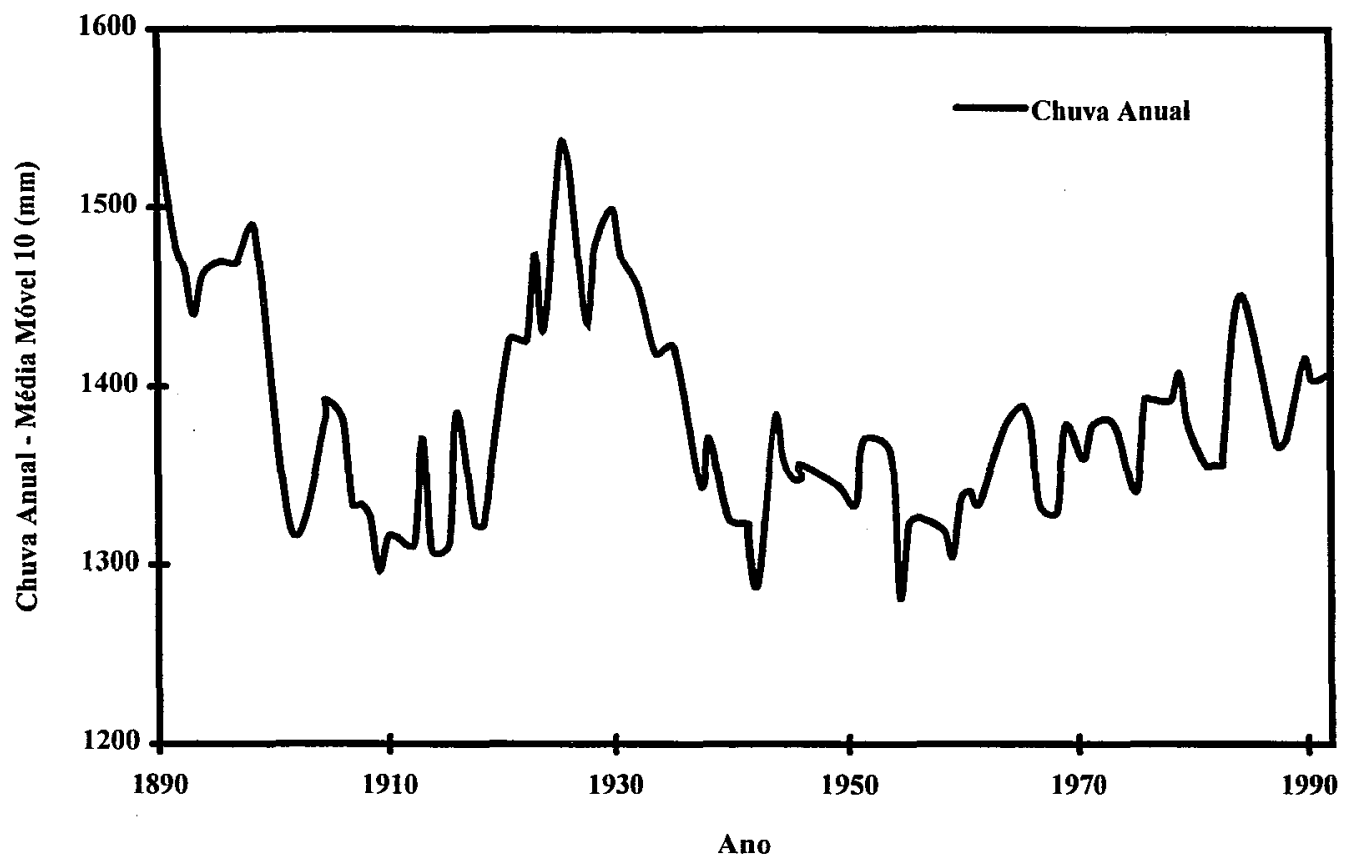

Figura 3.3 - Média móvel (ordem 10) da chuva anual durante o período de 1890 a 1992, em Campinas, SP. (adaptada de SENTELHAS et al., 1994) 
neste trabalho.

Procurando detalhar mais seu comportamento, fez-se a análise de tendência da precipitação para o trimestre mais úmido e para o mais seco do ano. Nenhuma das subbacias, nem a bacia toda, apresentou tendência significativa para o trimestre úmido. Para o trimestre seco porém, todas apresentaram tendência positiva com ruptura em 1969 segundo o método de Pettitt, e significância iniciando entre 1978 e 1981, segundo o método de Mann-Kendall (tabela 3.1).

(8) É interessante notar, a partir desses resultados, que o aumento das chuvas no período estudado não ocorreu como um aumento homogêneo durante todas as estações, como se poderia supor, mas sim que tem sido provocado principalmente pelo seu aumento no período seco, ou seja, os anos têm sido mais chuvosos porque os invernos têm sido cada vez menos secos na região.

\subsubsection{Vazão}

Os dados de lâmina d'água de vazão anual natural e medida líquidas, estão expressos na tabela 2.6. As sub-bacias do Jaguari e do Camanducaia mantêm-se praticamente todo o período acima da média da bacia como um todo. Esse comportamento pode ser encarado, a princípio como um reflexo da maior precipitação nessas regiões, embora outros fatores também sejam importantes na geração do deflúvio. A sub-bacia do Piracicaba, por sua vez, mantém-se abaixo da média da bacia toda, ao longo de todo o período. As duas outras se alternam acima e abaixo dela.

Na figura 3.4 uma leve tendência positiva é notada através da reta de regressão linear, cujo coeficiente angular é aproximadamente igual a 2, bem menor que o da 

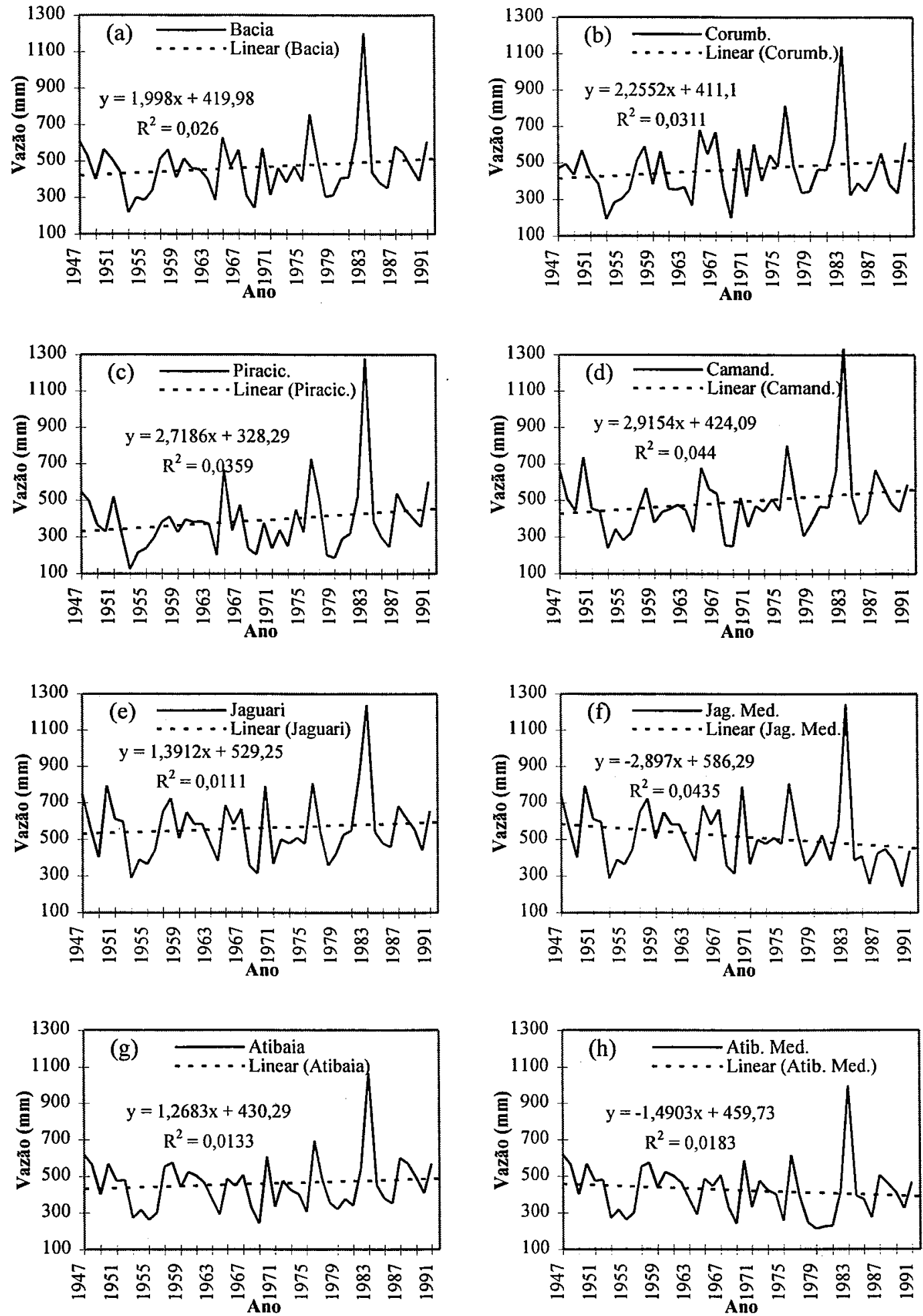

Figura 3.4 - Comportamento das séries de vazão natural líquida na bacia toda (a) e nas sub-bacias (b-e; g). Também são apresentadas as vazões medidas para as bacias do Jaguari e do Atibaia ( $\mathrm{e}$ h). A linha tracejada mostra a regressão linear para a série, associada à equação apresentada. 
precipitação. As regressões para as sub-bacias também são apresentadas e possuem aproximadamente o mesmo coeficiente angular, ou seja, a mesma tendência. Ao contrário, as figuras 3.4(f) e (h) mostram os dados de vazão medida para as sub-bacias do Jaguari e do Atibaia, que sofrem o efeito da operação de barragens. Ali, o coeficiente angular da reta de regressão de ambas as sub-bacias é negativo e em torno de 2 , o que sugere uma tendência levemente negativa.

Pelos resultados dos testes de Mann-Kendall e de Pettitt (tabela 3.2), pode se concluir que os dados de vazão natural líquida não apresentam tendência significativa, ao contrário do que seria de se esperar, considerando o aumento significativo detectado na precipitação anual. Note-se que, embora a reta de regressão apresente uma leve tendência positiva, esta não é estatisticamente significativa.

As séries anuais de vazão medida para a bacia do Jaguari e a do Atibaia porém, apresentam tendência decrescente significativa, de acordo com o método de Mann-Kendall. O teste de Pettitt, embora apresente um ligeiro pico no ano de 1967, não chega a determinar um ponto significativo de ruptura.

Uma conclusão importante, tirada a partir dessas duas observações, é que, apesar de a chuva ter aumentado na bacia, as barragens têm provocado uma diminuição significativa na água disponivel no leito de seus rios. Caso contrário, a tendência na vazão medida não deveria aparecer, concordando com a natural. Esse efeito pode vir a ser problemático diante do aumento da pressão causada pelo aumento populacional na bacia do rio Piracicaba e sua conseqüente maior demanda (item 1.2.) sobre os recursos hídricos.

Os dados trimestrais para a vazão natural líquida também não apresentaram tendência significativa (tabela 3.2). Os do trimestre seco contudo, apresentam leve tendência crescente, embora ela não chegue a ser significativa, o que está de acordo com o aumento 
Tabela 3.2 - Resultados obtidos pelo teste de análise de tendência de Mann-Kendall e pelo teste de mudança de médias de Pettitt para a vazão. São assinaladas as tendências negativas significativas e pontos de ruptura para os niveis de $5 \%(\sim), 10 \%(\sim)$ e acima de $10 \%$ (ns). Quando as tendências foram significativas, os anos de ruptura foram apresentados, mesmo que não significativos.

\begin{tabular}{|c|c|c|c|c|}
\hline \multicolumn{2}{|c|}{ Bacia } & anual & tru & trs \\
\hline $\begin{array}{l}\text { Corumb. } \\
\text { Natural }\end{array}$ & $\begin{array}{c}\text { Tend. } \\
\text { Ruptura } \\
\text { Nível Sig. }\end{array}$ & $\begin{array}{l}\text { ns } \\
\text { ns } \\
\text { ns }\end{array}$ & $\begin{array}{l}\mathrm{ns} \\
\mathrm{ns} \\
\mathrm{ns}\end{array}$ & $\begin{array}{l}1989 \sim \\
1961 \sim \sim \\
0,0381\end{array}$ \\
\hline $\begin{array}{l}\text { Piracic. } \\
\text { Natural } \\
\text { Líquida }\end{array}$ & $\begin{array}{c}\text { Tend. } \\
\text { Ruptura } \\
\text { Nível Sig. }\end{array}$ & $\begin{array}{l}\mathrm{ns} \\
\mathrm{ns} \\
\mathrm{ns}\end{array}$ & $\begin{array}{l}\text { ns } \\
\text { ns } \\
\text { ns }\end{array}$ & $\begin{array}{l}\text { ns } \\
\text { ns } \\
\text { ns }\end{array}$ \\
\hline $\begin{array}{l}\text { Jaguari } \\
\text { Natural } \\
\text { Líquida }\end{array}$ & $\begin{array}{c}\text { Tend. } \\
\text { Ruptura } \\
\text { Nível Sig. }\end{array}$ & $\begin{array}{l}\text { ns } \\
\text { ns } \\
\text { ns }\end{array}$ & $\begin{array}{l}\text { ns } \\
\text { ns } \\
\text { ns }\end{array}$ & $\begin{array}{l}\text { ns } \\
\text { ns } \\
\text { ns }\end{array}$ \\
\hline $\begin{array}{l}\text { Jaguari } \\
\text { Medida } \\
\text { Líquida }\end{array}$ & $\begin{array}{c}\text { Tend. } \\
\text { Ruptura } \\
\text { Nível Sig. }\end{array}$ & $\begin{array}{l}1989 \sim \\
1967 \mathrm{~ns} \\
0,1771\end{array}$ & $\begin{array}{l}1984 \sim ~ \\
1967 \sim ~ \\
0,0432\end{array}$ & $\begin{array}{l}\text { ns } \\
\text { ns } \\
\text { ns }\end{array}$ \\
\hline $\begin{array}{l}\text { Camand. } \\
\text { Natural }\end{array}$ & $\begin{array}{c}\text { Tend. } \\
\text { Ruptura } \\
\text { Nível Sig. }\end{array}$ & $\begin{array}{l}\mathrm{ns} \\
\mathrm{ns} \\
\mathrm{ns}\end{array}$ & $\begin{array}{l}\text { ns } \\
\text { ns } \\
\text { ns }\end{array}$ & $\begin{array}{l}\text { ns } \\
\text { ns } \\
\text { ns }\end{array}$ \\
\hline $\begin{array}{l}\text { Atibaia } \\
\text { Natural }\end{array}$ & $\begin{array}{c}\text { Tend. } \\
\text { Ruptura } \\
\text { Nível Sig. }\end{array}$ & $\begin{array}{l}\text { ns } \\
\text { ns } \\
\text { ns }\end{array}$ & $\begin{array}{l}\text { ns } \\
\text { ns } \\
\text { ns }\end{array}$ & $\begin{array}{l}\text { ns } \\
\text { ns } \\
\text { ns }\end{array}$ \\
\hline $\begin{array}{l}\text { Atibaia } \\
\text { Medida }\end{array}$ & $\begin{array}{c}\text { Tend. } \\
\text { Ruptura } \\
\text { Nível Sig. }\end{array}$ & $\begin{array}{l}1979 \sim \sim \\
1967 \mathrm{~ns} \\
0,3109\end{array}$ & $\begin{array}{l}1975 \sim ~ \\
1967 \sim \\
0,0432\end{array}$ & $\begin{array}{l}\text { ns } \\
\text { ns } \\
\text { ns }\end{array}$ \\
\hline $\begin{array}{c}\text { Bacia toda } \\
\text { Natural }\end{array}$ & $\begin{array}{c}\text { Tend. } \\
\text { Ruptura } \\
\text { Nível Sig. }\end{array}$ & $\begin{array}{l}\text { ns } \\
\text { ns } \\
\text { ns }\end{array}$ & $\begin{array}{l}\text { ns } \\
\text { ns } \\
\text { ns }\end{array}$ & $\begin{array}{l}\text { ns } \\
\text { ns } \\
\text { ns }\end{array}$ \\
\hline
\end{tabular}


na precipitação nesse período. Curiosamente, apenas a bacia do Corumbataí foge a esse padrão, com tendência negativa levemente significativa, pelo teste de Mann-Kendall, com ponto de ruptura bem definido em 1961, pelo teste de Pettitt. O fato de esta série ter sido reconstituída, no período de 47 a 73 , pode ter influenciado neste resultado.

Nas análises utilizando a vazão trimestral medida, detectou-se, para o período úmido, uma tendência negativa com significância para as bacias do Jaguari e do Atibaia, iniciando, respectivamente, em 1984 e 1975 de acordo com o teste de Mann-Kendall. Esses anos estão relacionados ao ano de início da reversão de água: 1982 para o Jaguari e 1975 para o Atibaia (ver item 1.1). Para ambas o ponto de ruptura ocorreu em 1967. Este ponto pode tanto estar relacionado às ações antrópicas, como a construção das barragens, quanto ao comportamento da série de precipitação. O trimestre seco não apresenta tendência negativa, provavelmente pelo aumento na precipitação verificado nesse período, compensando parcialmente a retirada de água pelo Sistema Cantareira. Outro fator seria que a construção das barragens teria causado uma regularização ou melhor distribuição da vazão no ano.

Como apresentado no item 1.2, a demanda d'água para 1990 era de aproximadamente $27 \mathrm{~m}^{3} / \mathrm{s}$, dos quais $15 \mathrm{~m}^{3} / \mathrm{s}$ são uso consuntivo, isto é, não retornam diretamente ao rio. A vazão natural normal do rio Piracicaba em Artemis é de aproximadamente $90 \mathrm{~m}^{3} / \mathrm{s}$ no trimestre seco, que é o período mais crítico em termos de oferta de água. Durante o período estudado, um aumento em torno de $49 \mathrm{~mm}$ foi observado para a entrada d'água via precipitação, o que corresponde a $20 \mathrm{~m}^{3} / \mathrm{s}$. Destes, $70 \%$ retornam à atmosfera, ou seja, apenas $6 \mathrm{~m}^{3} / \mathrm{s}(30 \%)$ escoam para o rio, compensando parte da perda. Supondo que todos os $15 \mathrm{~m}^{3} / \mathrm{s}$ fossem realmente perdidos, apesar do maior aporte de precipitação, a perda líquida ainda seria de $9 \mathrm{~m}^{3} / \mathrm{s}\left(15 \mathrm{~m}^{3} / \mathrm{s}-6 \mathrm{~m}^{3} / \mathrm{s}\right)$, o que corresponde a $10 \%$ da vazão normal para esse período seco. Porém, apesar dessa compensação, nenhuma tendência estatisticamente significativa foi notada na vazão natural. 
Ao longo das últimas décadas houve um aumento do consumo de água e o conseqüente aumento do uso consuntivo, sendo sua previsão para o ano $2010 \mathrm{de} 23 \mathrm{~m} / \mathrm{s}$ (São Paulo, 1994). Se considerarmos o mesmo ganho de $6 \mathrm{~m}^{3} / \mathrm{s}$ através da precipitação, a perda seria de $17 \mathrm{~m}^{3} / \mathrm{s}\left(23 \mathrm{~m}^{3} / \mathrm{s}-6 \mathrm{~m}^{3} / \mathrm{s}\right)$, o que corresponde a quase duas vezes a de 1990 . Mantendo-se essa tendência, em breve seria possível notar um declínio na descarga natural do rio Piracicaba, causando provavelmente uma situação de excassez de água.

Deve-se salientar que esses valores desconsideram a retirada através do Sistema Cantareira, já que são referentes à vazão natural. Para as sub-bacias do Atibaia e Jaguari, a tendência de queda na vazão medida já pode ser sentida, como resposta a essa exportação de água interbacias. É de se esperar que o declínio nas demais sub-bacias possam ser detectados no futuro, caso não sejam tomadas medidas preventivas.

\subsubsection{Evapotranspiração}

A figura 3.5, é a plotagem dos dados gerados no capítulo anterior através do Método do Balanço Hídrico (tabela 2.7). A sub-bacia mais regular em relação à média da bacia toda é a do Camanducaia, que se manteve com valores superiores por quase todo o período analisado. Na verdade ela apresentou valores de precipitação acima da média, porém seus valores de vazão não foram muito maiores que os das demais (tabelas 2.5 e 2.6), causando valores de evapotranspiração anual média maiores. As demais sub-bacia se altenaram em torno da média da sub-bacia.

Como seria de se esperar, com um aumento significativo na precipitação e uma estacionariedade ou queda na vazão, a evapotranspiração deveria apresentar tendência positiva. De fato, a figura mostra a reta de regressão para a bacia toda com coeficiente angular positivo, aproximadamente igual a 6. Para as sub-bacias, de uma maneira geral, as 

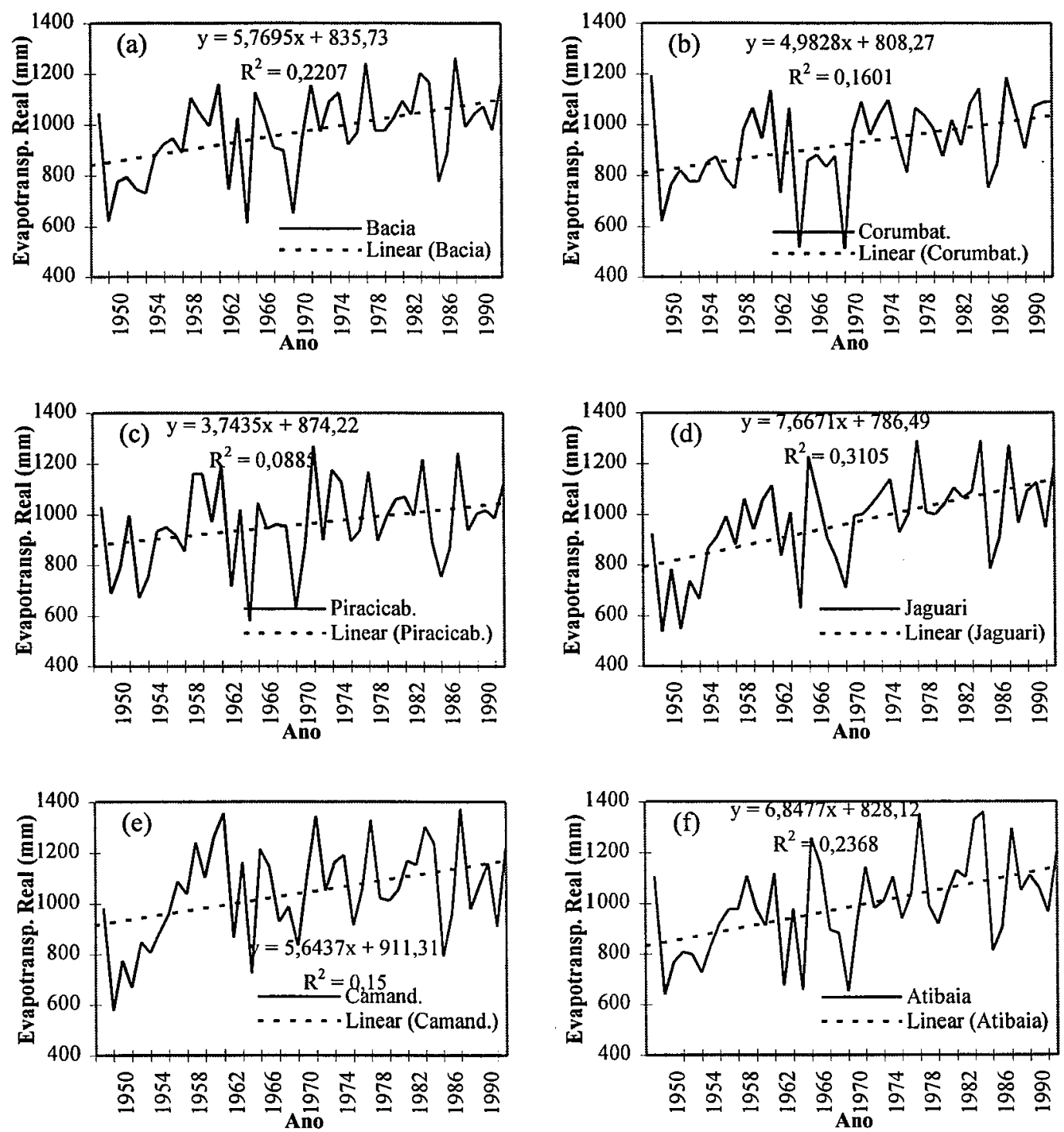

Figura 3.5 - Comportamento temporal das séries de evapotranspiração real an na bacia toda (a) e nas sub-bacias (b-f). A linha tracejada mostra a regressão linear para a série, associada à equação apresentada. 
Tabela 3.3 - Resultados obtidos pelo teste de análise de tendência de Mann-Kendall e pelo teste de mudança de médias de Pettitt para a evapotranspiração.São assinaladas as tendências positivas significativas e pontos de ruptura para os níveis de $5 \%\left(^{* *}\right), 10 \%\left({ }^{*}\right)$ e acima de $10 \%$ (ns). Quando as tendências foram significativas, os anos de ruptura foram apresentados, mesmo que não significativos.

\begin{tabular}{|c|c|c|c|c|}
\hline \multicolumn{2}{|c|}{ Bacia } & anual & tru & trs \\
\hline Corumb. & $\begin{array}{c}\text { Tend. } \\
\text { Ruptura } \\
\text { Nível Sig. }\end{array}$ & $\begin{array}{l}1976^{* *} \\
1968^{* *} \\
0,0128\end{array}$ & $\begin{array}{l}-- \\
-- \\
--\end{array}$ & -- \\
\hline Piracic. & $\begin{array}{c}\text { Tend. } \\
\text { Ruptura } \\
\text { Nivel Sig. }\end{array}$ & $\begin{array}{l}1991^{*} \\
1969 \mathrm{~ns} \\
0,2053\end{array}$ & $\begin{array}{l}-- \\
-- \\
--\end{array}$ & $\begin{array}{l}-- \\
-- \\
--\end{array}$ \\
\hline Jaguari & $\begin{array}{c}\text { Tend. } \\
\text { Ruptura } \\
\text { Nível Sig. }\end{array}$ & $\begin{array}{l}1957^{* *} \\
1969^{* *} \\
0,0048\end{array}$ & $\begin{array}{l}-- \\
-- \\
--\end{array}$ & $\begin{array}{l}-- \\
-- \\
--\end{array}$ \\
\hline Camand. & $\begin{array}{c}\text { Tend. } \\
\text { Ruptura } \\
\text { Nível Sig. }\end{array}$ & $\begin{array}{l}1955^{* *} \\
1954^{* *} \\
0,0432\end{array}$ & $\begin{array}{l}-- \\
-- \\
--\end{array}$ & $\begin{array}{l}-- \\
-- \\
--\end{array}$ \\
\hline Atibaia & $\begin{array}{c}\text { Tend. } \\
\text { Ruptura } \\
\text { Nível Sig. }\end{array}$ & $\begin{array}{l}1972 * * \\
1969^{* *} \\
0,0089\end{array}$ & $\begin{array}{l}-- \\
-- \\
--\end{array}$ & $\begin{array}{l}-- \\
-- \\
-\end{array}$ \\
\hline Bacia toda & $\begin{array}{c}\text { Tend. } \\
\text { Ruptura } \\
\text { Nível Sig. }\end{array}$ & $\begin{array}{l}1972 * * \\
1969 * * \\
0,0196\end{array}$ & $\begin{array}{l}-- \\
-- \\
--\end{array}$ & $\begin{array}{l}-- \\
-- \\
--\end{array}$ \\
\hline
\end{tabular}


retas de regressão possuem basicamente o mesmo coeficiente angular, ou seja, a mesma tendência positiva.

Os resultados dos teste de Mann-Kendall e de Pettitt (tabela 3.3) mostram todas as sub-bacias e também a bacia toda com tendência positiva, à excessão da sub-bacia do Piracicaba. Nesta, embora também haja tendência positiva, ela não chega a ser significativa. Nas sub-bacias do Corumbataí e Atibaia e na bacia toda, a tendência é positiva, passando a ser significativa por volta de 1973, com ponto de ruptura em 1968/1969. A bacia do Jaguari já começa a apresentá-la a partir do final da seca em 1955, mas seu pico de quebra ocorre em 1968/1969. Já a bacia do Camanducaia, apresenta como ponto de quebra mais importante a seca de 1951-1955, embora possua um ponto de quebra não significativo em 1968. Para a evapotranspiração não há dados trimestrais devido à inadequação do método utilizado a períodos menores que o anual, como já discutido no capítulo anterior.

Essa tendência de aumento da evapotranspiração, além do aumento na precipitação, deve estar relacionada ao uso do solo na região e a métodos de cultivo que tornem a água mais facilmente disponível à evapotranspiração. Caso contrário, se essas condições tivessem permanecido semelhantes, seria de se esperar um aumento na vazão em resposta ao aumento na precipitação. $\mathrm{O}$ aumento da área irrigada é um fator que poderia contribuir para isso, porém ela corresponde a somente 3\% da área total da bacia (SÃO PAULO, 1990).

Um melhor conhecimento das causas desse aumento na evapotranspiração deve ser objeto de estudos futuros, baseados na análise de mudanças no uso da terra e da cobertura vegetal através de sequiências de imagens de satélite. 


\section{Capítulo 4}

\section{Análise Espaço-Temporal}

A Análise de Componentes Principais Estandardizada foi empregada sobre as séries anuais de precipitação da bacia, como forma de estudar, simultaneamente, o seu comportamento tanto no espaço como no tempo. Procurou se detectar fatores influenciando a variabilidade e padrões espaço-temporais dos dados e também o agrupamento dos postos em regiões homogêneas.

\subsection{Breve Revisão Bibliográfica}

Como concluem EASTMAN \& MCKENDRY (1991), existe uma grande falta de técnicas estatísticas que possam lidar com eventos espaço-temporais e que apresentem coerência no espaço e no tempo simultaneamente. Porém, segundo eles, a Análise de Componentes Principais (ACP) apresenta possibilidades intrigantes, embora ainda haja muito a se desenvolver quanto à sua aplicação na análise de séries temporais e de mudanças climáticas.

ZULLO (1992) atribuiu a importância das técnicas multivariadas para a análise de 
dados climatológicos à sua capacidade de trabalhar com grande número de variáveis, como exige esse tipo de análise. Dentre essas técnicas, destaque especial foi dado à Análise de Componentes Principais (ACP), que o autor utilizou, aliada à análise de agrupamentos, para a deteç̧ão de padrões espaço-temporais de dados pluviométricos mensais do nordeste do Estado do Pará e para qüinquiídios do mês de setembro para todo o Estado de São Paulo.

Como se pode observar do trabalho de ZULLO (1992) e também, como sugeriu DYER (1975), a ACP pode ser utilizada em várias escalas espaciais e temporais. Esse último autor, com o intuito de reduzir o número de estações necessárias para utilização em modelos de previsão, utilizou a ACP para realizar a separação dos dados anuais de 154 estaç̃os pluviométricas do sul da África em regiões homogêneas e, dentro dessas regiões, escolher as mais representativas. $O$ autor conseguiu reduzir para 17 o número de estações representativas, estando elas dispersas pelas 10 regiões homogêneas delimitadas. Ainda em escala regional, PANDZIC \& TRNINIC (1992) aplicaram a ACP para os dados mensais de uma bacia de aproximadamente $58.000 \mathrm{~km}^{2}$ na Croácia, procurando relações entre fenômenos de descarga e precipitação de mesoescala e anomalias de pressão de macroescala. MOLTENI et al. (1983) analisaram dados diários de inverno da região norte da Itália, separados em médias de 3 e 5 dias, conseguindo detectar a influência de diferenças longitudinais, de anomalias orográficas e de diferentes padrões de circulação atmosférica na Europa, sobre a variabilidade dos dados.

Já em escala continental, LINS (1985) dispôs da ACP para o estudo de vazões anuais médias em todos os Estados Unidos, concluindo que as diferenças de latitude e as de longitude, além da continentalidade, são componentes importantes para a variabilidade dos dados. EASTMAN \& FULK (1993) estudaram o comportamento do índice de vegetação por diferença normalizada (NDVI) de uma série de 36 meses (1986-1988) de imagens do satélite oceanográfico NOAA-9 para toda a África, utilizando a ACP estandardizada. A partir dela, detectaram o comportamento padrão e a influência das 
estações do ano e do dipolo norte-sul, e também da Zona de Convergência Intertropical (ZCIT) e do fenômeno El Niño-Oscilação Sul (ENOS), sobre esse índice e sobre regiões específicas, cada componente sucessivo descrevendo um efeito cada vez mais localizado. Os autores destacaram a eficiência do método em isolar efeitos sazonais de grande escala, tendências nos valores e na variabilidade, e eventos anômalos, sendo uma poderosa ferramenta para aplicação em sensoriamento remoto e SGI.

Na bacia Amazônica, OBREGON \& NOBRE (1990) aplicaram a ACP com componentes rotacionados sobre dados mensais de precipitação de 28 estações. Além dos valores observados, utilizaram também a remoção do ciclo anual, encontrando padrões espaciais relacionados também ao dipolo norte-sul de máximas precipitações, à migração sazonal da ZCIT e ao ENOS. Na região sul da bacia observaram a existência da influência do ciclo sazonal da Zona de Convergência do Atlântico Sul. HIEZ et al. (1991) também utilizaram o método da ACP na análise pluviométrica anual da bacia. A técnica lhes permitiu detectar padrões espaciais de comportamentos para toda a região, destacando também a influência da ZCIT e da continentalidade sobre ela, embora esses autores discutam pouco a sua evolução temporal.

Com base nos trabalhos citados acima, pode se destacar algumas características importantes da ACP como, por exemplo, a variedade de escalas temporais em que pode ser aplicada, desde a anual (DYER, 1975; LINS, 1985; e HIEZ ET AL., 1991), passando pela mensal (ZULLO, 1992; PANDZIC \& TRNINIC, 1992; EASTMAN \& FULK, 1993; e OBREGON \& NOBRE, 1990), até à diária ou de qüinqüídios (ZULLO, 1992; e MOLTENI ET AL., 1983).

Outra característica dessa análise é a multiplicidade de formas com que ela pode ser empregada. A escolha da matriz inicial de dispersão dos dados, que é o primeiro passo para 
se realizar a análise, é um exemplo, sendo um aspecto importante apontado por ZULLO (1992). Pode se utilizar a matriz de covariância, que mantém a magnitude real das variâncias, ou a matriz de correlação, que pondera igualmente todas as variáveis, pois os dados originais são normalizados. Segundo o autor, o uso desta última é mais adequado para estudos meteorológicos nos quais as variáveis originais possuem unidades diferentes, ou quando são na mesma unidade, mas, com escalas de variabilidade muito distintas, como é o caso dos dados mensais ao longo do ano. A grande maioria dos trabalhos meteorológicos descritos aqui utilizam a matriz de correlação, ou seja, utilizam a ACP estandardizada. Alguns exemplos são os trabalhos de ZULLO (1992), PANDZIC \& TRNINIC (1992) e EASTMAN \& FULK (1993). Outro tipo de matriz é a de produtos cruzados, que incorpora tanto informações da média como da variabilidade de cada variável, utilizada por MOLTENI et al. (1983).

Outra opção da ACP é a utilização ou não de rotações ou transformações lineares dos autovetores, que é utilizada por autores como OBREGON \& NOBRE (1990) e MOLTENI et al. (1983), porém é combatida por LINS (1985), que não vê necessidade nem justificativa para ela, pois elimina as suas propriedades de máxima variância e de ortogonalidade.

Assim, optou-se neste trabalho pela utilização da ACP estandardizada, ou seja, utilizando como variáveis de estudo os postos distribuídos pela bacia, optou-se pelo emprego da matriz de correlação sem rotação.

\subsection{Método Utilizado na Análise Espaço-Temporal}

Segundo LINS (1985), o propósito da ACP é identificar a característica, recorrência e independência dos módulos de covariância entre variáveis dentro do grupo de dados. Isso 
pode ser alcançado pela transformação do grupo de variáveis originais, intercorrelacionadas, em um novo sistema de coordenadas, no qual os eixos são combinações lineares da variabilidade original e são mutuamente descorrelacionados. Esse autor e também PANDZIC \& TRNINIC (1992) descreveram como vantagens dessa análise, além da eliminação da dependência entre as variáveis:

- a redução das variáveis a um número fisicamente significante sẹm a perda significativa da informação contida na variabilidade dos dados, removendo ruídos ou componentes estocásticos e determinando padrões em grandes grupos de dados; - a sua eficiência na compressão dos dados, já que os primeiros componentes explicam uma grande porcentagem da variância dos dados (propriedade essa usada também na compressão de imagens orbitais com várias bandas como descrito por CRÓSTA (1993) e por CRACKNELL \& HAYES (1991));

- a possibilidade de explicação das causas físicas influenciando a variância e a covariância manifestada pelos dados; $\mathrm{e}$

- a possibilidade de regionalização espacial e o mapeamento dos padrões espaçotemporais dos dados.

Estas duas últimas qualidades foram as buscadas neste trabalho com o emprego dessa técnica.

\subsubsection{A Análise de Componentes Principais Estandardizada (ACPE)}

A ACPE baseia-se fundamentalmente na determinação dos autovalores e autovetores de uma matriz de correlação $(\mathrm{R})$ das variáveis originais. Neste estudo, as variáveis foram os postos distribuídos por toda a bacia, sendo os anos considerados como repetições ou observações. 
Os autovalores, de uma matriz quadrada e simétrica $N x M(N=M)$ qualquer, podem ser obtidos através de dois passos: a subtração de uma variável $\lambda$ de cada termo da sua diagonal principal (todo $r_{n, m}$ tal que $n=m$ ), o que produz como determinante da matriz um polinômio de ordem $m$; e a extração das $m$ raízes desse polinômio, que são propriamente os autovalores da matriz. Esses dois passos são exemplificados pelas expressões abaixo:

$$
R=\begin{array}{cccc}
r_{1,1}-\lambda & r_{1,2} & \ldots & r_{1, m} \\
r_{2,1} & r_{2,2}-\lambda & \ldots & r_{2, m} \\
\ldots & \ldots & & \ldots \\
r_{n, 1} & r_{n, 2} & \ldots & r_{n, m}-\lambda
\end{array}
$$

onde $\mathrm{R}$ é a matriz de correlação com o valor de $\lambda$ subtraído da sua diagonal principal, cujo determinante (D) é dado por:

$$
D=a * \lambda^{m}+b * \lambda^{m-1}+\ldots+z * \lambda^{0}
$$

onde $\quad a, b$ e $z$ são fatores de multiplicação e $m$ igual à ordem da matriz.

Extraídas e ordenadas de forma crescente as raízes $\lambda_{i}(i=1,2,3 \ldots, m)$, ou seja, os autovalores, tem-se $\lambda_{1} \geq \lambda_{2} \geq \ldots \geq \lambda_{\text {h }} \geq 0$. Substitui-se cada um deles em (4.1) para estimativa dos autovetores. O primeiro passo é, a partir do sistema de equações:

$$
\begin{aligned}
& \begin{array}{llllll}
r_{1,1}-\lambda_{i} & r_{1,2} & \ldots & r_{1, m} & u_{1} & 0
\end{array} \\
& \begin{array}{llllll}
r_{2,1} & r_{2,2}-\lambda_{i} & \cdots & r_{2, m} & * & u_{2}
\end{array}=0 \\
& \begin{array}{cccccc}
\cdots & \cdots & \cdots & \cdots & \cdots \\
r_{n, 1} & r_{n, 2} & \ldots & r_{n, m}-\lambda_{i} & u_{m} & 0
\end{array}
\end{aligned}
$$


obter os valores de $u_{i}$ que o satisfaçam, para cada substituição de $\lambda$. Cada conjunto de valores $e_{i}^{\prime}=\left[\mathrm{u}_{1 \mathrm{i}}, \mathrm{u}_{2 \mathrm{i}}, \ldots, \mathrm{u}_{\mathrm{mi}}\right]$ ( ' denota a transposição da matriz), correspondente a cada uma destas substituições, é um autovetor da matriz de correlação original.

Os componentes principais são combinações lineares como

$$
\begin{aligned}
& Y_{1}=e_{1}^{\prime} * Z=u_{11} * z_{1}+u_{21} * z_{2}+\ldots+u_{m 1} * z_{m} \\
& Y_{2}=e_{2}^{\prime} * Z=u_{12} * z_{1}+u_{22} * z_{2}+\ldots+u_{m 2} * z_{m} \\
& Y_{m}=e_{m}^{\prime} * Z=u_{1 m} * z_{1}+u_{2 m} * z_{2}+\ldots+u_{m m} * z_{m}
\end{aligned}
$$

tais que $\mathrm{Y}_{1}, \mathrm{Y}_{2}, \ldots, \mathrm{Y}_{\mathrm{m}}$ sejam totalmente descorrelacionadas entre si e cujas variâncias sejam as maiores possíveis. $\mathrm{Z}$ é a matriz de dados observados normalizados. Assim, o primeiro componente principal $\left(\mathrm{Y}_{1}\right)$ é a combinação linear que apresenta máxima variância, ou seja, a que maximiza $\operatorname{Var}\left(e_{1}^{\prime} Z\right.$ ) desde que satisfaça à condição $e_{1}^{\prime} e_{1}=1$ (que é igual à soma dos quadrados de $\left.u_{m 1}\right)$. O i-ésimo componente é aquele que maximiza $\operatorname{Var}\left({ }_{i} e^{\prime} Z\right)$ desde que satisfaça às condições $e_{\mathrm{i}}^{\prime} e_{\mathrm{i}}=1 \mathrm{e} \operatorname{Cov}\left(\boldsymbol{e}_{\mathrm{i}}^{\prime} \mathrm{Z}, \boldsymbol{e}_{\mathrm{k}}^{\prime} \mathrm{Z}\right)=0$ para qualquer $\mathrm{k}<\mathrm{i}$.

A importância ou representatividade de cada componente $\mathrm{Y}_{\mathrm{i}}$ é expressa pelo autovalor $\lambda_{\mathrm{i}}$ associado a ele, isto é, a proporção da variância total da população que é devida ao i-ésimo componente é dada por $\lambda_{\mathrm{i}}$, tal que:

$$
\begin{aligned}
& \text { Proporção da variân- } \\
& \text { cia total da população } \\
& \text { devida ao i-ésimo }=\frac{i}{\lambda_{h}} \\
& \quad \text { componente }
\end{aligned}
$$


pois,

$$
\text { Variância total da população }=\lambda_{1}+\lambda_{2}+\ldots+\lambda_{m}=m
$$

Se a maioria (em torno de 80 ou 90\%) da variância total da população pode ser atribuída aos dois ou três primeiros componentes, então esses componentes podem substituir as $m$ variáveis originais sem muita perda de informação. Ainda, os coeficientes $\mathrm{u}_{\mathrm{mi}}$ do autovetor $e_{i}^{\prime}$ também devem ser investigados, pois eles expressam a importância da variável $\mathrm{k}$ qualquer, para o i-ésimo componente. Isso porque o $\mathrm{u}_{\mathrm{ki}}$ é proporcional ao coeficiente de correlação entre $Y_{i}$ e $Z_{k}$. A equação abaixo mostra essa relação:

$$
\rho_{Y_{i}, Z_{k}}=u_{k i} \sqrt{\lambda_{i}} \quad i, k=1,2, \ldots, m
$$

onde $\rho_{\mathrm{Yi}, \mathrm{Zk}}$ é o coeficiente de correlação entre o componente $\mathrm{Y}_{\mathrm{i}}$ e a variável $\mathrm{k}$.

Uma descrição mais detalhada e com maior rigor estatístico, incluindo provas matemáticas para as expressões acima, podem ser encontradas em vários livros-textos como JOHNSON \& WICHERN (1982), DAVIS (1973), LAGARDE (1983) e PIMENTEL (1979).

Neste trabalho se utilizou os produtos da ACPE na análise do padrão espacial e temporal das séries de anuais de precipitação e na tentativa de explicitar algum fator influente sobre a sua variabilidade. Para obtê-los adaptou-se o programa em Fortran apresentado por DAVIS (1973). Como o padrão espacial e temporal da evapotranspiração real, da forma calculada aqui pelo $\mathrm{MBH}$, sofre muita influência do padrão espacial da vazão e também é função direta e simples da precipitação, a ACPE foi aplicada somente sobre esta última. 


\subsection{Resultados e sua Discussão}

\subsubsection{Análise Espaço-Temporal}

A tabela 4.1 e a figura 4.1 representam as porcentagens da variância total dos dados normalizados explicadas por cada um dos componentes, através de seu autovalor, de acordo com a equação (4.5). Segundo ZULLO (1992), embora não haja um método estabelecido para a retenção dos componentes, normalmente ela é feita até que a soma da variabilidade explicada por eles totalize aproximadamente $75 \%$. Ou então, simplesmente se retém os dois ou três primeiros componentes, desde de que eles expliquem uma proporção satisfatória da variabilidade total. Aqui, esse valor foi alcançado em torno do terceiro componente.

Na figura 4.2 estão apresentados apenas os resultados obtidos para os três primeiros componentes principais. Essas séries temporais representam três novas variáveis, responsáveis mais de $80 \%$ da variabilidade dos dados originais. As linhas tracejadas foram obtidas de acordo com a forma utilizada por JOLLIFFE (1986) e ZULLO (1992), e representam limites cujo valor é dado pela metade do valor absoluto do maior coeficiente. Os períodos que apresentarem valores absolutos maiores ou menores que esse limites, num determinado componente, são destacados, estando direta ou inversamente relacionados a tal componente, respectivamente. Cabe a quem analisa encontrar quais são os fatores, influenciantes sobre as variáveis originais, que apresentam comportamento temporal e espacial semelhantes a cada componente.

Como se pode ver na figura 4.2, o primeiro componente é o vetor característico, expressando o comportamento médio do conjunto de todos os postos ao longo dos anos. Segundo EASTMAN (1993) esse componente quase sempre representa o comportamento característico dos dados. Sendo assim, por definição ele deve estar correlacionado, da 
Tabela 4.1 - Autovalores e as porcentagens de variância explicada, simples e acumulada.

\begin{tabular}{|c|c|c|c|}
\hline & Autovalor & $\%$ & $\%$ acum. \\
\hline 1 & 24,726 & 74,93 & 74,93 \\
\hline 2 & 1,202 & 3,64 & $\mathbf{7 8 , 5 7}$ \\
\hline 3 & 1,054 & 3,19 & 81,76 \\
\hline 5 & 0,910 & 2,76 & 84,52 \\
\hline 6 & 0,709 & 2,15 & 86,67 \\
\hline 7 & 0,590 & 1,79 & 88,46 \\
\hline 8 & 0,499 & 1,51 & 89,97 \\
\hline 9 & 0,415 & 1,26 & 91,23 \\
\hline 10 & 0,333 & 1,01 & 92,24 \\
\hline 11 & 0,315 & 0,96 & 93,19 \\
\hline 13 & 0,274 & $\mathbf{0 , 8 3}$ & 94,02 \\
\hline 14 & 0,255 & 0,77 & 94,79 \\
\hline 15 & 0,230 & $\mathbf{0 , 7 0}$ & 95,49 \\
\hline 17 & 0,217 & 0,66 & 96,15 \\
\hline 18 & 0,201 & 0,61 & 96,76 \\
\hline 19 & 0,172 & 0,52 & 97,28 \\
\hline 20 & 0,138 & 0,42 & 97,70 \\
\hline 22 & 0,122 & 0,37 & 98,07 \\
\hline 25 & 0,114 & 0,35 & 98,41 \\
\hline 26 & 0,095 & 0,29 & 98,70 \\
\hline 27 & 0,088 & 0,27 & 98,97 \\
\hline 31 & 0,073 & 0,22 & 99,19 \\
\hline 32 & 0,060 & 0,18 & 99,37 \\
\hline 33 & 0,056 & 0,17 & 99,54 \\
\hline 36 & 0,039 & 0,12 & 99,66 \\
\hline 40 & 0,032 & 0,10 & 99,75 \\
\hline 41 & 0,022 & 0,07 & 99,82 \\
\hline 42 & 0,018 & 0,06 & 99,87 \\
\hline 45 & 0,014 & 0,04 & 99,92 \\
\hline 46 & 0,012 & 0,04 & 99,95 \\
\hline 48 & 0,009 & 0,03 & 99,98 \\
\hline 49 & 0,006 & 0,02 & 100,00 \\
\hline 55 & 0,001 & 0,00 & 100,00 \\
\hline
\end{tabular}

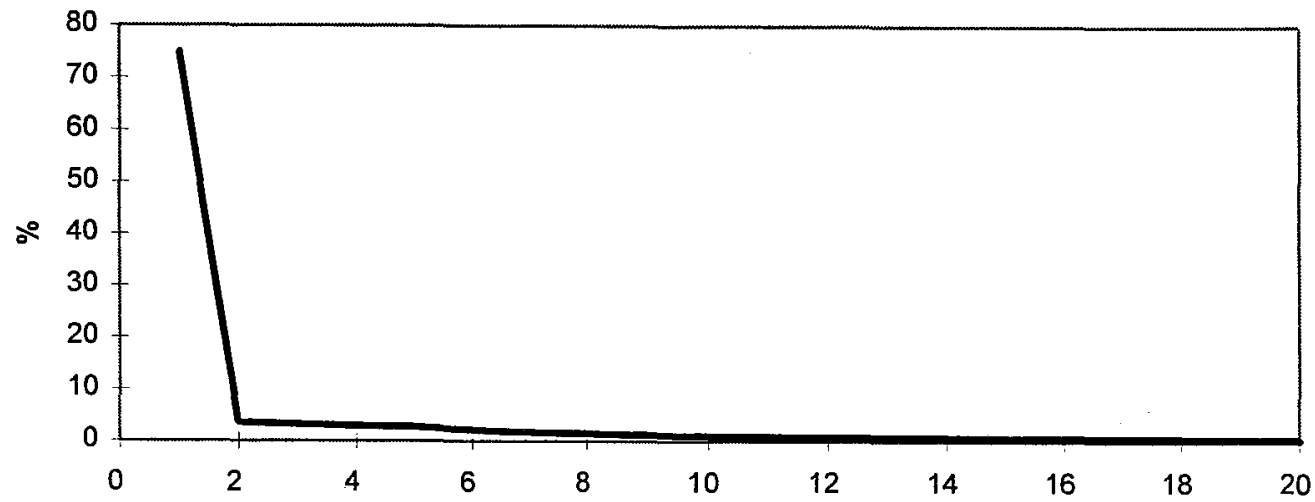

Figura 4.1 - Variação total explicada pelos 20 primeiros autovalores (\%). 

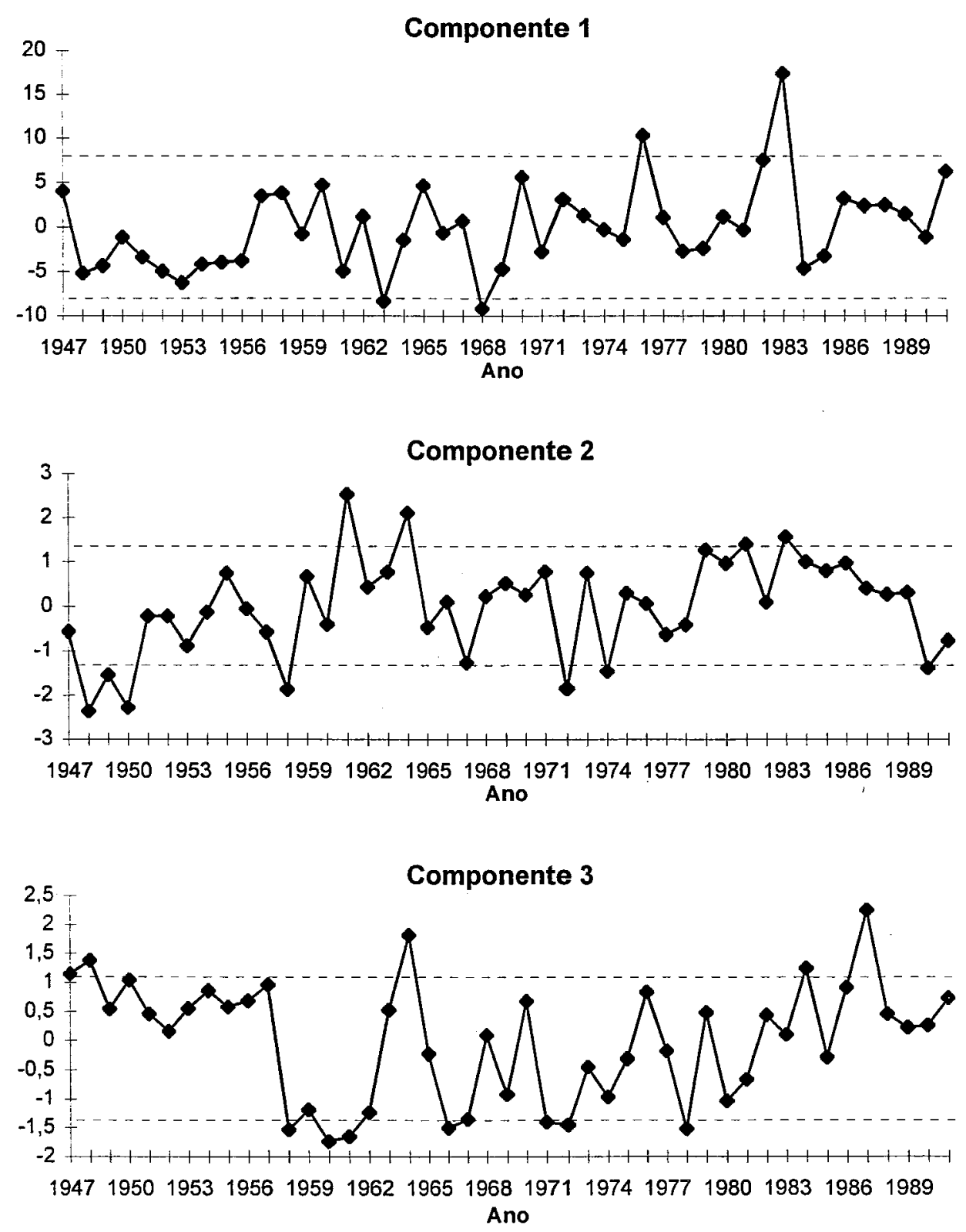

Figura 4.2 - Distribuição temporal dos três primeiros componentes principais gerados pela ACPE. 
melhor forma possível e com aproximadamente a mesma intensidade, a todas variáveis, ou postos. Espacialmente, isso pode ser observado na figura 4.3, que apresenta a pequena variação e os valores sempre positivos de $e^{\prime}$.

O segundo componente apresenta uma variação temporal interessante. Parece haver grupos de valores ora mais positivos, ora mais negativos. Procurando separar esses grupos, pode se chegar a um período de aproximadamente dez ou doze anos. Uma componente climática que pode exercer influência sobre a precipitação e com um ciclo nessa escala, é a atividade solar.

A figura 4.4(a) mostra a plotagem simultânea do segundo componente e da atividade solar. Essas duas séries aparentemente são inversamente correlacionadas, excetuando-se o período entre 1968 e 1982, que se apresenta conturbado. Porém, atentando-se para a grandeza dos valores das duas séries, na verdade parece haver um deslocamento entre o componente $2 \mathrm{e}$ a atividade solar. $\mathrm{O}$ deslocamento de melhor ajuste foi o de menos cinco anos para o componente 2 (figura 4.4 (b)), ou seja, o valor do componente 2 está melhor correlacionado com o valor de atividade solar de cinco anos atrás, mais uma vez excetuando o período conturbado de 1968 a 1982. Para este mesmo período aproximadamente, PINTO ${ }^{1}$ também encontrou esse comportamento conturbado ao estudar a correlação entre a atividade solar e a temperatura mínima anual para a cidade de Campinas.

A interpretação possível para esse deslocamento seria que a atividade solar ocorrida em determinado ano, somente influenciaria a precipitação de cinco anos depois. Esta suposição parece imprópria se baseada apenas nos dados disponíveis aqui. Além disso, mesmo assumindo como aceitável esse deslocamento, existe ainda o complicador de que invariavelmente os pontos de pico do componente 2 , tanto de mínimos quanto de máximos,

'PINTO, H.S. (Centro de Ensino e Pesquisa em Agricultura/UNICAMP, Campinas, SP) Comunicação pessoal, 


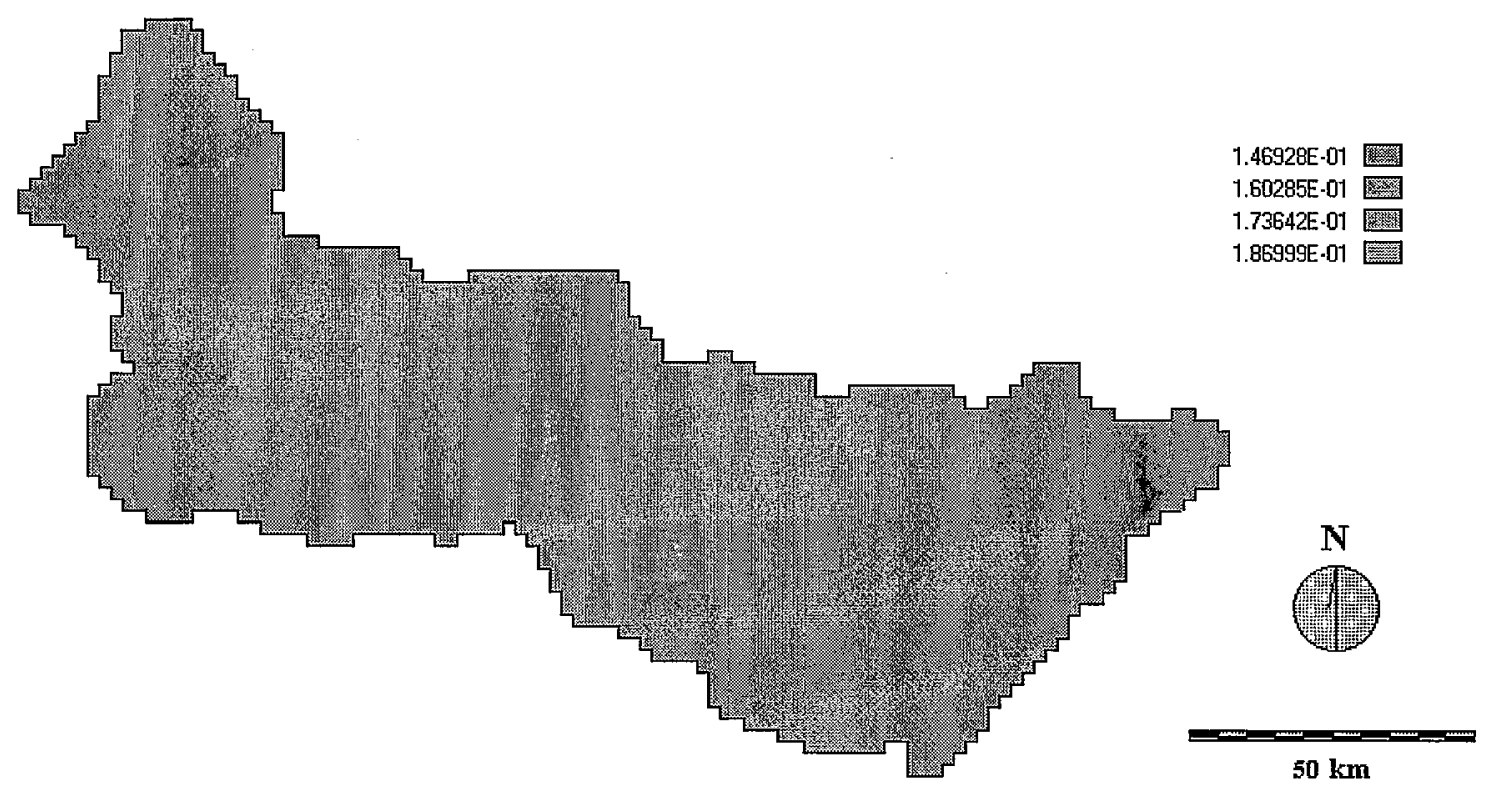

Figura 4.3 - Distribuição espacial do primeiro componente gerado pela ACPE. 
(a)

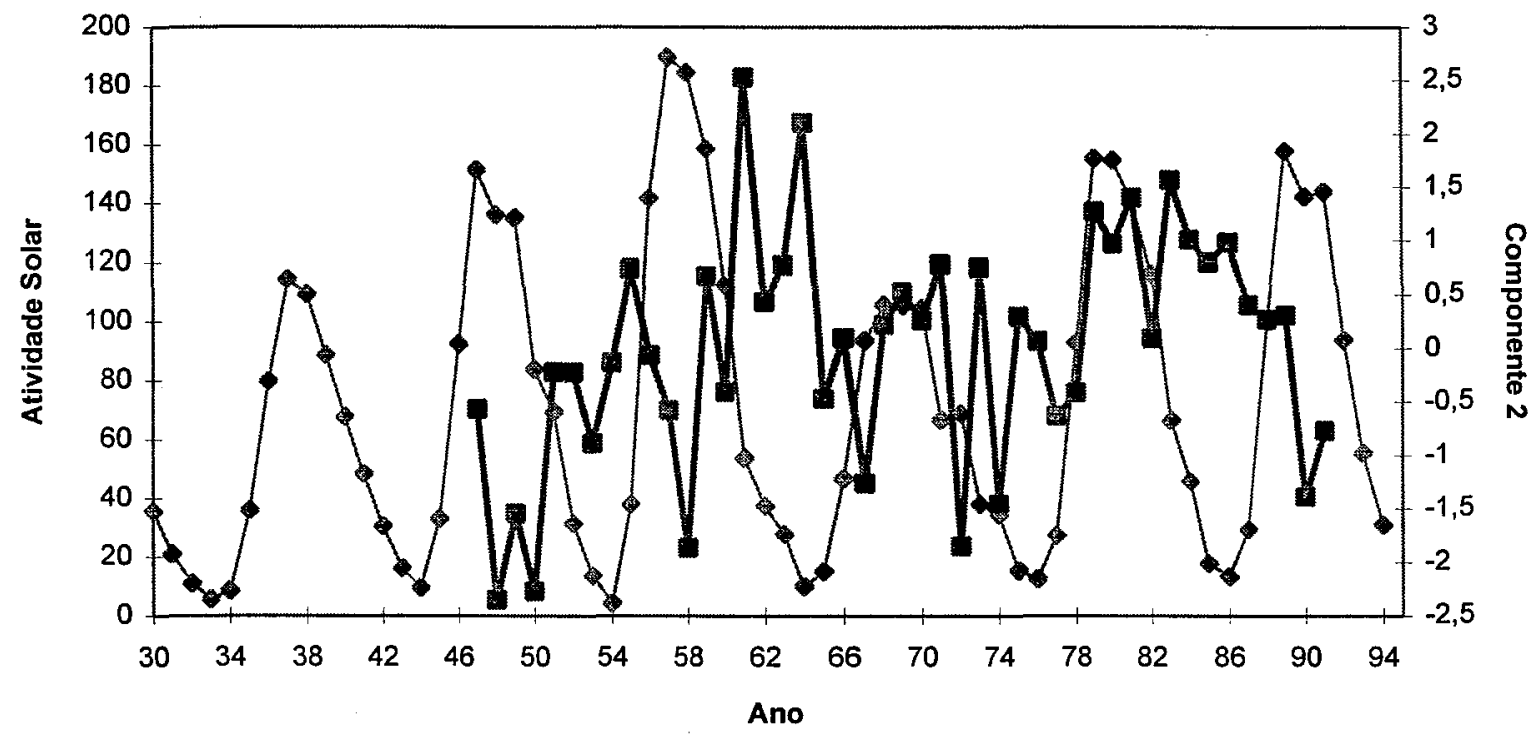

(b)

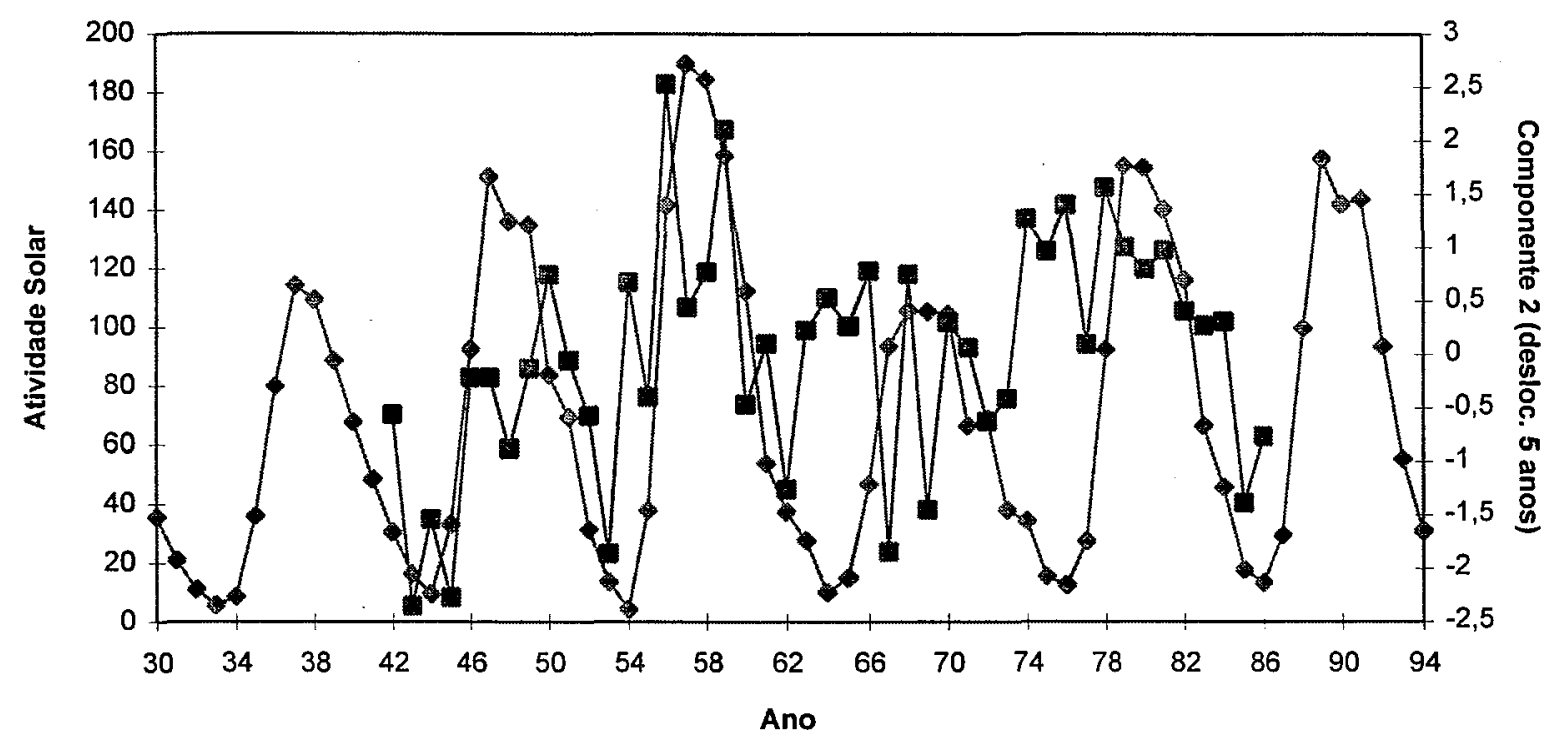

Figura 4.4 - Comparação entre o segundo componente e a atividade solar (a). Abaixo (b), o segundo componente foi deslocado de $\mathbf{- 5}$ anos. 
1995.

estão invertidos em relação à atividade solar, sugerindo alguma interferência ou sub-ciclo.

Ainda assim, mesmo diante de todas essas ressalvas, pode se concluir que a atividade solar exerce influência sobre a precipitação, hipótese reforçada pelos trabalhos de KING (1975) (que traz uma imensa lista de trabalhos dedicados ao tema "Relações Solclima"), de WILCOX (1975). Além desses, STOZKOV et al. (1994a e 1994b) (realizados em conjunto com a equipe do CEPAGRI/UNICAMP) realizaram estudos sobre a influência de explosões solares sobre a precipitação diária nos Estados de São Paulo e Ceará, encontrando boa correlação. Um estudo mais aprofundado e detalhado a respeito dessa influência sobre os parâmetros meteorológicos/climáticos da bacia do rio Piracicaba seria bastante interessante.

A figura 4.5 mostra o padrão espacial para o segudo componente. Nela se observa a orientação das isolinhas no sentido sudoeste-nordeste, principalmente na região central da bacia, com correlação positiva maior no extremo leste, no início da serra, e negativa no extremo oeste. Esse padrão espacial é muito parecido com o do trimestre seco (capítulo 2), no qual a influência das frentes-frias que se deslocam pelo oceano é tanto mais fraca quanto maior a continentalidade. $\mathrm{O}$ segundo componente então, além da atividade solar, está relacionado à influência das frentes frias de inverno (que também estão relacionadas às temperaturas mínimas anuais estudadas por PINTO,citado acima) sobre a precipitação.

O comportamento temporal a partir do terceiro componente não permitiu uma associação rápida com nenhuma outra variável que pudesse estar influenciando a precipitação na bacia de maneira geral. Espacialmente porém, no terceiro componente (figura 4.6), uma correlação positiva predomina sobre a região centro-sul da bacia. Uma correlação negativa é observada nas regiões de serra. A figura mostra, de maneira muito fiel, o processo de entrada de frentes polares do trimestre úmido, com distribuição das isolinhas 


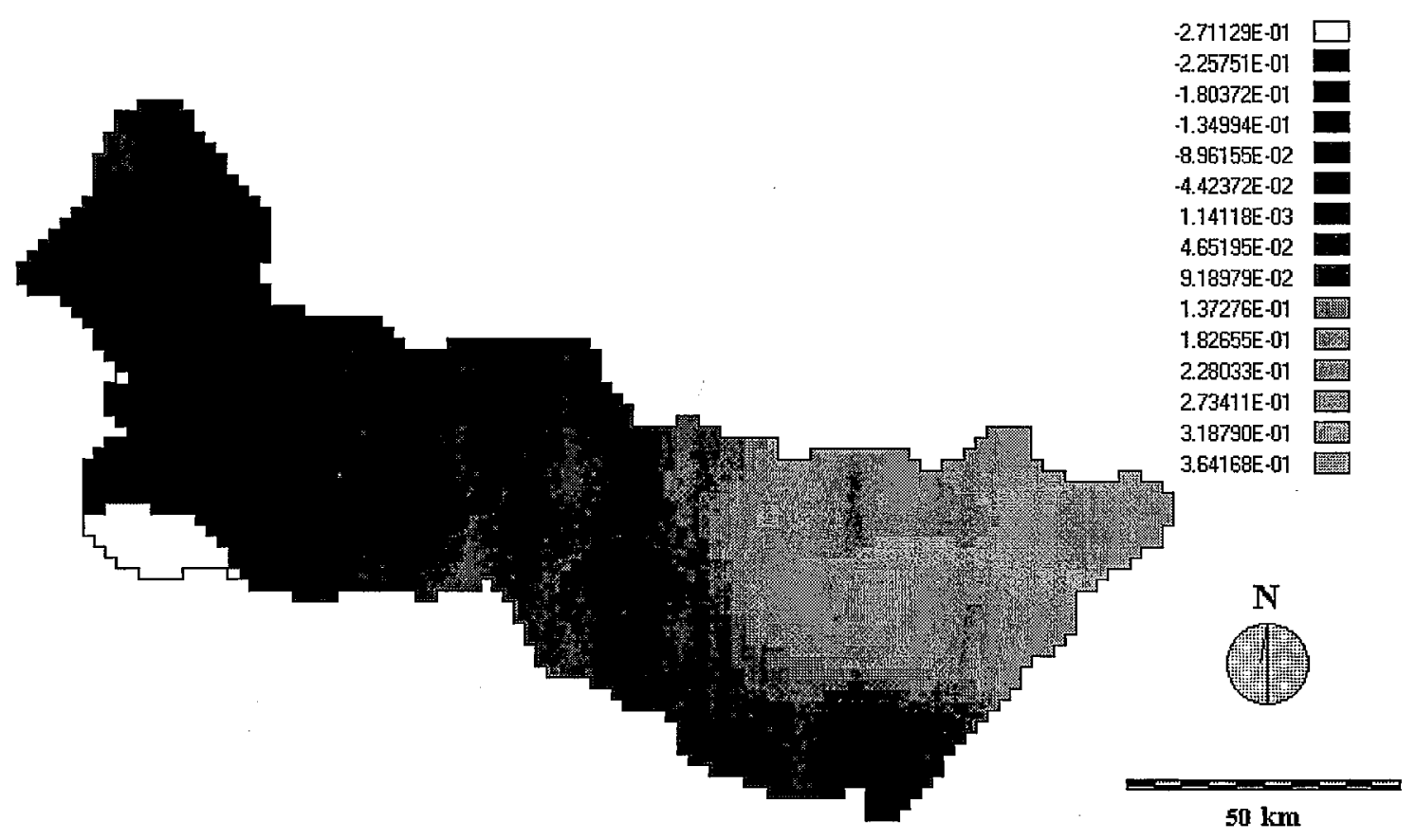

Figura 4.5 - Distribuição espacial do segundo componente gerado pela ACPE. 


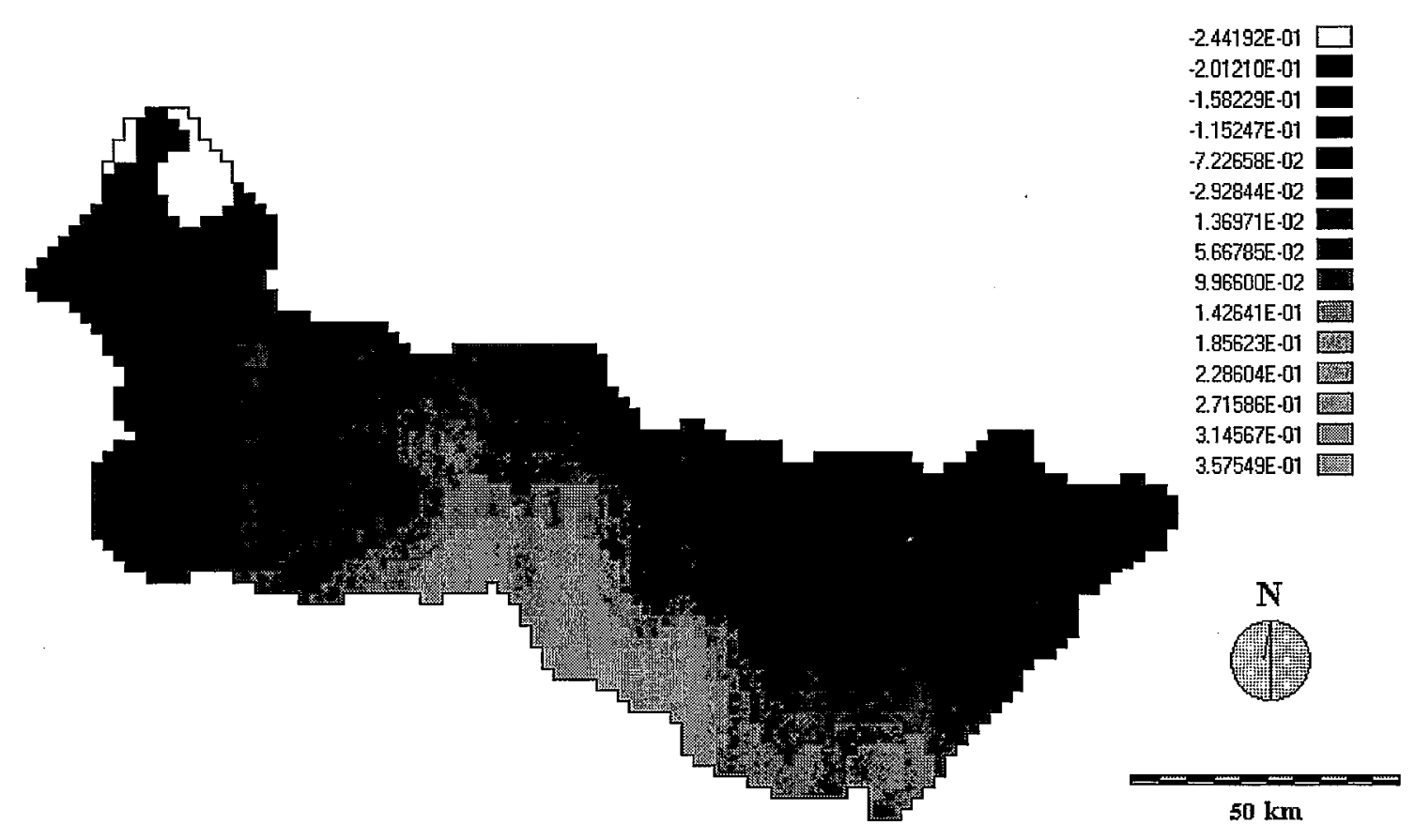

Figura 4.6 - Distribuição espacial do terceiro componente gerado pela ACPE. 
no sentido noroeste-sudeste. Como descrito por FENTRAN FILHO (1982), esse deslocamento se dá preferencialmente por via continental (capítulo 2), sendo facilitado pela depressão periférica, e delimitado pela serra da Mantiqueira a leste, e pela região escarpada a oeste da bacia. Esse componente deve, portanto, estar inversamente relacionado à atuação dessas massas de ar com deslocamento continental.

Os demais componentes, espacialmente, parecem destacar fenômenos mais locais, como analisam EASTMAN \& FULK (1993). Eles são porém de difícil reconhecimento e análise, não se conseguindo uma interpretação clara. Entretanto, esses três primeiros componentes são muito semelhantes aos três primeiros encontrados por ZULLO (1992) para o Estado de São Paulo.

\subsubsection{Análise de Agrupamentos}

Outra característica importante da ACP, como já citado, é a possibilidade de agrupamento das variáveis originais ou postos. Cada componente representa uma nova variável, que explica a maior parte possível da variância dos dados, e apresenta um valor $\mathrm{u}_{\mathrm{mi}}$ de correlação entre ele e cada posto $\mathrm{m}$. Com base nos usada no agrupamento é a plotagem de um diagrama cartesiano, com o primeiro e o segundo componentes. Os postos que apresentarem valores semelhantes para a combinação ângulo/distância, em relação a um ponto central, podem ser agrupados e considerados com comportamento semelhante quanto a esses componentes, ao longo de toda a série.

A figura 4.7(a) mostra essa plotagem e a delimitação de cinco grupos. Pode se notar que um dos postos não se encaixa bem a nenhum grupo, porém ele é pouco expressivo, exercendo apenas uma pequena influência no processo de interpolação, como posto vizinho. Por essa razão ele não foi encarado como um grupo à parte e nem fez parte de um outro 
(a)
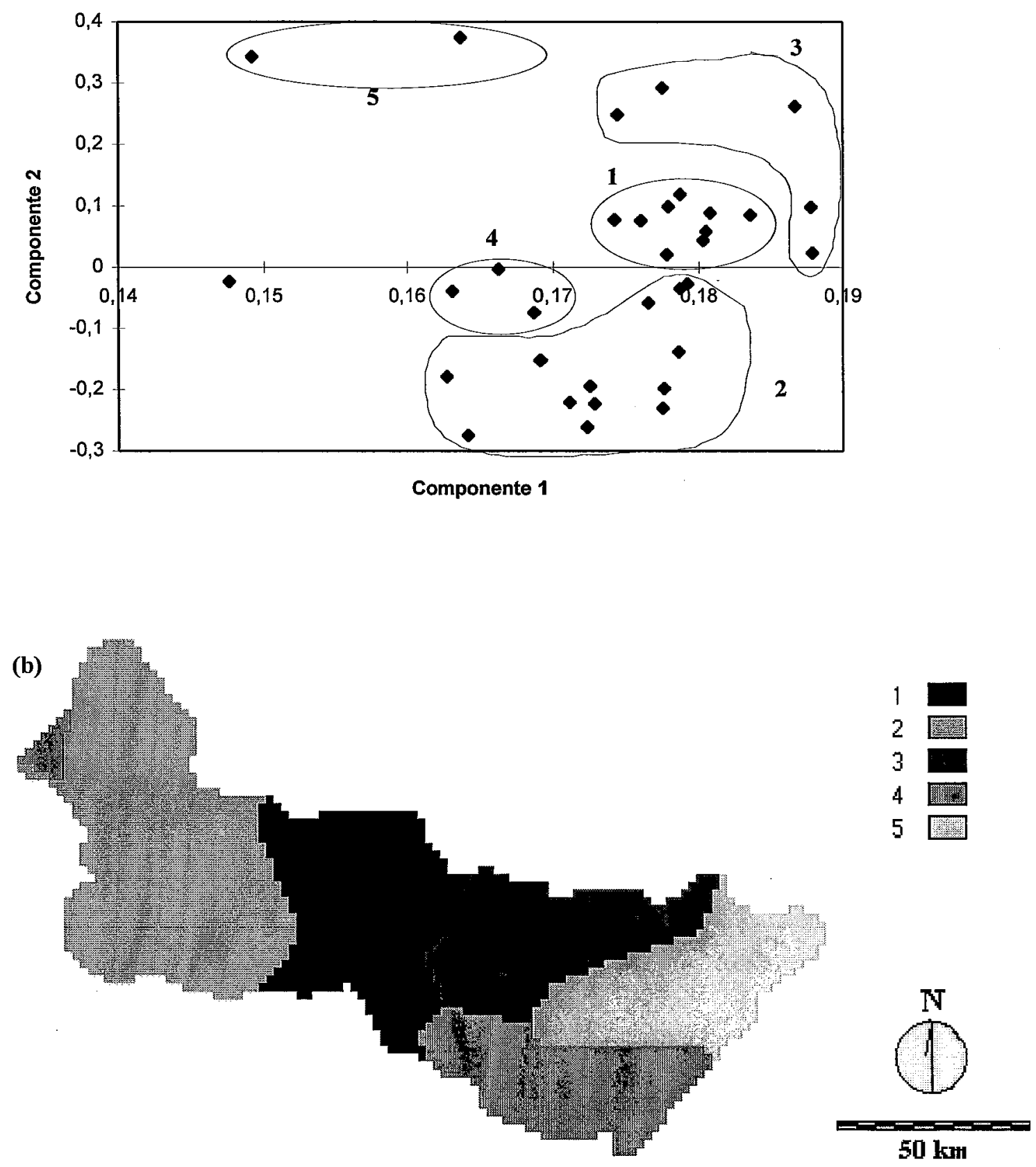

Figura 4.7 - Representação simultânea do primeiro e segundo componentes (a). As regiões delimitadas pelos polígonos representam os grupos obtidos. Abaixo (b), esses grupos estão representados sobre a bacia. 
grupo.

A figura 4.7(b), que representa a distribuição espacial desses grupos na bacia, é coerente com o comportamento das séries dos postos e tem um aspecto muito interessante, pois lembra muito a divisão de sub-bacias adotada, embora a precipitação não tenha necessariamente nenhuma relação com essa divisão de sub-bacias. Concorda, inclusive, com a discussão sobre a separação da sub-bacia do Jaguari em duas, apresentada no capítulo 2. Faz também uma separação da região da sub-bacia do Piracicaba. É curiosa também, a similaridade entre os postos da sub-bacia do Atibaia, no início da serra da Mantiqueira, e um posto, também situado num início de serra, a oeste da sub-bacia do Corumbataí. 


\section{Capítulo 5}

\section{Conclusões}

Procurou se fazer aqui uma síntese das principais observações obtidas pela análise e discussão dos resultados dos capítulos anteriores. Fez-se, preliminarmente, uma avaliação dos métodos utilizados e posteriormente, uma exposição das principais conclusões que puderam ser obtidas a partir de sua aplicação.

Neste trabalho procurou se utilizar algumas ferramentas disponíveis ao mapeamento e à análise temporal de dados hidrológicos, particularmente sobre as séries temporais da bacia do rio Piracicaba, com o objetivo de conhecer seu comportamento ao longo do período de 1947 a 1991. Está distante, porém, de ser uma análise completa e exaustiva sobre as técnicas utilizadas com esses fins e também está distante de esgotar o estudo sobre esse comportamento. Ao contrário disso, este trabalho procurou trazer à discussão algumas questões sobre as características hidrológicas da bacia, destacadas através dessas técnicas. Assim, guiando-se por esse objetivo e analisando os resultados obtidos, pôde se fazer as considerações apresentadas nos ítens que seguem. 


\subsection{Dos Métodos Utilizados}

A interpolação através do Método do Inverso do Quadrado da Distância exibiu um padrão de distribuição espacial muito semelhante a outros mapas de dados normais, já apresentados para a bacia. Nesse sentido, a utilização do Sistema Geográfico de Informações (SGI) IDRISI foi de grande valia, permitindo a geração de um verdadeiro atlas pluviométrico digital sobre a região. Além disso, também facilitou sobremaneira a geração automática das lâminas médias totais de água precipitada e evapotranspirada das sub-bacias.

Não como uma limitação do SGI-IDRISI, mas sim da falta de dados disponíveis para uma análise mais detalhada do ciclo hidrológico da bacia através do Método do Balanço Hídrico, a estimativa pontual da evapotranspiração real apresentou índices de discrepância elevados quando comparados a outros métodos, sugerindo a necessidade de criação de um banco de dados meteorológicos mais completo e complexo.

A utilização de mapas de vazão com uma variação espacial contínua; e não homogênea para cada sub-bacia, como a que foi empregada aqui, seria importante para evitar os problemas encontrados na estimativa de seu valor, principalmente na sub-bacia do Jaguari, cujo relevo não é homogêneo em toda a sua extensão. Isso foi reforçado, de certa forma, pelo agrupamento obtido pela Análise de Componentes Principais Estandardizada (ACPE). Um número maior de postos fluviométricos, com dados que cobrissem o período estudado, permitiria a melhoria da sua resolução espacial. Porém, não houve problemas quanto à geração das séries anuais de lâmina média d'água evapotranspirada por sub-bacia, para a utilização nos métodos estatísticos de Mann-Kendall e Pettitt.

A combinação desses dois testes apresentou-se eficiente na detecção e avaliação da significância das tendências e dos pontos de ruptura nas séries anuais, com vantagens sobre o método da regressão linear. A ACPE é de interpretação complexa e, de certa forma, 
subjetiva. Porém, contribuiu com eficiência para a determinação dos principais fatores influentes sobre a precipitação e, também, no agrupamento das regiões na bacia com comportamento temporal semelhante.

Embora os métodos empregados sejam independentes, eles apresentaram resultados complementares e coerentes entre si, como se verá na discussão a seguir.

\subsection{Dos Resultados Obtidos}

Com respeito às características espaciais, é suficientemente claro que a influência do período úmido no comportamento espacial dos dados pluviométricos anuais é muito maior que a do período seco, considerando a sua maior contribuição em termos volumétricos, como foi observado. Porém, nos anos úmidos extremos, a influência do período normalmente seco sobre a precipitação total anual é bastante importante na determinação do seu padrão espacial. Essa observação sugere que os anos muito úmidos assim o são porque o período normalmente seco é também muito úmido.

Cronologicamente, isso também é verdadeiro, observando-se que a tendência detectada de aumento dos totais anuais se deve, principalmente, à tendência de aumento da precipitação encontrada no período seco, podendo se afirmar que os anos estão sendo mais úmidos porque os invernos estão sendo menos secos, em termos de volume d'água. Portanto, tanto espacial como cronologicamente, a influência do período seco fica reforçada.

Para a vazão reconstituída líquida nenhuma tendência foi detectada, como se devia esperar pelo aumento significativo da precipitação. Isso poderia estar ocorrendo como resultado de uma mudança no uso da terra, que aumentasse a perda de água por evapotranspiração, ou por outra via qualquer. Porém, esta hipótese não pôde ser 
comprovada por não se ter disposto aqui de dados sobre a evolução do uso da terra.

As vazões medidas nas sub-bacias do Jaguari e do Atibaia, que sofrem influência da retirada de água pelo Sistema Cantareira, apresentam tendência de queda, ao contrário do esperado pelo aumento da precipitação. Isso expressa a atuação desse sistema sobre a diminuição da água no leito desses rios. Mantendo-se essa tendência de queda, provavelmente em breve será possível notar, estatisticamente, um declínio na descarga em toda a bacia do rio Piracicaba, causando talvez uma situação de escassez de água. Essa tendência de queda provavelmente não foi ainda significativa pelo aumento da precipitação e também porque o efeito do declínio ocorrido nessas duas sub-bacias é diluido pela contribuição das demais, sendo mascarado no posto final em Artemis. A combinação desse aumento na precipitação e estabilidade (ou até queda) na vazão provocou uma tendência positiva para a evapotranspiração em todas as sub-bacias, excetuando-se a do rio Piracicaba.

Tanto pela análise espacial dos dados como pela ACPE, ficou clara a influência diferenciada das frentes frias do período úmido e seco sobre o comportamento espacial da precipitação na bacia, respondendo também por boa parte de sua variabilidade ao longo dos anos. Outra variável responsável por boa parte da variabilidade temporal dos dados é a atividade solar. A ACPE sugere que esta exerça influência sobre a precipitação a longo prazo, ou seja, a atividade solar em determinado ano só afetaria a precipitação de alguns anos após. Seria como se houvesse um sistema acumulador dessa energia na atmosfera, que só a liberasse anos depois. Ou então, que para atuar sobre essa região, teria que percorrer um longo trajeto de processos atmosféricos.

O agrupamento dos postos em regiões homogêneas, pela ACPE, foi muito adequado, podendo ser adotado para um estudo hidrológico melhor ajustado, principalmente por apresentar grande coerência com a divisão de sub-bacias e por reforçar a idéia de subdivisão da bacia do Jaguari. Pode ser adotado ainda, caso se deseje reduzir o número de postos 
utilizados, facilitando análises futuras, escolhendo-se um, ou alguns, postos de cada grupo.

\subsection{Considerações Finais}

Diante do quadro agravante da disponibilidade da água na bacia, espera-se que este trabalho tenha contribuído de alguma forma para a gestão desse recurso, seja através dos resultados obtidos, ou então, através da sugestão da utilização das técnicas empregadas aqui, principalmente a utilização dos SGIs como ferramenta de manipulação dos dados hidrológicos. Um estudo mais aprofundado dos fatores influentes sobre o regime pluviométrico da região, detectados pela $\mathrm{ACPE}$, poderia contribuir para uma melhor interpretação do funcionamento do sistema atmosférico atuante sobre a região. Uma outra linha interessante para a continuidade desse tipo de análise espaço-temporal de parâmetros hidrológicos, baseada num SGI e partindo para os modelos determinísticos, seria a Análise de Modelos Distribuídos. 


\section{Referências Bibliográficas}

ASSAD, E.D. (coord.) Chuvas nos cerrados: análise e espacialização. EMBRAPACPAC/SPI. Brasília, 1994. 423p.

ASSAD, E.D. \& SANO, E.E. (ed.) Sistema de informações geográficas: aplicações na agricultura. EMBRAPA-CPAC. Brasília, 1993. 274p.

AYABE, E.I.; PISANI, A.; ZIVIERI, J.N.; BENVENUTI, L.; MATSUBARA, C.T.; OLIVEIRA, J.L.; CORDA, N. Acompanhamento hidrológico diário da bacia do rio Piracicaba. In: SIMPÓSIO BRASILEIRO DE HIDROLOGIA E RECURSOS HÍDRICOS, 4., Fortaleza, 1981. Anais. Fortaleza, 1981. vol.1, p.103-114.

BLANCO, H.G. \& GODOY, H. Cartas das chuvas do Estado de São Paulo. IAC/SCA. Campinas, 1967. 12 cartas.

CHRISTOFOLETTI, A.L.H. Estudo sobre a sazonalidade da precipitação na bacia do Piracicaba. São Paulo, 1991. 238p. (Mestrado - Faculdade de Filosofia, Letras e Ciências Humanas/USP) 
COSTA, A.R. Modelo de previsão de vazão em tempo real - aplicação à bacia do rio Piracicaba. São Carlos, 1989. (Doutorado - Escola de Engenharia de São Carlos/USP)

CRACKNELL, A.P. \& HAYES, L.W.B. Introduction to remote sensing. Taylor \& Francis Ltd., 1991. 293p.

CRÓSTA, A.P. Processamento Digital de Imagens de Sensoriamentto Remoto. ed. rev. IG/UNICAMP. Campinas, 1993. 170p

DAVIS, J.C. Statistics and data analysis in geology. Nova Yorque, John Wiley \& Sons, 1973.

DEMARÉE, G.R. An indication of climatic change as seen from the rainfall data of a Mauritanian Station. Theoretical and Applied Climatology, Brussels, 42:139-147. 1990.

DEMARÉE, G.R. and NICOLIS, C. Onset of Sahelian drought viewed as a fluctuation induced transition. Quart. J. Roy. Meteor. Soc., Bruxelles, 116:221-238. 1990.

DOORENBOS, J. \& PRUITT, W.O. Guidelines for predicting crop water requirements. Revised edition. Roma, Food and Agriculture Organization of the United NationsFAO/ONU, 1977. 144p. FAO irrigation and dranaige papers 24.

DUNNE, T. \& LEOPOLD L.B. - Water in the Environmental Planning. W.H. Freeman and Company, San Francisco. 1978. 
DYER, T.G.J. - The assignment of rainfall stations into homogeneous groups: an appliction of principal component analysis. Quart. J. Roy. Meteor. Soc., 101:1005-1013. 1975.

ESSERY, C.I. - Influence of season and balance period on the construction ot catchment water balances. J. Hydrol., Amsterdam, 130:171-187. 1992.

EASTMAN, J.R. - IDRISI Version 4.0 - Technical Reference. Clark University, Massachusetts, USA.1992.

- IDRISI Version 4.0 - User's Guide. Clark University, Massachusetts, USA.1992a.

- IDRISI Version 4.1 - Update Manual. Clark University, Massachusetts, USA.1993.

EASTMAN, J.R. \& FULK, M. - Long sequence time series evaluation using standardized principal components. Photogrammetric Engineering \& Remote Sensing. 59(6):991996. June 1993.

EASTMAN, J.R. \& MCKENDRY, J.E. - Explorations in geographic information systems technology, Volume 1 - Change and time series analysis. Geneva. UNITAR European Ofice. 1991.

FELTRAN FILHO, A. Contribuição à análise fluviométrica da bacia do rio Piracicaba. Rio Claro. 1982. 188p. (Mestrado - Instituto de Geociências e Ciências Exatas/ UNESP) 
FELTRAN FILHO, A. \& CHRISTOFOLETTI, A. Análise de Freqüências dos fluxos da bacia do rio Piracicaba (Estado de São Paulo) In: SIMPÓSIO BRASILEIRO DE HIDROLOGIA E RECURSOS HÍDRICOS, 4., Fortaleza, 1981. Anais. Fortaleza, 1981. vol.1, p.487-502.

FILL, H. D. em ABRH - Modelos para Gerenciamento de Recursos Hídricos. Nobel/ABRH., 1987.

GANZELI, J.P. Aspectos ambientais do planejamento dos recursos hídricos: a bacia do rio Piracicaba. In: TAUK, S.M.; GOBBI, N.; FOWLER H.G. Análise ambiental: uma visão multidisciplinar. São Paulo, UNESP/FAPESP, 1991. p.108-113.

GENOVEZ, A.M. Modelo estocástico das vazões mensais do rio Tietê em Cumbica. São Carlos, 1982. 128p. (Mestrado - Escola de Engenharia de São Carlos/USP)

GOSSENS, C. \& BERGER, A. Annual and seasonal climatic variations over the northern hemisphzre and Europe during the last century. Annales Geophysicae. Louvain-laNeuve, 4(B,4):385-400, 1986.

GUYOT, J.L.; MOLINIER, M.; GUIMARÃES, V.; CUDO, K.J.; OLIVEIRA, E. Balanço hídrico da bacia do rio Negro. In: SIMPÓSIO BRASILEIRO DE RECURSOS HÍDRICOS, 10., Gramado, 1993. Anais. Gramado, ABRH, 1993. Vol.2, p.535-544.

HIEZ, G.; COCHONNEAU, G.; SÉCHET, P.; FERNANDES, U.M. Aplicação do método do vetor regional à análise da pluviometria anual da bacia amazônica. In: SIMPÓSIO BRASILEIRO DE RECURSOS HÍDRICOS, 9., Rio de Janeiro, 1991. Anais. Rio de Janeiro, ABRH, 1991. Vol.1, p.367-377. 
JAAKKO POYRY ENGENHARIA LTDA, São Paulo. Convênio Consórcio Intermunicipal das Bacias dos Rios Piracicaba e Capivari - Departamento de Águas e Energia Elétrica. Plano Diretor de Captação e Produção de Água para Abastecimento Público nas Bacias dos Rios Piracicaba e Capivari. São Paulo, 1992.

JOLLIFFE, I.T. Principal componente analysis. New York, Springer-Verlag, 1986. 271p.

JOHNSON, R.A. \& WICHERN, D.W. Applied multivariate statistical analysis. New Jersey, Prentice-Hall, 1982. 594p.

KING, J.W. Sun-weather relationships. Aeronautics and Astronautics, 13(4): 10-19. Abril, 1975.

LAGARDE, J. Initiation à l'analise des données. Paris, Dunod. 1983. 158p.

LEOPOLO, P.R.; FRAKEN,W.; SALATI, E. Balanço hídrico de pequena bacia hidrográfia em floresta amazônica de terra firme. Acta Amazonica, 12(2): 333-337. 1982.

LINS, H.F. Interannual streamflow variability in the United States based on principal components. Water resources research, 21(5):691-701. May, 1985.

MARTINELLI, L.A. (coord.) Impactos causados pela atividade humana sobre a carga orgânica e inorgânica em rios da bacia do Piracicaba. Projeto proposto ao programa PADCT. Piracicaba, CENA-USP, 1994.

MATOS, I.S. \& MATTOS, A. Aplicação de um modelo de balanço hídrico na bacia do rio Jacaré Guaçu. In: SIMPÓSIO BRASILEIRO DE HIDROLOGIA E RECURSOS HÍDRICOS, 4., Fortaleza, 1981. Anais. Fortaleza, 1981. vol.1, p.545-557. 
MOLINIER, M.; MAIA, A.C.S.; SANTOS, D.F. Balanço hídrico da bacia amazônica. Metodologia e primeiros resultados. In: SIMPÓSIO BRASILEIRO DE RECURSOS HÍDRICOS, 9., Rio de Janeiro, 1991. Anais. Rio de Janeiro, ABRH, 1991. Vol.1, p.158-167.

MOLINIER, M.; CUDO, K.J.; GUIMARÃES, V. Disponibilidade de água na bacia amazônica. In: SIMPÓSIO INTERNACIONAL DE ESTUDOS AMBIENTAIS EM FLORESTAS TROPICAIS ÚMIDAS. FOREST'92, 2., Rio de Janeiro, 1992. Anais. Rio de Janeiro, 1992.

MOLTENI, F.; BONELLI, P.; BACCI, P. Precipitation over northern Italy: a discription by means of principal component analysis. Journal of Clim. Appl. Meteor., 22: 1738$1752,1983$.

OBREGON, G.O. \& NOBRE, C.A. Principal component analysis of precipitation fields over the amazon river basin. Climanálise - Contribuições Reproduzidas na Íntegra, São José dos Campos, 5(7):35-46. Julho, 1990.

OLIVER, H.R. The availability of evaporation data in space and time for use in water balance computations. In: New approaches in water balance computations (Proceedings of the Hamburg workshop, august) IAHS Publ. $n^{\circ} 148.1983$.

PANDZIC, K. \& TRNINIC, D. Principal component analysis of a river basin discharge and precipitation anomaly fields associated with the global circulation. J. Hydrol., Amsterdam, 132:343-360. 1992. 
PEREIRA, A.R. Apostila da disciplina LFM704-Evapo(transpi)ração - Curso de Pósgraduação em agrometeorologia da Escola Superior de Agricultura "Luiz de Queiroz". Piracicaba. 1992.

PETTITT, A.N. A non-parametric approach to the change-point problem. Applied Statistics, 28(2):126-135. 1979.

PIMENTEL, R.A. Morphometrics - The multivariate analysis of biological data. Dubuque, Kendall/hunt Publishing Company, 1979.

PROCHNOW, M.C.R. A qualidade das águas na bacia do rio Piracicaba. Rio Claro, 1981 (Mestrado - Instituto de Geociências e Ciências Exatas do Campus de Rio Claro/UNESP)

PROCHNOW, M.C.R. Análise ambiental da sub-bacia do rio Piracicaba: subsídios ao seu planejamento e manejo. Rio Claro, 1990 (Doutorado - Instituto de Geociências e Ciências Exatas do Campus de Rio Claro/UNESP)

ROCHA, H.R.; NOBRE, C.A.; BARROS, M.C. Variabilidade natural de longo prazo no ciclo hidrológico da Amazônia. Climanálise - Contribuições Reproduzidas na Íntegra, São José dos Campos, 4(12):36-42. Dezembro, 1989.

ROSA, J.C.L. Plano global dos recursos hídricos na bacia do rio Piracicaba. Engenharia, São Paulo, 481: 25-27, 1991. 
SÁ, T.D.A.; PINTO, H.S.; ZULLO, S.A.; HOTTA, L.K. Avaliação espacial e cartografia das chuvas de primavera no Estado de São Paulo através de técnicas de análise multivariada, como subsídio ao estabelecimento de cronogramas agrícolas regionais. In: CONGRESSO BRASILEIRO DE AGROMETEOROLOGIA, 6., Maceió, 1989. Anais. Maceió, INPE-SBA-UFAL, 1989. p.24-28.

SÃO PAULO, Companhia de Saneamento Básico do Estado de São Paulo. Data Oper Sistema Cantareita. Governo do Estado de São Paulo. São Paulo. 1989

SÃO PAULO, Conselho Estadual de Recursos Hídricos; Comitê Coordenador do Plano e do Sistema Estadual de Recursos Hídricos; Grupo Técnico do Plano Estadual de Recursos Hídricos. Plano estadual de recursos hídricos - Primeiro plano do Estado de São Paulo - 1990. Governo do Estado de São Paulo, 1990

SÃO PAULO - Consórcio Intermunicipal das Bacias dos Rios Piracicaba e Capivari Programa de investimentos para recuperação e proteção das bacias dos rios Piracicaba e Capivari. São Paulo, 1992.

SÃO PAULO, Departamento de Águas e Energia Elétrica - Plano global dos recursos hídricos da bacia do Piracicaba - $1^{\text {a }}$ etapa, 8 volumes. Coplasa S.A. - Engenharia de Projetos. São Paulo. 1984.

SÃO PAULO, Departamento de Águas e Energia Elétrica - Estudo de águas subterrâneas Região administrativa 5: Campinas. Governo do Estado de São Paulo. São Paulo. 1985.

SÃO PAULO, Departamento de Águas e Energia Elétrica - Plano global dos recursos hídricos da bacia do Piracicaba - $2^{\mathrm{a}}$ etapa, 8 volumes. Tecnosan. 1986. 
SÃO PAULO, Fundação de Desenvolvimento Administrativo. Alternativas de Gestão do Meio Ambiente da Bacia do Rio Piracicaba. São Paulo. Fundap. 1991.

SÃO PAULO, Secretaria do Meio Ambiente. Bacia do rio Piracicaba. Estabelecimento de metas ambientais e reenquadramento dos corpos d'água. Secretaria do Meio Ambiente. 1994.

SCHÄDLER, B. Long water balance time series in the upper basins of four important rivers in Europe - indicators for climatic changes? In: The influence of climatic change and climatic variability on the hydrologic regime and water resources. (Proceedings of the Vancouver Symposium. August 1987) IAHS Publ. n¹68. 1987.

SCHORODER, R. Contribuição e curso anual das precipitações no Estado de São Paulo. Bragantia, Campinas, 15(18):193-249. 1956.

SENTELHAS, P.C.; CAMARGO, A.P.; CAMARGO, M.B.P.; ALFONSI, R.R. Um século de desmatamento: efeitos no regime térmico, pluvial e no balanço hídrico em Campinas, SP. Revista Brasileira de Agrometeorologia, Santa Maria, 2:99-103, 1994.

SERRA FILHO, R. \& PINTO, H.S. Surveying and automatic mapping of São Paulo State, Brazil: a geographic information system with enfasis on land use. In: ANNUAL MEETING ASP, 51, Washington DC, 1985. Technical papers. Washington DC, American Soc. of Photogrametry, 1985. Vol. 1, 229-236.

SETZER, J. Contribuição para o estudo da chuva do Estado de São Paulo. São Paulo, Escola Profissional Salesiana, 1946. 239p. 
SETZER, J. Atlas climático e ecológico do Estado de São Paulo. Comissão Interestadual das Bacias do Paraná-Uruguai - CESP, São Paulo, 1966. 60p.

SNEYERS, R. Sur l'analyse statistique des séries d'observations. Note Technique $\mathrm{N}^{\circ} 143$, OMM - No 415, Genève, 1975. 192p.

SNEYERS, R.; VANDIEPENBEECK, M.; VANLIERDE, R.; DEMAREE, G.R. Climatic changes in Belgium as appearing from the homogenized series of observations made in Brussels - Uccle (1833-1988) In: SCHIETECAT, G.D. (ed.) Contributions à l'étude des changements de climat. Bruxelles, Institut Royal Meteorologique de Belgique, 1990. Publications Série No 124. p.17-20.

THOM, H.C.S. Some methods of climatological analysis. Geneva, WMO, s.d.. 52p. Technical note $\mathrm{N}^{\circ} 81$. WMO-N ${ }^{\circ} 103$.

TUCCI, C.E.M. \& BELTRAME, L.F.S. Evaporação e evapotranspiração. In: TUCCI, C.E.M. (org.) Hidrologia - Ciência e Aplicação. Porto Alegre, UFRGS/Edusp/ABRH, 1993. cap.7, p.253-287.

UNESCO Guia metodológica para la elaboración del balance hidrico de América del Sur.Montevideo, Rostlac, 1982.130p.

VIEIRA, D.B. Contribuição ao estudo do aproveitamento hidro-agrícola da bacia do rio Piracicaba. 1970. (Mestrado - Escola de Engenharia de São Carlos/USP) 
VILLA NOVA, N.A. \& REICHARDT, K. Evaporação e evapotranspiração. In: RAMOS, F.; OCCHIPINTI, A.G.; VILLA NOVA, N.A.; REICHARDT, K.; MAGALHÃES, P.C.; CLEARY, R.W. Engenharia Hidrológica. Rio de Janeiro, ABRH/Editora UFRJ, 1989. Coleção ABRH de recursos hídricos, volume 2. p.143-197.

WEI, E.C. \& MCGUINNESS, J.L. Reciprocal distance squared method - A computer technique for estimating areal precipitation. Illinois, Agricultural Research Service U.S. Department of Agriculture, 1973. Repport ARS-NC-8. 30p.

WILCOX, J.M. Solar activity and the weather. Journal of Atmospheric and Terrestrial Physics, 37: 237-256, 1975.

ZULLO, S.A.; HOTTA, L.K.; PINTO, T.D.A.; ZULLO JUNIOR, J. Aplicações de técnicas de análise multivariada na avaliaçào espacial da precipitação pluviométrica no Estado de São Paulo. In: XV REUNIÃO REGIONAL DA ASSOCIAÇÃO BRASILEIRA DE ESTATÍSTICA E II SIMPÓSIO NACIONAL DE MÉTODOS QUANTITATIVOS, Juiz de Fora, 1989. Anais. Juiz de Fora, ICE/UFJF, 1989.

ZULLO, S.A. Aplicação das técnicas de componentes principais e agrupamentos em pluviometria: análises do nordeste paraense e Estado de São Paulo. 1992. 101p. (Mestrado - Instituto de Matemática, Estatística e Ciência da Computação/UNICAMP) 


\section{Apêndice}

\section{Comparação da Evapotranspiração Real}

Os métodos utilizados para a checagem dos valores da evapotranspiração real, obtida pelo método do Balanço Hídrico (descrito no item 2.2.2.c), foram o método de Turc e o Thornthwaite \& Mather, sugeridos por UNESCO (1982).

\section{A.1. O Método de Turc}

Esse método estima a evapotranspiração real anual (ETR) utilizando, como parâmetros, a precipitação anual e a temperatura média anual. A ETR pode ser obtida pela equação (a.1):

$$
E T R=\frac{P}{\sqrt{0,9+\frac{P^{2}}{L^{2}}}}
$$

onde ETR é a evapotranspiração real anual em mm; 
$\mathrm{P}$ é a precipitação total anual em mm; e

L é um parâmetro heliotérmico dado pela expressão abaixo:

$$
L=300+(25 * \theta)+\left(0,05 * \theta^{3}\right),
$$

sendo $\theta$ a temperatura média anual $\mathrm{em}{ }^{\circ} \mathrm{C}$.

\section{A.2. O Método de Thornthwaite \& Mather (1955)}

A evapotranspiração real mensal sequencial, calculada pelo programa SEQUENCE desenvolvido no departamento de Física e Meteorologia da ESALQ, foi totalizada para obtenção dos valores anuais. Ela foi obtida considerando-se a capacidade de água disponível no solo (CAD) igual a $100 \mathrm{~mm}$.

Por ser bastante difundido e de conhecimento geral esse método não será detalhado aqui. A sua formulação e os passos necessários para da obtenção da ETR são descritos por vários autores como UNESCO (1982), VILLA NOVA \& REICHARDT (1989) e PEREIRA (1992), dentre outros.

A seguir são apresentadas as tabelas obtidas para a comparação dos métodos que geraram a figura 2.7. Nelas as discrepâncias são a porcentagem representada pelos valores absolutos dos desvios, tomando como base sempre o segundo método, isto é:

$$
\text { Discrepância } \%=\frac{\left(1^{\circ} \text { método }-2^{\circ} \text { método }\right)}{2^{\circ} \text { método }} * 100
$$


Tabela a.1-Comparação dos resultados obtidos pelos métodos de estimativa da evapotranspiração real anual (mm) para a cidade de Monte Alegre do Sul. (MBH=Método do balanço hídrico;Turc=Método de Turc;ThM=Método de Thorthnwaite \& Mather)

\begin{tabular}{|c|c|c|c|c|c|c|}
\hline \multicolumn{7}{|c|}{ MONTE ALEGRE DO SUL } \\
\hline \multirow[b]{2}{*}{ Ano } & \multicolumn{3}{|c|}{ Evapotranspiração Estimada (mm) } & \multicolumn{3}{|c|}{ Discrepância entre os métodos (\%) } \\
\hline & MBH & Ture & ThM & MBH-Turc & MBH- ThM & Turc-ThM \\
\hline 1947 & 1220 & 966 & & 26,35 & & \\
\hline 1948 & 574 & 811 & 808 & 29,27 & 28,99 & 0,39 \\
\hline 1949 & 861 & 878 & 787 & 1,97 & 9,40 & 11,60 \\
\hline 1950 & 865 & 959 & 797 & 9,82 & 8,48 & 20,30 \\
\hline 1951 & 884 & 864 & 762 & 2,30 & 16,03 & 13,42 \\
\hline 1952 & 950 & 903 & 829 & 5,19 & 14,58 & 8,93 \\
\hline 1953 & 863 & 820 & 885 & 5,20 & 2,48 & 7,30 \\
\hline 1954 & 881 & 873 & 774 & 0,89 & 13,81 & 12,80 \\
\hline 1955 & 1059 & 888 & 835 & 19,32 & 26,88 & 6,34 \\
\hline 1956 & 950 & 856 & 849 & 10,99 & 11,96 & 0,87 \\
\hline 1957 & 1231 & 952 & 860 & 29,29 & 43,13 & 10,70 \\
\hline 1958 & 1067 & 962 & 886 & 10,93 & 20,48 & 8,62 \\
\hline 1959 & 1178 & 995 & 893 & 18,35 & 31,99 & 11,52 \\
\hline 1960 & 1326 & 985 & 836 & 34,63 & 58,67 & 17,86 \\
\hline 1961 & 714 & 873 & 799 & 18,24 & 10,61 & 9,33 \\
\hline 1962 & 1115 & 929 & 822 & 20,04 & 35,58 & 12,94 \\
\hline 1963 & 779 & 892 & 733 & 12,70 & 6,23 & 21,68 \\
\hline 1964 & 1146 & 917 & 799 & 24,92 & 43,40 & 14,80 \\
\hline 1965 & 991 & 972 & 875 & 1,94 & 13,29 & 11,13 \\
\hline 1966 & 831 & 924 & 851 & 10,02 & 2,40 & 8,47 \\
\hline 1967 & 910 & 935 & 853 & 2,67 & 6,64 & 9,57 \\
\hline 1968 & 825 & 797 & 814 & 3,49 & 1,39 & 2,03 \\
\hline 1969 & 1133 & 924 & 868 & 22,62 & 30,46 & 6,39 \\
\hline 1970 & 1400 & 1009 & 866 & 38,78 & 61,71 & 16,52 \\
\hline 1971 & 1029 & 901 & 867 & 14,26 & 18,73 & 3,91 \\
\hline 1972 & 1251 & 977 & 874 & 28,00 & 43,22 & 11,89 \\
\hline 1973 & 1290 & 1001 & 917 & 28,81 & 40,74 & 9,26 \\
\hline 1974 & 879 & 907 & 822 & 3,07 & 6,88 & 10,26 \\
\hline 1975 & 1171 & 970 & 720 & 20,77 & 62,72 & 34,73 \\
\hline 1976 & 1399 & 1015 & 855 & 37,83 & 63,61 & 18,71 \\
\hline 1977 & 1022 & 980 & 909 & 4,27 & 12,43 & 7,83 \\
\hline 1978 & 1041 & 905 & 889 & 15,02 & 17,10 & 1,81 \\
\hline 1979 & 1065 & 917 & 871 & 16,17 & 22,33 & 5,30 \\
\hline 1980 & 1182 & 988 & 893 & 19,65 & 32,38 & 10,64 \\
\hline 1981 & 1215 & 971 & 852 & 25,13 & 42,68 & 14,03 \\
\hline 1982 & 1271 & 1016 & 882 & 25,15 & 44,10 & 15,14 \\
\hline 1983 & 1171 & 1079 & 899 & 8,51 & 30,21 & 20,00 \\
\hline 1984 & 797 & 921 & 853 & 13,43 & 6,58 & 7,91 \\
\hline 1985 & 960 & 902 & 879 & 6,44 & 9,16 & 2,56 \\
\hline 1986 & 1482 & 1018 & 902 & 45,64 & 64,22 & 12,75 \\
\hline 1987 & 959 & 979 & 906 & 2,04 & 5,80 & 8,00 \\
\hline 1988 & 1101 & 979 & 840 & 12,49 & 31,10 & 16,55 \\
\hline 1989 & 1200 & 956 & 841 & 25,59 & 42,69 & 13,62 \\
\hline 1990 & 991 & 933 & 931 & 6,22 & 6,49 & 0,25 \\
\hline Média & 1051 & 936 & 848 & 16,33 & 25,62 & 10,90 \\
\hline Desvio & 197,8 & 59,7 & 47,9 & 11,53 & 18,90 & 6,61 \\
\hline C.V & 18,8 & 6,4 & 5,7 & 70,64 & 73,78 & 60,67 \\
\hline Máximo & 1482 & 1079 & 931 & 45,64 & 64,22 & 34,73 \\
\hline Mínimo & 574 & 797 & 720 & 0,89 & 1,39 & 0,25 \\
\hline
\end{tabular}


Tabela a.2 - Comparação dos resultados obtidos pelos métodos de estimativa da evapotranspiração real anual (mm) para a cidade de Campinas. ( $\mathrm{MBH}=$ Método do balanço hídrico ; Ture=Método de Turc; ThM=Método de Thorthnwaite \& Mather)

\begin{tabular}{|c|c|c|c|c|c|c|}
\hline \multicolumn{7}{|c|}{ CAMPINAS } \\
\hline \multirow[b]{2}{*}{ Ano } & \multicolumn{3}{|c|}{ Evapotranspiração Estimada (mm) } & \multicolumn{3}{|c|}{ Discrepância entre os métodos (\%) } \\
\hline & MBH & Ture & ThM & MBH-Ture & MBH- ThM & Turc-ThM \\
\hline 1956 & 915 & 878 & & 4,26 & & \\
\hline 1957 & 1023 & 984 & 907 & 3,93 & 12,75 & 8,49 \\
\hline 1958 & 744 & 937 & 938 & 20,61 & 20,69 & 0,11 \\
\hline 1959 & 583 & 833 & 906 & 29,97 & 35,68 & 8,14 \\
\hline 1960 & 747 & 900 & 829 & 17,03 & 9,90 & 8,59 \\
\hline 1961 & 427 & 781 & 786 & 45,31 & 45,67 & 0,66 \\
\hline 1962 & 799 & 886 & 846 & 9,78 & 5,55 & 4,69 \\
\hline 1963 & 534 & 780 & 729 & 31,57 & 26,75 & 7,04 \\
\hline 1964 & 1054 & 928 & 841 & 13,60 & 25,36 & 10,35 \\
\hline 1965 & 1018 & 984 & 920 & 3,41 & 10,64 & 6,99 \\
\hline 1966 & 728 & 893 & 876 & 18,52 & 16,87 & 2,02 \\
\hline 1967 & 729 & 907 & 873 & 19,58 & 16,49 & 3,84 \\
\hline 1968 & 533 & 728 & 784 & 26,75 & 32,03 & 7,21 \\
\hline 1969 & 801 & 837 & 911 & 4,35 & 12,11 & 8,12 \\
\hline 1970 & 1150 & 1039 & 934 & 10,72 & 23,09 & 11,17 \\
\hline 1971 & 793 & 859 & 902 & 7,69 & 12,12 & 4,80 \\
\hline 1972 & 907 & 950 & 904 & 4,50 & 0,38 & 5,11 \\
\hline 1973 & 910 & 949 & 977 & 4,07 & 6,84 & 2,88 \\
\hline 1974 & 813 & 893 & 838 & 8,97 & 2,99 & 6,58 \\
\hline 1975 & 1048 & 945 & 774 & 10,87 & 35,41 & 22,14 \\
\hline 1976 & 1227 & 1025 & 884 & 19,75 & 38,86 & 15,96 \\
\hline 1977 & 991 & 1007 & 928 & 1,62 & 6,76 & 8,51 \\
\hline 1978 & 663 & 823 & 828 & 19,47 & 19,90 & 0,53 \\
\hline 1979 & 1080 & 947 & 924 & 14,08 & 16,84 & 2,42 \\
\hline 1980 & 1036 & 973 & 923 & 6,52 & 12,29 & 5,41 \\
\hline 1981 & 930 & 918 & 832 & 1,33 & 11,84 & 10,38 \\
\hline 1982 & 1344 & 1056 & 894 & 27,27 & 50,39 & 18,17 \\
\hline 1983 & 1261 & 1117 & 932 & 12,88 & 35,28 & 19,85 \\
\hline 1984 & 796 & 935 & 920 & 14,90 & 13,43 & 1,73 \\
\hline 1985 & 755 & 875 & 887 & 13,74 & 14,88 & 1,33 \\
\hline 1986 & 1271 & 1031 & 946 & 23,25 & 34,37 & 9,02 \\
\hline 1987 & 901 & 995 & 884 & 9,49 & 1,89 & 12,57 \\
\hline 1988 & 817 & 960 & 874 & 14,89 & 6,49 & 9,87 \\
\hline 1989 & 781 & 907 & 864 & 13,88 & 9,58 & 5,00 \\
\hline 1990 & 986 & 974 & 969 & 1,19 & 1,73 & 0,53 \\
\hline Média & 888,4 & 926,7 & 881,3 & 13,99 & 18,41 & 7,36 \\
\hline Desvio & 218,3 & 83,4 & 57,3 & 9,98 & 13,24 & 5,54 \\
\hline C.V & 24,6 & 9,0 & 6,5 & 71,33 & 71,91 & 75,26 \\
\hline Máximo & 1344 & 1117 & 977 & 45,31 & 50,39 & 22,14 \\
\hline Mínimo & 427 & 728 & 729 & 1,19 & 0,38 & 0,11 \\
\hline
\end{tabular}


Tabela a.3-Comparação dos resultados obtidos pelos métodos de estimativa da evapotranspiração real anual $(\mathrm{mm})$ para a cidade de Limeira.(MBH=Método do balanço hídrico; Turc=Método de Turc; ThM=Método de Thorthnwaite \& Mather)

\begin{tabular}{|c|c|c|c|c|c|c|}
\hline \multicolumn{7}{|c|}{ LIMEIRA } \\
\hline \multirow[b]{2}{*}{ Ano } & \multicolumn{3}{|c|}{ Evapotranspiração Estimada (mm) } & \multicolumn{3}{|c|}{ Discrepância entre os métodos (\%) } \\
\hline & MBH & Turc & ThM & MBH-Turc & MBH- ThM & Turc-ThM \\
\hline 1947 & 1107 & 960 & & 15,36 & & \\
\hline 1948 & 705 & 870 & 803 & 18,96 & 12,22 & 8,33 \\
\hline 1949 & 894 & 888 & 819 & 0,66 & 9,14 & 8,42 \\
\hline 1950 & 1121 & 951 & 743 & 17,88 & 50,97 & 28,08 \\
\hline 1951 & 723 & 868 & 746 & 16,71 & 3,14 & 16,30 \\
\hline 1952 & 944 & 896 & 834 & 5,41 & 13,25 & 7,44 \\
\hline 1953 & 991 & 846 & 906 & 17,07 & 9,38 & 6,57 \\
\hline 1954 & 1017 & 898 & 767 & 13,19 & 32,64 & 17,18 \\
\hline 1955 & 941 & 864 & 858 & 8,92 & 9,70 & 0,71 \\
\hline 1956 & 823 & 822 & 864 & 0,13 & 4,74 & 4,86 \\
\hline 1957 & 1140 & 944 & 871 & 20,74 & 30,92 & 8,43 \\
\hline 1958 & 1221 & 1004 & 925 & 21,67 & 32,01 & 8,50 \\
\hline 1959 & 968 & 937 & 856 & 3,35 & 13,06 & 9,39 \\
\hline 1960 & 1136 & 970 & 837 & 17,07 & 35,70 & 15,91 \\
\hline 1961 & 624 & 822 & 808 & 24,13 & 22,77 & 1,80 \\
\hline 1962 & 957 & 912 & 852 & 4,98 & 12,32 & 6,99 \\
\hline 1963 & 508 & 764 & 740 & 33,47 & 31,35 & 3,18 \\
\hline 1964 & 945 & 852 & 814 & 10,87 & 16,08 & 4,70 \\
\hline 1965 & 904 & 988 & 856 & 8,46 & 5,59 & 15,35 \\
\hline 1966 & 973 & 918 & 865 & 6,00 & 12,46 & 6,10 \\
\hline 1967 & 1012 & 968 & 798 & 4,50 & 26,82 & 21,35 \\
\hline 1968 & 567 & 688 & 749 & 17,54 & 24,30 & 8,20 \\
\hline 1969 & 902 & 856 & 793 & 5,32 & 13,69 & 7,95 \\
\hline 1970 & 1266 & 996 & 905 & 27,16 & 39,95 & 10,06 \\
\hline 1971 & 1026 & 896 & 886 & 14,57 & 15,75 & 1,03 \\
\hline 1972 & 1204 & 980 & 888 & 22,80 & 35,56 & 10,39 \\
\hline 1973 & 1178 & 962 & 925 & 22,39 & 27,33 & 4,03 \\
\hline $\begin{array}{l}1974 \\
1975\end{array}$ & $\begin{array}{c}1059 \\
948\end{array}$ & $\begin{array}{l}969 \\
911\end{array}$ & $\begin{array}{l}825 \\
724\end{array}$ & $\begin{array}{l}9,26 \\
4,07\end{array}$ & $\begin{array}{l}28,40 \\
30,95\end{array}$ & $\begin{array}{l}17,52 \\
25,83\end{array}$ \\
\hline 1976 & 1209 & 1021 & 888 & 18,38 & 36,09 & 14,96 \\
\hline 1977 & 996 & 1008 & 899 & 1,15 & 10,81 & 12,10 \\
\hline 1978 & 1039 & 900 & 820 & 15,50 & 26,67 & 9,67 \\
\hline 1979 & 1008 & 870 & 889 & 15,92 & 13,33 & 2,24 \\
\hline 1980 & 1096 & 944 & 912 & 16,12 & 20,12 & 3,44 \\
\hline 1981 & 1098 & 941 & 790 & 16,68 & 38,92 & 19,07 \\
\hline 1982 & 1183 & 1000 & 874 & 18,32 & 35,38 & 14,42 \\
\hline 1983 & 1037 & 1093 & 906 & 5,12 & 14,50 & 20,68 \\
\hline 1984 & 712 & 861 & 803 & 17,30 & 11,32 & 7,22 \\
\hline 1985 & 898 & 879 & 783 & 2,20 & 14,69 & 12,22 \\
\hline 1986 & 1340 & 990 & 915 & 35,36 & 46,40 & 8,15 \\
\hline 1987 & 959 & 977 & 932 & 1,85 & 2,91 & 4,85 \\
\hline 1988 & 934 & 944 & 832 & 1,10 & 12,31 & 13,57 \\
\hline 1989 & 1182 & 962 & 858 & 22,90 & 37,75 & 12,09 \\
\hline 1990 & 1092 & 961 & 951 & 13,58 & 14,81 & 1,08 \\
\hline Média & 991 & 922 & 844 & 13,50 & 21,77 & 10,24 \\
\hline Desvio & 182,1 & 73,4 & 59,0 & 8,80 & 12,47 & 6,61 \\
\hline C.V & 18,4 & 8,0 & 7,0 & 65,19 & 57,29 & 64,52 \\
\hline Máximo & 1340 & 1093 & 951 & 35,36 & 50,97 & 28,08 \\
\hline Mínimo & 508 & 688 & 724 & 0,13 & 2,91 & 0,71 \\
\hline
\end{tabular}


Tabela a.4-Comparação dos resultados obtidos pelos métodos de estimativa da evapotranspiração real anual (mm) para a cidade de Piracicaba. (MBH=Método do balanço hídrico;

Turc=Método de Turc; ThM=Método de Thorthnwaite \& Mather)

\begin{tabular}{|c|c|c|c|c|c|c|}
\hline \multicolumn{7}{|c|}{ PIRACICABA } \\
\hline \multirow[b]{2}{*}{ Ano } & \multicolumn{3}{|c|}{ Evapotranspiração Estimada (mm) } & \multicolumn{3}{|c|}{ Discrepância entre os métodos (\%) } \\
\hline & MBH & Turc & ThM & MBH-Turc & MBH- ThM & Turc-ThM \\
\hline 1947 & 1012 & 1003 & & 0,90 & & \\
\hline 1948 & 729 & 921 & 885 & 20,87 & 17,62 & 4,10 \\
\hline 1949 & 796 & 889 & 852 & 10,44 & 6,56 & 4,33 \\
\hline 1950 & 1034 & 974 & 870 & 6,21 & 18,83 & 11,88 \\
\hline 1951 & 680 & 894 & 809 & 23,95 & 15,93 & 10,54 \\
\hline 1952 & 753 & 849 & 915 & 11,32 & 17,69 & 7,18 \\
\hline 1953 & 955 & 861 & 957 & 10,86 & 0,18 & 9,95 \\
\hline 1954 & 965 & 927 & 914 & 4,06 & 5,58 & 1,46 \\
\hline 1955 & 884 & 882 & 945 & 0,17 & 6,48 & 6,64 \\
\hline 1956 & 865 & 877 & 880 & 1,34 & 1,75 & 0,42 \\
\hline 1957 & 1158 & 1000 & 915 & 15,85 & 26,54 & 9,23 \\
\hline 1958 & 1225 & 1050 & 988 & 16,72 & 24,01 & 6,24 \\
\hline 1959 & 978 & 980 & 945 & 0,24 & 3,48 & 3,73 \\
\hline 1960 & 1244 & 1043 & 901 & 19,22 & 38,05 & 15,79 \\
\hline 1961 & 665 & 868 & 868 & 23,36 & 23,40 & 0,06 \\
\hline 1962 & 1008 & 957 & 889 & 5,34 & 13,37 & 7,61 \\
\hline 1963 & 574 & 817 & 793 & 29,78 & 27,61 & 3,09 \\
\hline 1964 & 1039 & 918 & 795 & 13,16 & 30,62 & 15,44 \\
\hline 1965 & 989 & 1053 & 954 & 6,10 & 3,62 & 10,36 \\
\hline 1966 & 991 & 974 & 897 & 1,71 & 10,48 & 8,62 \\
\hline 1967 & 986 & 1019 & 917 & 3,24 & 7,55 & 11,15 \\
\hline 1968 & 640 & 749 & 797 & 14,59 & 19,67 & 5,94 \\
\hline 1969 & 906 & 890 & 942 & 1,76 & 3,85 & 5,51 \\
\hline 1970 & 1239 & 1051 & 1013 & 17,92 & 22,32 & 3,73 \\
\hline 1971 & 939 & 921 & 1038 & 2,01 & 9,54 & 11,32 \\
\hline 1972 & 1213 & 989 & 904 & 22,71 & 34,18 & 9,35 \\
\hline 1973 & 1109 & 973 & 991 & 13,95 & 11,95 & 1,76 \\
\hline $\begin{array}{l}1974 \\
1075\end{array}$ & 938 & $\begin{array}{l}961 \\
056\end{array}$ & 874 & 2,36 & $\begin{array}{l}7,38 \\
9,78\end{array}$ & 9,98 \\
\hline $\begin{array}{l}197 / 5 \\
1976\end{array}$ & $\begin{array}{c}945 \\
1149\end{array}$ & $\begin{array}{c}956 \\
1039\end{array}$ & 861 & $\begin{array}{c}1,16 \\
10,59\end{array}$ & $\begin{array}{c}9,78 \\
26,91\end{array}$ & $\begin{array}{l}11,07 \\
14.75\end{array}$ \\
\hline 1977 & $\begin{array}{l}1149 \\
900\end{array}$ & $\begin{array}{l}1039 \\
1013\end{array}$ & $\begin{array}{l}905 \\
954\end{array}$ & $\begin{array}{l}10,39 \\
11,16\end{array}$ & $\begin{array}{c}20,91 \\
5,70\end{array}$ & $\begin{array}{c}14,15 \\
6,15\end{array}$ \\
\hline 1978 & 1033 & 911 & 906 & 13,40 & 14,07 & 0,59 \\
\hline 1979 & 1010 & 897 & 951 & 12,63 & 6,25 & 5,67 \\
\hline 1980 & 1055 & 924 & 799 & 14,12 & 32,05 & 15,71 \\
\hline 1981 & 1017 & 965 & 849 & 5,39 & 19,78 & 13,65 \\
\hline 1982 & 1213 & 1084 & 996 & 11,91 & 21,83 & 8,87 \\
\hline 1983 & 881 & 1162 & 1017 & 24,16 & 13,33 & 14,27 \\
\hline 1984 & 714 & 906 & 801 & 21,18 & 10,86 & 13,09 \\
\hline 1985 & 841 & 905 & 925 & 7,04 & 9,09 & 2,20 \\
\hline 1986 & 1234 & 1046 & 1023 & 18,02 & 20,67 & 2,24 \\
\hline 1987 & 897 & 1019 & 1026 & 11,96 & 12,57 & 0,69 \\
\hline 1988 & 976 & 1008 & 969 & 3,21 & 0,68 & 4,02 \\
\hline 1989 & 1040 & 992 & 974 & 4,84 & 6,74 & 1,81 \\
\hline 1990 & 1000 & 996 & 951 & 0,37 & 5,13 & 4,75 \\
\hline Média & 964 & 957 & 915 & 10,71 & 14,50 & 7,32 \\
\hline Desvio & 168,7 & 78,2 & 68,1 & 7,99 & 9,79 & 4,69 \\
\hline C.V & 17,5 & 8,2 & 7,4 & 74,63 & 67,52 & 64,05 \\
\hline Máximo & 1244 & 1162 & 1038 & 29,78 & 38,05 & 15,79 \\
\hline Mínimo & 574 & 749 & 793 & 0,17 & 0,18 & 0,06 \\
\hline
\end{tabular}

